\title{
SEO y Periodismo \\ Marco de optimización global como \\ parte del emprendimiento en \\ cibermedios
}

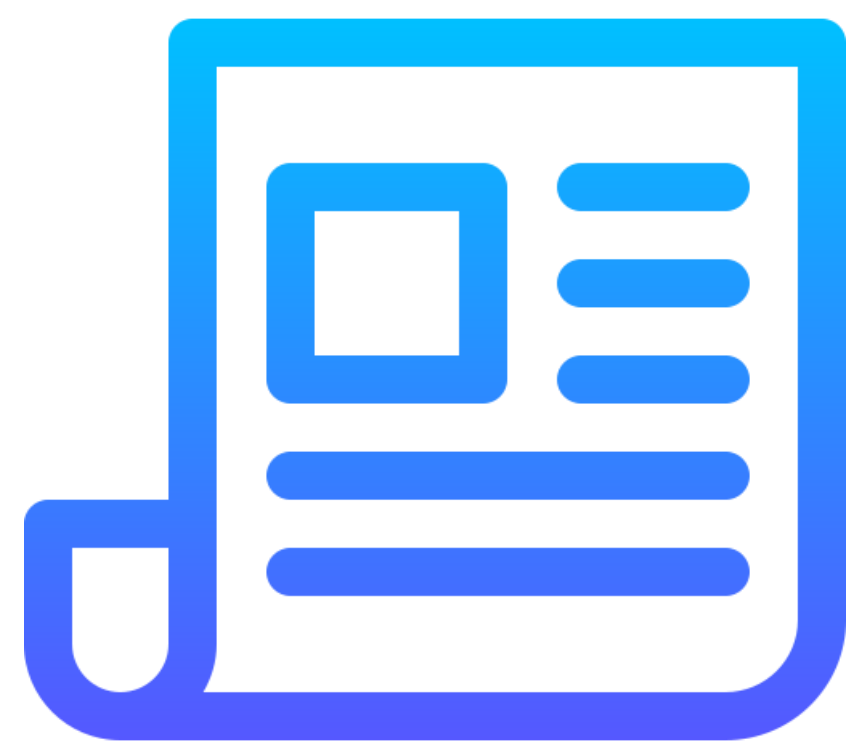

Carlos Lopezosa, Lluís Codina, Carlos Gonzalo-Penela

Prólogo a cargo de Carles Pont-Sorribes

\section{DIGIDOC}

Grup de Recerca

en Documentació Digital

i Comunicació Interactiva

Una publicación de la Serie DigiDoc-EPI

Mayo 2020 


\section{Grupo de Investigación DigiDoc}

UPF

Roc Boronat, 138, desp. 53.804

08018 Barcelona

www.upf.edu/digidoc/

Contacto: +34935421311 | digidoc@upf.edu

Mayo 2020

Obra distribuida bajo una licencia CC BY-NC-SA 4.0

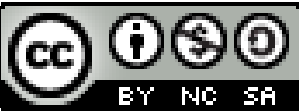

Forma recomendada de citación

Lopezosa, Carlos; Codina, Lluís; Gonzalo-Penela, Carlos (2020). SEO y Periodismo. Marco de optimización global como parte del emprendimiento en cibermedios. Barcelona:

Departamento de Comunicación. Serie DigiDoc-Tendencias. Mayo 2020 DOI:

http://dx.doi.org/10.31009/informesdcom.2020.01

Icon made by Freepik from https://www.flaticon.com

Serie Editorial DigiDoc

Un entregable de la Colección Proyecto Comunicación Interactiva (PCI).

Con el soporte de los proyectos "Narración interactiva y visibilidad digital en el documental interactivo y el periodismo estructurado". RTI2018-095714-B-C21

(MICINN/FEDER), Ministerio de Ciencia, Innovación y Universidades (España).

NS RTI02/2020

Una producción de

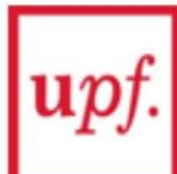

Universitat Pompeu Fabra Barcelona
Departament de Comunicació
Con el soporte de

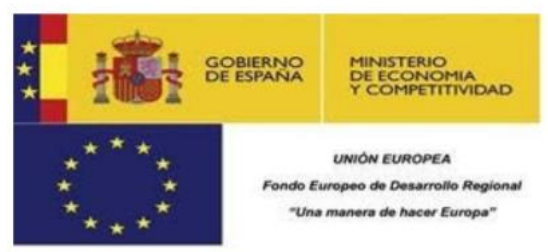




\section{Sobre los autores}

Carlos Lopezosa es doctor en Ciencias de la Información y colaborador del Grupo de Investigación DigiDoc. Es especialista en SEO y estrategias de monetización basados en contenidos de calidad. Es profesor asociado del grado de Periodismo de la UPF y del Máster Online en Buscadores y SEO/SEM de la Barcelona School of Management. Contacto: carlos.lopezosa@upf.edu

Lluís Codina es doctor en Ciencias de la Información. Coordina el Seminario de Investigación del Grupo DigiDoc (UPF) y forma parte del equipo de dirección, como IP, del proyecto de investigación del Plan Estatal de I+D+i dentro del que se inscribe este entregable. Es coordinador del Máster Universitario en Comunicación Social (MUCS) de la UPF. Su página personal: www.lluiscodina.com. Contacto: lluis.codina@upf.edu

Carlos Gonzalo es doctor en Comunicación Social por la Universidad Pompeu Fabra de Barcelona y Diplomado en Estudios Avanzados en 'Información y Documentación en la Era Digital' por la Universitat de Barcelona. Ha trabajado como Senior Information Analyst y Team Leader en el buscador Ask.com, y ha sido consultor de comunicación digital en la agencia Atrevia y analista digital en la editorial Penguin Random House. En la actualidad es profesor en el Máster en Buscadores de la Universidad Pompeu Fabra y director académico del posgrado en SEO y Social Media para comunicadores de la UPF Barcelona School of Management. Contacto: carlos.gonzalo@upf.edu 
PRÓLOGO

Por Carles Pont-Sorribes

PRIMERA PARTE: FUNDAMENTOS Y ASPECTOS CONCEPTUALES

1. Introducción

1.1 Objeto de estudio

1.2 Objetivos generales

1.3 Preguntas de investigación

2. Marco teórico

2.1 SEO y cibermedios

2.2 SEO semántico

2.3 Search eXperience Optimization

2.4 SEO y comunicación audiovisual

2.5 Noticias en buscadores: Google General, Google News e índice de noticias de Google España

2.6 SEO como parte de la sostenibilidad

\section{SEGUNDA PARTE: MARCO DE OPTIMIZACIÓN GLOBAL DEL SEO EN PERIODISMO}

3.1 Revisiones sistematizadas

3.2 Entrevistas semiestructuradas

4. Estrategias y protocolos

4.1 Framework de SEO semántico para cibermedios

4.2 Protocolo de análisis SXO para cibermedios

4.3 Estrategias SEO en Cibermedios para Google, Google News e Índice de Noticias de Google

5. Marco global: el Departamento de SEO y la Redacción

5.1. Función del Departamento de SEO

5.1.1. Tipos de SEO

5.1.2. Uso de herramientas SEO

5.1.3. Política de enlaces patrocinados

5.1.4. Formación SEO

5.2. La redacción

5.2.1. Principio de la doble titulación

5.2.2. Plataformas

5.2.3. Palabras clave, frases clave y conceptos

5.2.4. Chequeo y optimización SEO de la noticia

TERCERA PARTE: ENTREVISTAS Y CONCLUSIONES

6. Entrevistas: el SEO según sus profesionales y expertos

7. Conclusiones

BIBLIOGRAFÍA CITADA Y CONSULTADA

Anexos 


\section{PRÓLOGO \\ SEO: una brújula para el periodismo \\ Por Carles Pont-Sorribes}

Mayo 2020

El periodismo ha evolucionado históricamente conforme lo ha hecho la tecnología. Hoy no será diferente. Ante una situación de catarsis profesional y de transformación del modelo de negocio, la adaptación a las Tecnologías de la Información y la Comunicación (TIC) es tarea indispensable para la subsistencia en el mercado informativo.

El informe que han elaborado Carlos Lopezosa, Lluís Codina y Carlos Gonzalo-Penela sobre SEO y periodismo es un trabajo extraordinario para que medios, periodistas y gestores conozcan, precisamente, uno de estos retos tecnológicos. El interés de este trabajo radica en entender el uso de estrategias de posicionamiento en buscadores, el Search Engine Optimization (SEO).

Buscadores y plataformas como Google, YouTube, Twitter, Facebook o Instagram contribuyen a transformar el sector periodístico. Los medios de comunicación en la época de Internet tienen un objetivo prioritario: quedar bien posicionados en los grandes buscadores y obtener buena visibilidad para sus lectores.

Cada vez es más importante que los cibermedios tengan presencia destacada en agregadores de noticias o en redes sociales, mediante los cuales, obtienen tráfico en sus páginas web. Pero tener un buen posicionamiento del contenido informativo en los diferentes buscadores y plataformas no es fácil; solo con una estrategia clara de SEO se puede conseguir.

El trabajo de Lopezosa, Codina y Gonzalo-Penela explica con detalle el posicionamiento en buscadores para cibermedios a través de diferentes estudios de caso sobre la visibilidad web en medios digitales; la caracterización de diferentes tipos de SEO, como el SEO semántico, el VSEO, o el SXO; y la aplicación directa de estrategias de posicionamiento dentro de una redacción.

Los autores nos recuerdan que cada vez es más común encontrar en las redacciones de los medios de comunicación expertos en SEO, pero alertan que "todavía existe un largo camino para hacer que converja, de manera adecuada, el periodismo y el posicionamiento en buscadores". 
Éste es, sin duda, uno de los mayores retos. El otro, no menos importante, es conseguir una formación adecuada para los futuros periodistas. En el ámbito del aprendizaje hay que incidir para encontrar a los mejores profesionales, investigadores y docentes para dar a los periodistas herramientas básicas y una adecuada formación en SEO.

Los periodistas no es necesario que se conviertan en expertos en una materia que no es la suya, pero de igual forma que un informador debe conocer el funcionamiento de una cámara de televisión o de un programa para edición de textos, debería tener nociones claras del posicionamiento web para poder rentabilizar mejor su trabajo. Proporcionar las competencias básicas en SEO es tarea de las Facultades de Comunicación, especialmente en las carreras de Periodismo. Pero, a la par, los colegios profesionales, las asociaciones de prensa o los sindicatos deberían capitanear la formación en este ámbito para aquellas personas que necesitan reciclarse y que desde hace años ejercen la profesión periodística sin tener conocimiento de nuevas herramientas de posicionamiento.

En el ámbito profesional, la aplicación SEO ya está en casi todas las redacciones de forma más o menos integrada. Pero como nos recuerdan los autores de la investigación que aquí se presenta, aún queda mucho camino por recorrer. Por ejemplo: "existe una relación compleja entre los medios de comunicación y Google. Se trata de una relación de amor y odio por parte de los medios de comunicación".

Somos de la opinión que se trata de hacer posible lo inevitable. Es decir, todos los actores deben ver como una oportunidad esta connivencia entre medios y buscadores.

Las grandes corporaciones necesitan demostrar ante la opinión pública que comparten los valores éticos y democráticos de la libertad de información y opinión que encarna la prensa. Mientras que los medios de comunicación necesitan, inevitablemente, el concurso de estas empresas tecnológicas para poder ser vistos en el gran aparador virtual. Solo con una estrategia adaptativa, que tenga en cuenta la innovación, será posible que los medios mantengan audiencias. Además, necesitan atraer a los targets más jóvenes que, como es sabido, consumen la información de forma muy diferente a las personas de más edad.

En otro orden de cosas, la estrategia SEO puede ser vista como una nueva oportunidad para la sostenibilidad siempre que sea de modo bien entendido. Un ejemplo es la venta de enlaces de autoridad cada vez más extendida entre los medios. Se puede hacer de forma transparente y mediante códigos exigentes de autorregulación: "Estos enlaces de terceros se publican como parte del contenido de estos medios digitales a cambio de una contraprestación económica. 
El propósito de este nuevo modelo de negocio es el de mejorar la autoridad web y por consiguiente las posiciones en los resultados de búsqueda de estos anunciantes", explican Lopezosa, Codina y Gonzalo-Penela. Se trata de hacer de la necesidad virtud siempre que se observen principios estrictos, como los que separan contenido editorial de contenido patrocinado, tal como señalan los autores.

Los agregadores de noticias en línea tipo Google News o Yahoo! News o las redes sociales ya son el gran bazar informativo para millones de ciudadanos. Cada vez serán menos quienes irán al quiosco para reservar su ejemplar de periódico en papel. De igual forma, menos personas recordarán una dirección web para acceder a un medio concreto o se conectarán a una hora determinada al informativo radiofónico o televisivo en tiempo real.

El consumo de noticias es multiplataforma y sus lectores, oyentes o telespectadores, llegan por múltiples canales y a todas horas. El periodismo ya no puede presentar las noticias de igual forma para la web que para la lectura móvil o para ser visto o leído en una plataforma como Twitter o Instagram.

La investigación que han elaborado Carlos Lopezosa, Lluís Codina y Carlos GonzaloPenela concluye que hay una necesidad de desarrollo de estrategias de posicionamiento en buscadores por parte de los medios de comunicación online. Los cibermedios necesitan obtener más lectores y dar mayor visibilidad a sus contenidos. Y, además, precisan ofrecerlas a un público objetivo específico.

Los autores no solamente identifican el principal problema, sino que aportan soluciones y proponen nuevas líneas de investigación que pasan por la creación de herramientas de auditoría SEO; estrategias de posicionamiento en buscadores; y formación en SEO y visibilidad web. Proponen nuevos análisis que ayudaran a ampliar el cómo y el porqué del SEO a través de nuevas observaciones participantes a otros cibermedios nacionales e internaciones.

\section{Estrategias de posicionamiento para combatir fake news}

El interés de la investigación que aquí se presenta tiene un largo recorrido que tiene gran conexión con la actualidad. Una de las lecciones que nos ha dejado la crisis del Covid-19 es que la información de calidad es extraordinariamente valiosa para los sistemas democráticos. La emergencia sanitaria se ha convertido en una pandemia informativa, una "infodemia" en palabras de la Organización Mundial de la Salud (OMS). 
La burbuja informativa del coronavirus se ha caracterizado, en gran parte, por información falsa (fake news). Y la inventiva y las teorías de la conspiración han llegado a crear contenidos en los que se avanza que existen remedios naturales para curar el virus; o que es un intento del "Estado profundo" para controlar el crecimiento de la población.

Estas informaciones han dado la vuelta al mundo en cuestión de segundos, pero muchas también han sido desmentidas con gran rapidez gracias a los medios de comunicación o a las plataformas sociales.

Una buena estrategia SEO por parte de los grandes medios ha sido imprescindible para reducir el ruido ambiental y poder llegar a audiencias segmentadas. Un interés que, a nuestro entender, no solo era de los grandes medios de comunicación sino también de los gobiernos, que querían combatir la desinformación.

Los medios de comunicación que trabajan con rigor y que tienen la deontología como un elemento central de su trabajo tienen una buena oportunidad para combatir con mejor eficacia la propagación o el contraste de las denominadas fake news quedando privilegiados en las búsquedas y el posicionamiento de los grandes buscadores. Éstos, como se ha demostrado en la crisis del Covid-19, han alardeado de luchar contra la desinformación y han dado prioridad a la lucha contra la información no verificada. En este contexto, los medios de comunicación convencionales, aquejados por una transformación imparable, deben orientar su brújula en mejorar su optimización global de SEO e implantar en sus redacciones una cultura del posicionamiento en buscadores que les permitirá encontrar un buen norte con más prontitud. Leer los consejos de la investigación de Lopezosa, Codina y Gonzalo-Penela es un primer paso. ¡Disfrútenla!

Carles Pont-Sorribes es periodista, académico e investigador en periodismo. Es director de la Cátedra Ideograma-UPF y miembro del Grupo de Investigación en Comunicación Política POLCOM. Es director del Grado en Periodismo de la Universitat Pompeu Fabra.

Citación

Pont-Sorribes, Carles (2020). "SEO: una brújula para el periodismo". En: Lopezosa, Carlos; Codina, Lluís; Gonzalo-Penela, Carlos. SEO y Periodismo. Marco de optimización global como parte del emprendimiento en cibermedios. Barcelona: Departamento de Comunicación. Serie DigiDoc-Tendencias. Mayo 2020 


\title{
SEO y periodismo: \\ Marco de optimización global como parte del emprendimiento en cibermedios
}

\author{
[en] SEO and journalism: \\ Global optimization framework as part of digital news media \\ entrepreneurship
}

Por Carlos Lopezosa (UPF), Lluís Codina (UPF) y Carlos Gonzalo-Penela (UPF)

\begin{abstract}
Resumen
Este trabajo propone un marco integral para la optimización del posicionamiento en buscadores y está dirigido sobre todo a periodistas y comunicólogos. También, por supuesto, a profesores de las materias de SEO en grados de Periodismo o materias relacionadas. Para ello, se presentan los componentes principales que inciden en el marco global de optimización del SEO que afecta a un medio digital o cibermedio. Nuestra mirada está dirigida sobre todo a nuevos medios y al emprendimiento en periodismo. De este modo, este informe presenta, de una forma integrada, los aspectos esenciales que una redacción periodística debe tener en cuenta para poner en marcha estrategias de SEO y en definitiva para incrementar la visibilidad de sus producciones en las plataformas digitales. Además, incluye las entrevistas efectuadas a profesionales del SEO y el periodismo para completar, gracias a estas visiones, una propuesta holística sobre SEO y medios de comunicación.
\end{abstract}

Palabras clave

Posicionamiento web, SEO, periodismo, cibermedios, periodismo digital, medios de comunicación digitales, Google, YouTube, visibilidad web.

Abstract

This research proposes a comprehensive framework for the optimization of search engine positioning and is principally of interest to journalists; communication experts; and academic professors of SEO subjects in Journalism or related disciplines. It presents the main factors that affect the global SEO optimization framework which, in turn, affects a digital or a cybermedia. Our attention is mainly drawn to new media and journalism entrepreneurship. We recount in an integrated way the essential aspects that a journalistic newsroom must take under consideration to implement SEO strategies and, therefore, to increase the visibility of its productions on digital platforms. Transcription of interviews with SEO experts and journalism professionals are included. In that manner, we offer a holistic proposal on SEO in the media.

Keywords

Web positioning, SEO, journalism, digital media, digital journalism, digital media, Google, YouTube, web visibility. 


\section{PRIMERA PARTE FUNDAMENTOS Y ASPECTOS CONCEPTUALES}

\section{Introducción}

Los sitios web forman parte, actualmente, de uno de los escenarios más importantes de acceso a la información. Bajo esta circunstancia, los medios de comunicación se han visto obligados a adaptar sus rutinas productivas y sus estrategias comunicativas (Rodríguez-Martínez et al, 2012) para formar parte del ecosistema de la web. Esto ha provocado que los cibermedios se hayan convertido en uno de los pilares fundamentales para difundir noticias y para atraer nuevos lectores.

Cada vez es más frecuente encontramos con mayor concentración de sitios web afines a los medios de comunicación, de hecho, en la actualidad, la gran mayoría de los diarios en papel cuentan con su versión digital (Rodríguez-Martínez et al, 2010) y lo mismo sucede con las principales radios y televisiones.

Estamos ante una época de cambio, que ha propiciado que los medios de comunicación $y$, concretamente, los cibermedios se hayan transformado en entidades complejas, con cualidades casi únicas dependiendo de cada medio de comunicación. Estas cualidades vienen dadas por:

- El contexto de cada empresa periodística, es decir, de sus recursos humanos, técnicos y tecnológicos (Iglesias-García, 2012).

- Sus limitaciones intrínsecas, como pudieran ser el todavía peso de la edición en papel, o la falta de formación vinculada con los nuevos perfiles profesionales que está demandando el propio sector.

A esto hay que sumarle la entrada de unos nuevos actores, que están modificando el sector periodístico y sobre todo están perjudicando la rentabilidad de dichos medios de comunicación; se trata de las grandes plataformas de Internet como Google, Facebook, Twitter, etc. que cuentan, entre sus modelos de negocio, la explotación de la información digital.

Si bien es cierto que, los actuales cibermedios españoles cuentan ya con más de 20 años de historia (Salaverría, 2007), todavía existen muchos retos que deben superar. No solo han tenido, y están teniendo, que adaptar su modelo empresarial - muy distinto a los modelos tradicionales -, sino que, además, esta adaptación precisa de innovaciones 
constantes si se quiere competir por las audiencias, ya que los cambios de Internet son muy rápidos.

Por lo tanto, nos encontramos con cambios tecnológicos que no solo afectan al modelo de negocio, sino que también obliga a los cibermedios a reorientar constantemente sus contenidos y estrategias (Rodríguez-Martínez et al, 2010; Suárez-Sucre2017). También se ven envueltos en este escenario de cambio los propios profesionales de este sector que se ven obligados a conocer las últimas tendencias tecnológicas para aplicarlas a sus noticias, mientras se abre el debate de si estas tendencias afectan o no a la labor social del periodismo (López, 2017; Muerza, 2017) y a la calidad de las noticias.

Dentro de estos cambios tecnológicos, se abren paso nuevas estrategias empresariales que se relacionan con el uso de técnicas o estrategias de posicionamiento en buscadores, en inglés Search Engine Optimization (SEO), que ayudan a mejorar la visibilidad web de las noticias y por tanto aumentan las posibilidades de aparecer en los lugares preferentes de los resultados de búsqueda de Google, Bing, Yandex, Baidu, entre otros. Todo ello se traduce en la obtención de mayor tráfico web (lectores).

\subsection{Objeto de estudio}

El objeto de estudio del trabajo que presentamos en este informe es el Search Engine Optimization (en adelante, SEO) aplicado a los medios de comunicación en línea (cibermedios), y más concretamente, las diferentes formas de optimización que se pueden aplicar a la producción periodística.

\subsection{Objetivos generales}

El objetivo principal de este trabajo es el desarrollo y presentación de una investigación integral sobre SEO y medios de comunicación online. Para ello proponemos diferentes estudios sobre la caracterización de diferentes tipos de SEO como el SEO semántico, el VSEO (optimización del posicionamiento en vídeos), o el SXO (optimización de la experiencia del usuario) sobre la aplicación directa de estrategias de posicionamiento dentro de una redacción y sobre la percepción de acuerdo sobre el SEO en medios digitales desde el punto de vista de los consultores en posicionamiento en buscadores.

A partir del objetivo principal anteriormente señalado, los objetivos concretos que hemos derivado para este trabajo son los siguientes:

1. Caracterizar el SEO semántico, el VSEO, y el SXO, identificar sus principales componentes de acuerdo con la corriente principal entre académicos y profesionales de este ámbito y plantear, de este modo, metodologías y procesos de aplicación en medios de comunicación online. 
2. Aportar una serie de recomendaciones de aplicación SEO en cibermedios tanto, en los ya existentes como en los nuevos proyectos de emprendimiento periodístico. 


\subsection{Preguntas de investigación}

De acuerdo con estos objetivos, las preguntas de investigación que nos hemos formulado para llevar a cabo este estudio son las siguientes:

1. ¿Es posible identificar sin ambigüedad las características del SEO semántico, el VSEO, y el SXO y sus principales elementos como una estrategia eficaz de visibilidad y posicionamiento web real para medios de comunicación digitales?

2. ¿Es factible aportar una serie de recomendaciones de aplicación SEO para optimizar la visibilidad de las producciones periodísticas?

\section{Marco teórico}

Internet se ha consolidado como uno de los escenarios predominantes para el acceso a la información. Ante esta circunstancia, los medios de comunicación han tenido que adaptar su trabajo diario y sus estrategias de comunicación (Rodríguez-Martínez et al, 2012) convirtiendo a los medios digitales en un pilar fundamental para la difusión de noticias.

A esto hay que sumarle que muchos usuarios consumen noticias a través de los buscadores como Google, Bing, entre otros, que incluyen en sus resultados las noticias de terceros, es decir, de los medios de comunicación digitales. Además, estas noticias no solo se consumen a través de estas plataformas, sino que los usuarios solo consultan aquellas páginas que ocupan una posición preferente dentro del buscador, es decir, las que ocupan las primeras posiciones.

Aparecer en estos lugares preferentes no es sencillo, para ello, los medios digitales deben aplicar una serie de técnicas o procesos, comúnmente conocidos como estrategias de posicionamiento en buscadores, o Search Engine Optimization (SEO).

\subsection{SEO y cibermedios}

De este modo, el SEO consiste en un conjunto de técnicas que se llevan a cabo tanto dentro como fuera de un sitio web para tener mayores posibilidades de aparecer en los principales resultados de búsqueda. Esto provoca que el contenido posicionado tenga mayor visibilidad y por tanto mayor tráfico web, como ya hemos señalado. 


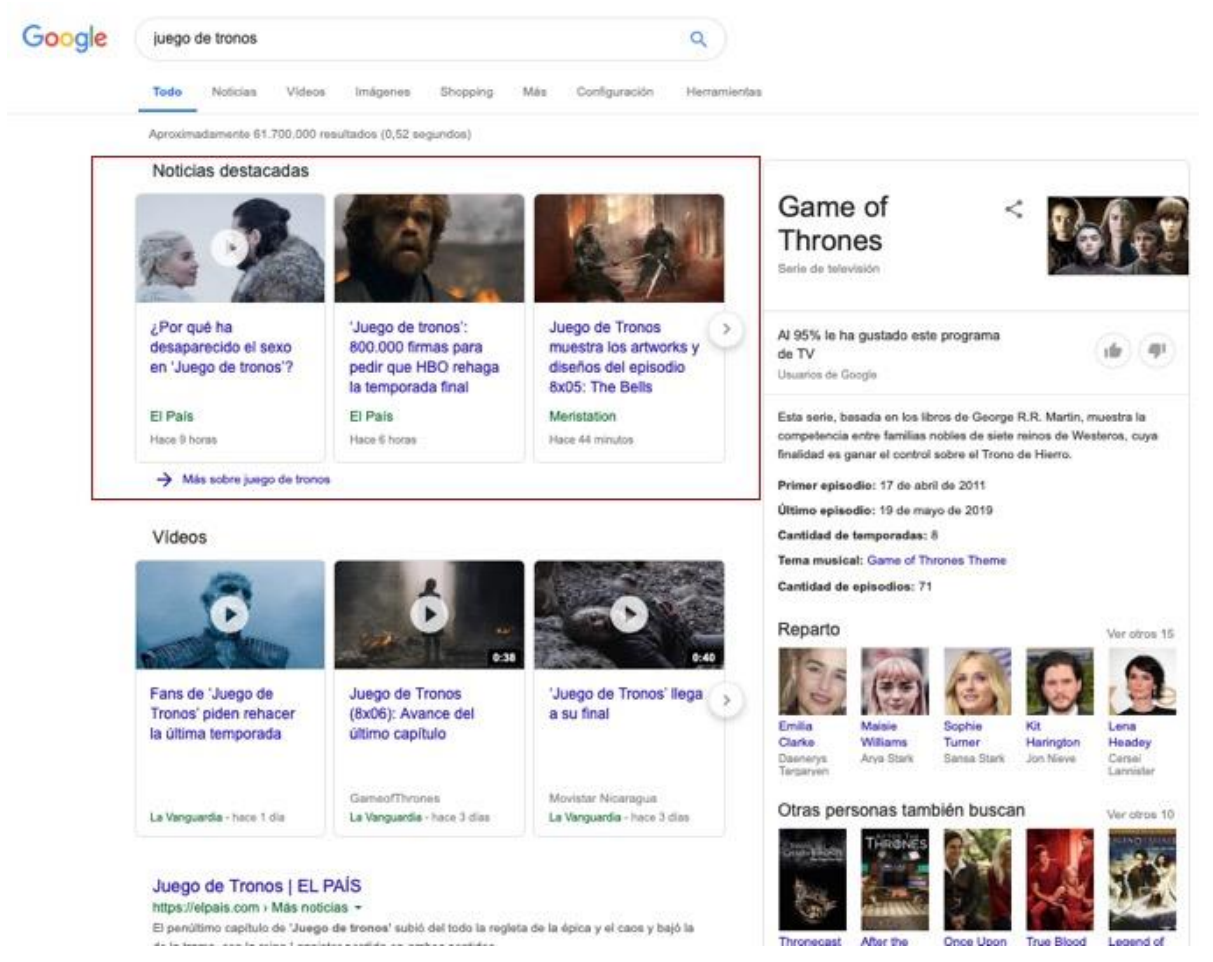

Figura 1: Resultados de búsqueda con base en la consulta "juego de tronos". En el recuadro rojo se recogen los resultados en primera posición que corresponden a noticias de cibermedios.

Como sea, estamos en un contexto en el que la diversificación de la industria periodística en Internet ha supuesto muchos cambios en las rutinas periodística, principalmente propiciadas por los nuevos vectores para la difusión informativa, los buscadores (Smyrnaios, Rebillard, 2015).

En consecuencia, ante el auge de estos buscadores, el periodismo tradicional se vio envuelto, hace ya más de una década, en desafíos importantes (Carlson, 2007). Por otro lado, el aumento de las noticias en línea ha significado una creciente competencia y a la vez una creciente dependencia de las empresas de comunicación frente a los motores de búsqueda.

Desde el punto de vista de los editores, esta tendencia es tanto un problema como una necesidad (Smyrnaios, 2015) ya que gran parte del tráfico web proviene de los buscadores y los medios de comunicación han debido adaptarse en la medida de sus posibilidades.

Como sea, la función social, que acabaron adoptando tempranamente los motores de búsqueda, fue la de ayudar a los usuarios a acceder al contenido más relevante en cada caso (Machill, et al 2008) y es por este motivo por el que el periodismo no puede ignorar el SEO. 
De este modo, la visibilidad web se ha revelado esencial para obtener más lectores, por lo que ha sido necesario hacer entender a las redacciones de los medios que es esencial crear un proceso de trabajo que contemple estrategias de posicionamiento (Giomalakis, Veglis, 2015).

A pesar del tiempo transcurrido, diversos estudios sobre SEO y medios de comunicación demuestran que todavía existe un espacio de mejora entre las rutinas periodísticas y las rutinas SEO (Smyrnaios, Sire 2014; Giomalakis, veglis, 2015a;).

$Y$, aunque cada vez es más frecuente encontrar en las redacciones expertos en SEO, siempre existe la necesidad de hacer que converja, de manera adecuada, el periodismo y el posicionamiento en buscadores.

En cualquier caso, la aplicación del SEO en las redacciones de todo el mundo es variada y su aplicación no es universal. Los esfuerzos para las prácticas SEO se ven limitados por el tiempo, los recursos y el apoyo de la administración de los medios, así como por cuestiones técnicas no relacionadas directamente con las páginas web (Dick, 2011).

Las primeras aproximaciones prácticas entre ambos espectros se realizaron en el año 2009 (Asser, 2012) en la redacción de BBC News, con la creación de un doble encabezado. Éste se caracterizaba por mantener los titulares de los índices sin cambios a la vez que introducía un texto más largo y optimizado para la búsqueda.

Esto provocó que, entre la segunda mitad de 2009, y la primera mitad de 2011, las visitas a la sección noticias de BBC News aumentaran un $57 \%$ y las visitas, en conjunto de toda la web, creciesen un $34 \%$.

No es de extrañar que las labores de SEO en BBC News se vieran recompensada. De hecho, el estudio de Reuters Institute denominado Digital News Report (Newman, David Levy, 2014) sobre audiencias en Reino Unido confirmó que el $14 \%$ de los usuarios que buscaban noticias de última hora, lo hacían a través de los buscadores.

En definitiva, existen diferentes maneras de aplicar el SEO en las redacciones, y todas ellas se deberían de barajar si se quiere conseguir más lectores, sin embargo, debido a las complejas rutinas productivas dentro de una redacción y la casuística de cada medio (recursos económicos, resistencia al cambio, estrategia gerencial, etc.), en muchas ocasiones, el SEO es complicado de asimilar y de aplicar.

En cualquier caso, existen algunos ejemplos en forma de procedimientos de aplicación de estrategias SEO y aunque no exista un consenso total sobre ellos, sí existen patrones que comienzan a generalizarse como son el mencionado doble titular promovido por BBC News. 


\subsection{SEO semántico}

La semántica es la parte de la lingüística que estudia el significado de las expresiones en el lenguaje humano. Extrapolado a la web, la semántica trata del significado de los contenidos que se encuentran en un sitio web.

Las personas entienden el significado de los contenidos web cuando los lee, sin embargo, los programas que rastrean webs no entienden el significado de lo que rastrean. Esto hace que la reproducción de los contenidos rastreados precise de capas intermedias que hagan de traductor.

La web semántica intenta establecer una interfaz intermedia que ayude al motor de búsqueda a interpretar los datos de la web. Esa capa intermedia, clasifica los contenidos a través de marcados semánticos que identifican los significados, esto permite dar un salto cualitativo en la obtención de resultados de búsqueda, haciendo que éstos sean más eficaces y refinados.

La web semántica ha afectado a los resultados de búsqueda y esto, a su vez, está afectando a los medios de comunicación ya que se está imponiendo el SEO semántico en los resultados de búsqueda.

Imaginemos que queremos ir al cine esta tarde y hemos decidido ver la película Blade Runner 2049. Si hacemos una búsqueda de este film comprobaremos que unos nuevos resultados de búsqueda están colonizando la primera página de Google, relegando a un segundo plano los resultados tradicionales.

Si desglosamos la búsqueda que hemos realizado, veremos lo siguiente: 


\title{
Cartelera de Blade Runner 2049
}

Todos los horarios corresponden a la CET

\begin{tabular}{|c|c|c|c|c|c|}
\hline \multicolumn{2}{|l|}{ Hoy } & \multicolumn{2}{|c|}{ Mañana } & \multirow{2}{*}{$\begin{array}{l}\text { mar., } 7 \text { nov. } \\
\text { Noche }\end{array}$} & \multirow[t]{2}{*}{ mié., 8 nov. } \\
\hline Cualquier hora & Mañana & Tarde & Media tarde & & \\
\hline \multicolumn{6}{|c|}{ Palau Balaña - Mapa } \\
\hline Estándar 19:00 & & & & & \\
\hline \multicolumn{6}{|c|}{ Filmax Granvía - Mapa } \\
\hline \multicolumn{6}{|l|}{ Estándar $19: 45$} \\
\hline \multicolumn{6}{|c|}{ Arenas de Barcelona Multicines - Mapa } \\
\hline Estándar 18:50 & $21: 45$ & & & & \\
\hline Mác & pases & & & & \\
\hline
\end{tabular}

Figura 2: Resultados de búsqueda con base en la consulta "Blade Runner 2049". Información en tiempo real

Este resultado de búsqueda nos dice, en tiempo real, los horarios de los cines para aquellos usuarios que busquen Blade Runner 2049 con la intención de ir a verla. Vemos, además, que arroja resultados geolocalizados, puesto que se tiene en cuenta nuestra ubicación. El motivo de que aparezcan estos tres cines y no otros es porque son los cines que mejor SEO semántico están realizando.

\author{
Blade Runner 2049 (2017) - FilmAffinity \\ https://www.filmaffinity.com/es/film236626.html v \\ *t*t*k Valoración: 7,3/10 - 15.921 votos \\ 6 oct. 2017 - Blade Runner 2049 es una pelicula dirigida por Denis Villeneuve con Ryan Gosling, \\ Harrison Ford, Ana de Armas, Jared Leto, .... Año: 2017. \\ Denis Villeneuve · Blade Runner · 2036: Nexus Dawn (C) · Ana de Armas
}

Figura 3: Resultados de búsqueda con base en la consulta "Blade Runner 2049". Resultado de búsqueda en forma de Rich snippet o resultado enriquecido

Los así llamados rich snippets, o "datos enriquecidos", nos dan, en este caso, una puntuación en forma de estrellas, puntuación del 1 al 10 e información de número de personas que votaron esta película. Incluye también enlaces relacionados (director, otras adaptaciones, etcétera). Se trata de un resultado de valoración que ayuda al usuario a saber si la película ha gustado o no. Por lo tanto, sirve como resultado de búsqueda de prescripción. 


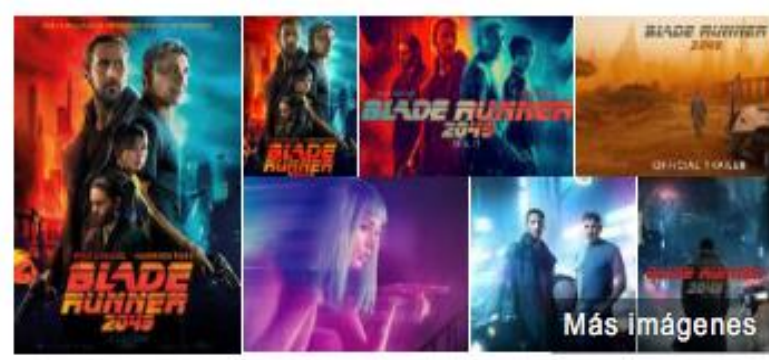

\section{Blade Runner 2049}

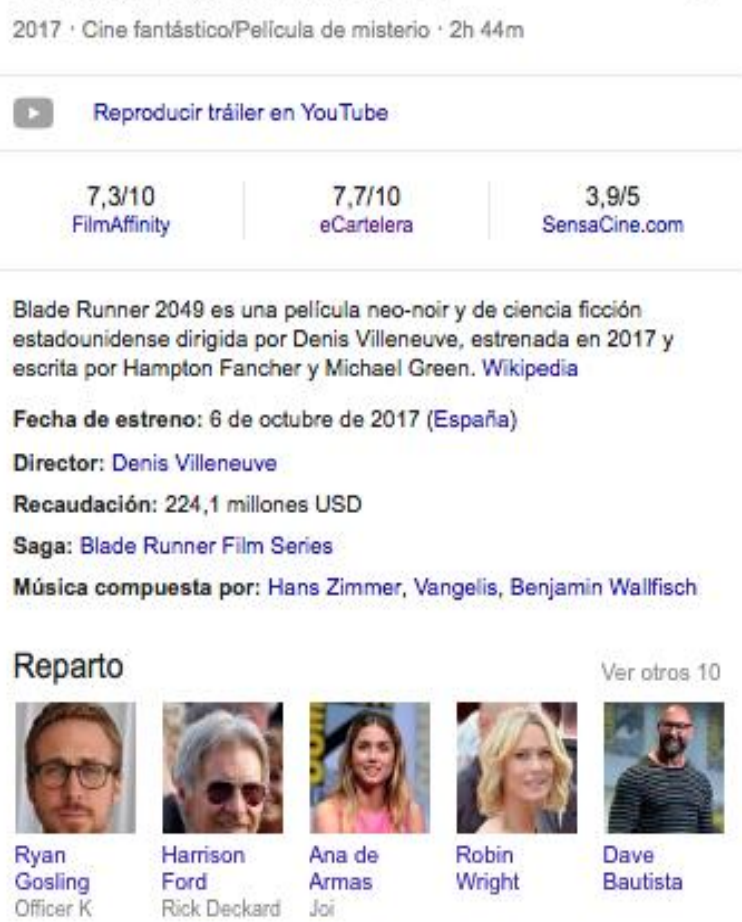

Figura 4: Resultados de búsqueda con base en la consulta "Blade Runner 2049". Resultado de búsqueda en forma de Gráficos de conocimiento

Este gráfico de conocimiento nos muestra imágenes de la película, desde el póster promocional, pasando por fotogramas concretos, un enlace al tráiler, la fecha de lanzamiento, el nombre del director, la duración de la película, su recaudación, información sobre el reparto, y lo más importante, la puntuación de tres portales de crítica de cine: FilmAffinity, eCartelera y SensaCine.com.

¿Por qué aparecen estos tres resultados, pero no aparecen los medios de comunicación líderes en crítica de cine como pudieran ser Fotogramas, Cinemania, etc.? La reflexión es sencilla, porque los tres portales anteriores están haciendo una labor más eficiente de su SEO semántico.

El término SEO semántico, aunque con pequeñas aproximaciones en 2004 y posteriormente en 2008, comienza a cobrar fuerza a partir de 2010 (Tamas Doszkocs, 2010; Briggs, 2012; Mashable, 2012; DiSilvestro, 2013; Brown, 2013; Kosaka, 2016; 
Wells, 2017; Paolini, 2017; Schubert, 2017), cuando empiezan a desarrollarse aproximaciones teóricas sobre este concepto.

Con base en la evolución del término, nos encontramos con un avance que incluye:

- Una primera fase centrada en el buscador y que reconoce que los buscadores son capaces de devolver resultados de búsqueda personalizados, entendiendo el contexto y la forma en la que el usuario realiza la búsqueda.

- Una segunda fase focalizada en la optimización semántica, o lo que es lo mismo a la optimización de la intencionalidad de la búsqueda en el contexto de cada usuario.

Por lo tanto, el SEO semántico se encarga de ayudar a los motores de búsqueda a devolver las consultas más adecuadas, independientemente de si el usuario utiliza términos de búsqueda obvios o no. Desarrollar estrategias de SEO semántico ayuda a los buscadores a entender mejor el contenido de un sitio web y favorece la posibilidad de aparecer en estos resultados de forma enriquecida.

En definitiva, los medios de comunicación deben adaptarse al SEO Semántico y aplicarlo si no se quiere aparecer en un segundo plano en los resultados de búsqueda. Para ello, deben enfrentarse a dos retos importantes. El primero hace referencia al trabajo periodístico y a sus profesionales, ya que deben adaptarse a estrategias de SEO si quieren aparecer en los resultados de búsqueda. Y el segundo reto hace hincapié en los nuevos resultados de búsqueda de las noticias, ya que a mayor optimización de SEO semántico mayores posibilidades se tendrán de aparecer en los resultados de manera enriquecida, ofreciendo una mayor inmediatez para el lector, al mismo tiempo que se incrementa la ya dura competencia entre medios por copar los primeros resultados en los buscadores.

\subsection{Search eXperience Optimization}

El Search eXperience Optimization (en adelante SXO) es un novedoso campo de estudio que incorpora al SEO "tradicional" aspectos de optimización de la experiencia de usuario tales como la arquitectura de la información, las taxonomías y la buscabilidad, junto con aspectos del SEO convencional como la optimización de contenido, el uso de palabras clave, o la incorporación de metadatos. 
Son muchos los autores (Cutts, 2012; Potter, 2012; Villanueva, 2013; Munroe, 2015; Arora, 2016; Chasinov, 2017) los que han teorizado y apoyado el concepto SXO como elemento fundamental para el posicionamiento web. Esta nueva forma de hacer SEO viene precedida del propio enfoque de los actuales buscadores, que utilizan métricas en donde interviene el comportamiento humano para determinar si los resultados de búsqueda ofrecidos son correctos o no (Arora, 2016; Gandhi, 2017).

Es por este motivo por el que el SEO tradicional está evolucionando hacia el SXO, un conjunto de técnicas que se enfocan a los usuarios (Templeman, 2016; Chasinov, 2017; Wang, 2016). Es decir, estamos pasando de posicionar el contenido en base a palabras clave (SEO tradicional) a posicionarlo de manera que el usuario se sienta cómodo en una página web, navegue por más contenido y regrese nuevament porque la web visitada le ha gustado o le ha ofrecido la información que necesitaba (Villanueva, 2013).

Por lo tanto, podemos considerar el SXO como el conjunto de estrategias o técnicas utilizadas para optimizar la interacción de los usuarios con el contenido de un sitio web (Munroe, 2015; Pérez-Montoro y Codina, 2016; Wang, 2016; Gandhi, 2017; Manish y Roohi, 2013).

Por lo tanto, para obtener una mejor posición en los buscadores, las páginas web deben centrarse en ofrecer la mejor experiencia de usuario posible, ya que buscadores como Google son capaces de encontrar e interpretar señales de usuario, que utilizan para posicionar, en sus resultados, unos contenidos u otros (Arora, 2016; Kukoo, 2016).

A la vista de lo anterior, y considerando que las propuestas tanto de definición del SXO como de las técnicas que lo configuran son una realidad solvente como campo de estudio y de aplicación, los medios de comunicación online tienen el reto de aplicar estas técnicas e incluso de crear sus propios procedimientos de Search eXperience Optimization si quieren obtener mejores ratios de visibilidad web en buscadores.

\subsection{SEO y comunicación audiovisual}

El periodismo, sin duda bajo la fuerte influencia de Internet, es cada vez más visual. Como parte de esta tendencia, así como de otras presiones concurrentes, hace tiempo que los principales medios de comunicación disponen de canales en YouTube.

Mediante estos canales, los medios de comunicación disponen de una plataforma adicional donde difundir sus producciones periodísticas. Es una estrategia comprensible dada la importancia de YouTube como fuente de información para una gran cantidad de ciudadanos. De hecho, se considera que es el segundo buscador más importante del mundo, justo después de Google (Spencer, 2018). 
El vídeo se está convertido en uno de los contenidos de consumo predominantes en Internet. Esto está provocando que los motores de búsqueda estén teniendo cada vez más en cuenta este tipo de formato en sus resultados.

De hecho, el estudio de Searchmetrics publicado en 2018 sobre búsquedas universales, es decir, aquellas que se obtienen a nivel global, confirmó que cuando realizamos una búsqueda por móvil, el $23 \%$ de los resultados que se obtienen son vídeos, mientras que cuando llevamos a cabo una búsqueda por ordenador, este porcentaje es del $22 \%$ (Jarboe, 2018).

A esto hay que sumarle que las webs centradas en ofrecer vídeos cada vez tienen un mayor protagonismo. Según MWP, el vídeo en línea representa en 2018 la mitad de todo el tráfico en el móvil y se espera que, en 2021, el tráfico de video constituya el $81 \%$ de todo el tráfico web, tanto en móvil como en ordenador. (Kakarr, 2018).

Ante el auge y poder del vídeo, no es de extrañar que nos encontremos con que YouTube se haya convertido, según el Ranking Alexa, en el segundo sitio web más popular del mundo ya que cuenta con 30 millones de visitas al día y sus usuarios pasan una media de 8 minutos navegando por sus páginas, (Richards, 2018).

El protagonismo de YouTube se ve reflejado también en su cuota de mercado, de hecho, el $92 \%$ del mercado de los vídeos está en sus manos. Por el contrario, el $8 \%$ restante lo compiten principalmente los sitios web de Vimeo, Dailymotion y Vevo (Jarboe, 2018).

Además, YouTube está considerado no solo una de las webs más importantes sino también es el segundo buscador con más tráfico en el mundo (Spencer, 2018), por detrás de Google y por delante de Bing.

Ante estas circunstancias, los cibermedios cada vez están apostando más por el formato audiovisual y por la creación de canales en YouTube para dinamizar y promover sus vídeos.

En este sentido, los medios de comunicación están adoptando un enfoque emprendedor en cuanto al uso del vídeo. Según algunos autores, este nuevo enfoque viene dado principalmente por la percepción que éstos tienen sobre plataformas como Google, Facebook o YouTube (Kalogeropoulos; Kleis, 2017) a las que las consideran esenciales como herramientas de oportunidad de negocio.

Para muchos analistas, YouTube es una de las grandes plataformas de vídeo, por lo que cada vez es más frecuente encontrarnos con canales de cibermedios en esta plataforma.

Ante esta circunstancia cada vez son más las aproximaciones e investigaciones llevadas a cabo sobre YouTube y sobre noticias en formato vídeo. Los principales campos de 
investigación en la actualidad sobre cibermedios y esta plataforma hacen hincapié en la interactividad entre periodista y usuario, sobre la calidad de la producción del vídeo, del contenido y sobre la objetividad del mismo.

Hay autores que están estudiando el análisis de la interactividad entre periodista y usuario desde el punto de vista del contenido y de los elementos noticiosos producidos por la interactividad entre usuario, periodista y vídeo (como pudiera ser análisis de los comentarios del vídeo, entre otras cosas) (Al Nashmi et al, 2017); incluso algunos teóricos han planteado su propio marco de trabajo capaz de analizar la interactividad y el compromiso de los usuarios frente a una noticia en formato vídeo subida a YouTube (Ksiazek et al 2016).

Otra de las grandes iniciativas llevadas a cabo por los investigadores sobre cibermedios, vídeos y YouTube, tiene que ver con el éxito en el número de reproducciones por parte de usuarios. Se confirma que los vídeos que siguen un estándar de calidad en la producción del vídeo y un contenido con más puntos de vista son los que suelen tener mayor éxito (Peer, Ksiazek 2011).

Por nuestra parte, consideramos que otro de los elementos a tener en cuenta para el éxito o fracaso de un vídeo pasa por tener una mayor visibilidad. Para ello, a continuación, mostramos una revisión sobre la optimización de vídeos, con especial énfasis en la plataforma/buscador YouTube.

YouTube tiene un algoritmo de posicionamiento diferente al de Google (Jarboe, 2018; Fons, 2018a). Este algoritmo interno es el que permite ordenar los vídeos que se muestran en los resultados de búsqueda (Yu, 2015).

Como en el caso de otros buscadores, el objetivo del algoritmo de posicionamiento de YouTube es el de ayudar a los usuarios a encontrar los vídeos que quieren ver, con base en la relevancia de los mismos (Jarboe, 2018). Es decir, YouTube clasifica todos los vídeos relevantes por orden de tiempo de visionado, recompensando los vídeos que son más atractivos.

Tal como sucede con Google y las páginas web, para que los vídeos obtengan mayor visibilidad, es necesario que éstos aparezcan entre los primeros resultados del buscador de YouTube.

Para conseguir esta posición destacada, cada vez es más frecuente que los administradores de los canales apliquen estrategias de SEO que ayudan a este objetivo. EI SEO en YouTube consiste en el conjunto de procedimientos que se aplican a los vídeos que se suben a esta plataforma para obtener mayor visibilidad no solo en el motor de búsqueda de YouTube sino también en Google, Bing, etc. 
Se trata de la aplicación de un conjunto de buenas prácticas para que los motores de búsqueda sean capaces de ofrecer a los usuarios los mejores resultados cuando buscan vídeos.

Existe algunos ejemplos teóricos en forma de procedimientos y recomendaciones sobre SEO en YouTube, llevados a cabo por una gran parte de los principales estudiosos en el campo del posicionamiento de vídeos (Yu, 2015; Choudhari, 2015; Bhallab, 2015; Litsa, 2016; Bonelli, 2017; Hollings, 2017; Boachie, 2017; Spencer, 2018; Dean, 2018; Fons, 2018; Smarty, 2018; Jarboe, 2018).

En resumen, existen diversas recomendaciones en forma de estrategias, o técnicas sobre cómo se deberían realizar las labores de SEO en YouTube para que los vídeos que se publiquen puedan aparecer en lugares preferentes de los resultados de búsqueda de YouTube y de este modo obtener más visualizaciones.

\subsection{Noticias en buscadores: Google General, Google News e índice de noticias de Google España}

Existe una serie de índices de Google que pueden incorporar noticias, en concreto, tenemos los siguientes:

- índice general, también llamado búsqueda universal, de Google;

- Google News, esto es, el servicio especializados en noticias (desactivado en España);

- índice de noticias de Google España, esto es, el apartado que contiene solamente noticias, presentado en forma de una pestaña o una opción de navegación de la búsqueda universal.

Como decimos, en cada uno de estos índices pueden aparecer contenidos generados por medios de comunicación, por lo que, para un periodista es importante conocer sus diferencias y situarlos en su propio contexto.

El índice general de Google está concebido para dar respuestas a todo tipo de búsquedas, independientemente de que sean informacionales y de actualidad o no, mientras que en Google News y el índice de noticias de Google España solo se recogen noticias actualizadas (Osman, 2017).

El índice de noticias de Google España, como veremos a lo largo de este apartado, nace de la salida del servicio Google News de España, y aunque devuelve resultados noticiosos, existen claras diferencias entre ambos índices de noticias. 


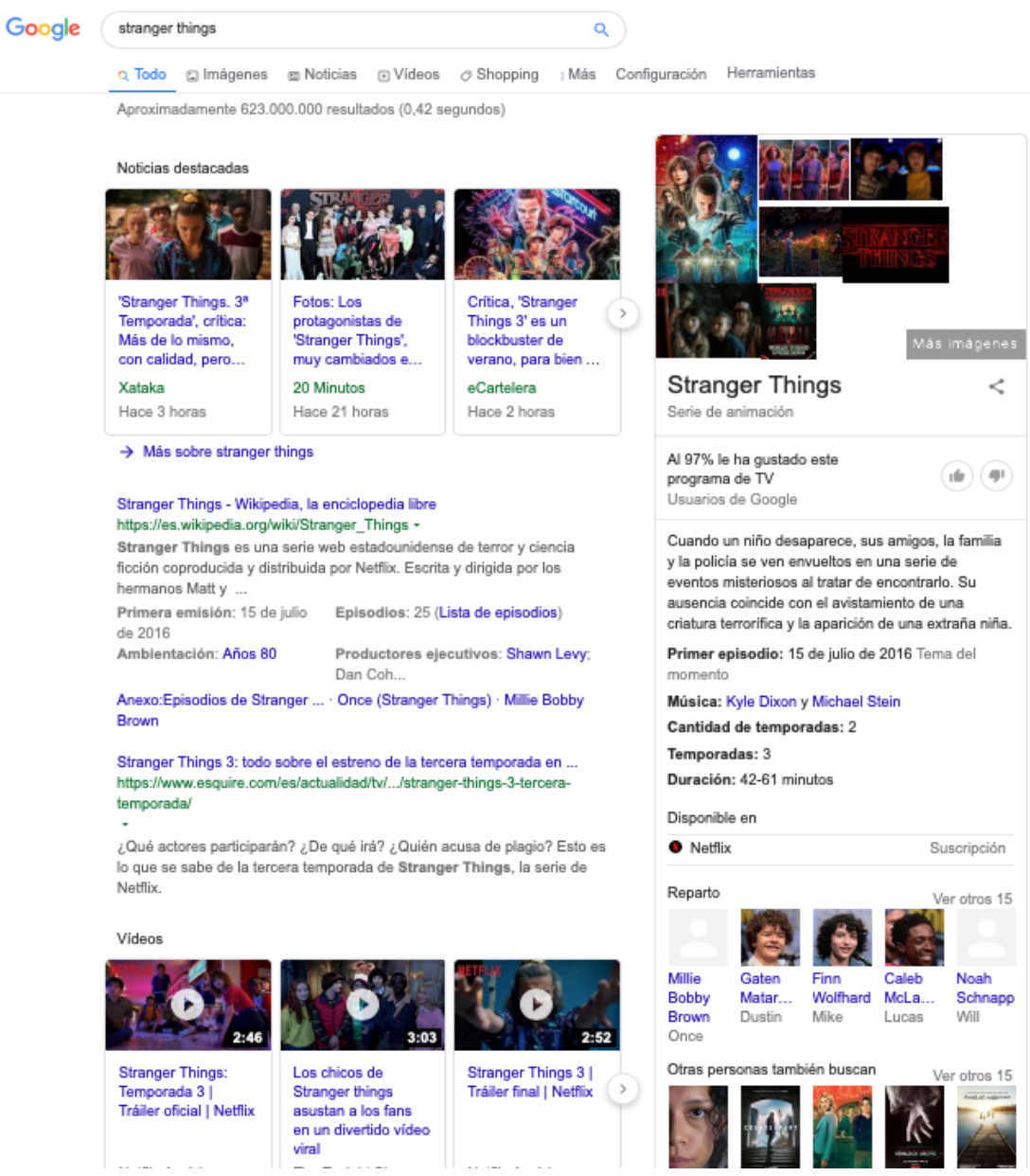

Figura 5: Índice general de Google. En la imagen se muestran los resultados de búsqueda para la palabra "Stranger Things". Se muestra tanto noticias como otro tipo de resultados

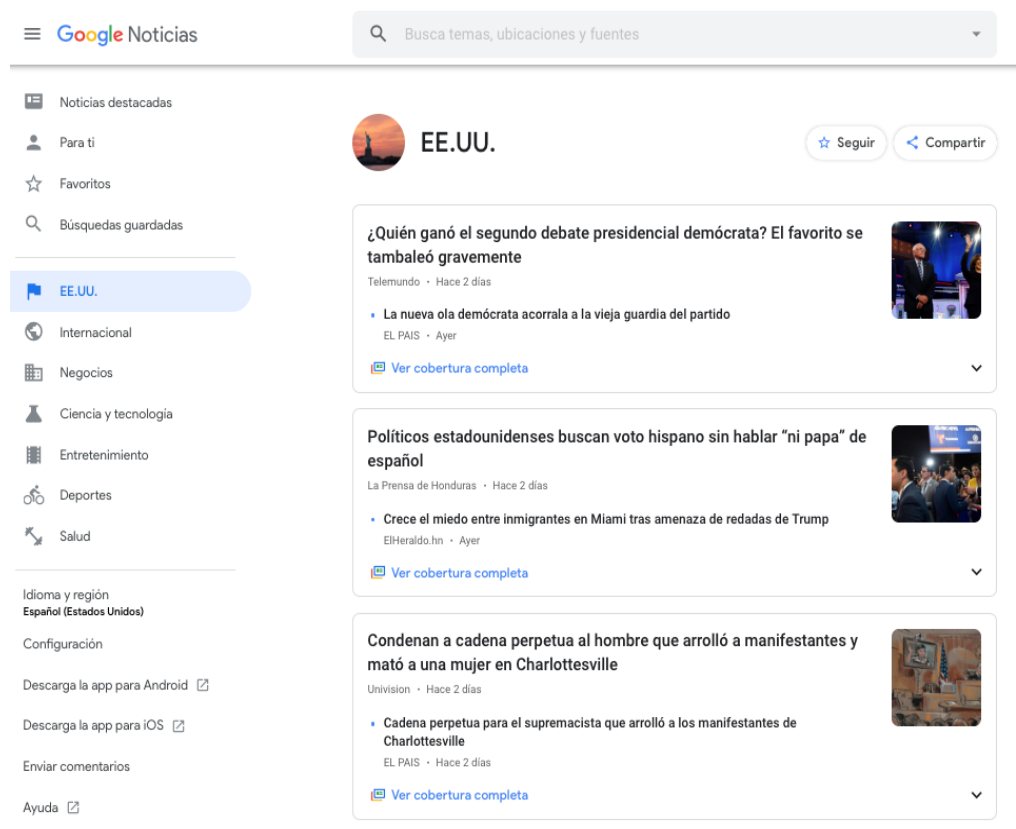


Figura 6: Portada de Google News EEUU. En la imagen se muestra la portada del día 30 de junio de 2019. En la parte de la izquierda se muestran los servicios específicos y secciones de Google News y en la parte de la derecha la portada con las noticias más destacadas del día en Estados Unidos.

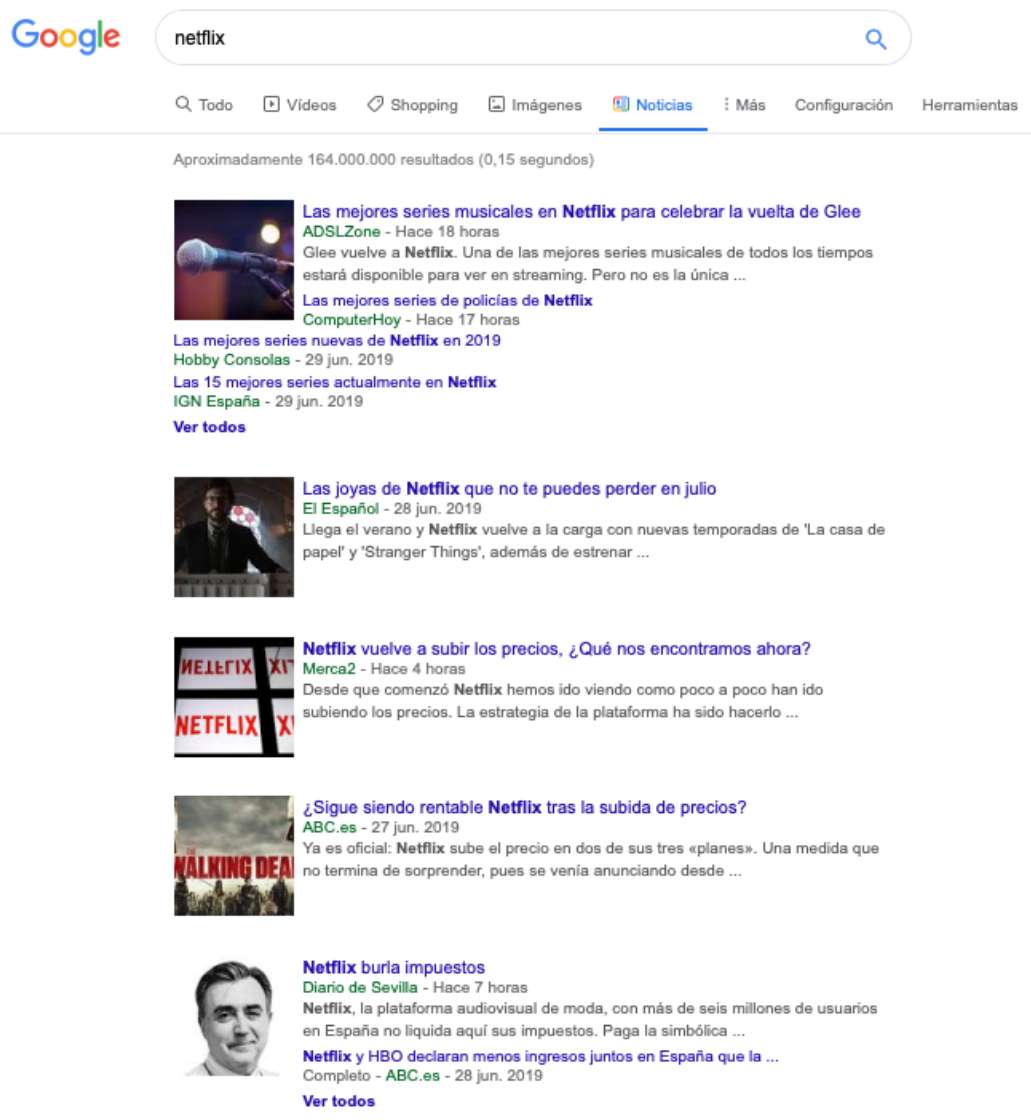

Figura 7: Resultados de búsqueda del índice de Noticias de Google España para la palabra "Netflix". Los resultados incluyen las últimas noticas sobre Netflix con un título, la fecha de publicación y en algunas ocasiones una pequeña descripción de la noticia.

De acuerdo con la propia Google (y como confirman los estudios), tanto Google News como el índice de noticias de Google España recompensan el contenido periodístico original e independiente, tomando en consideración al editor de origen (Sullivan, 2019) y ubicándoles en la parte más alta de los resultados de búsqueda.

Por lo tanto, si una web no es de noticias no podrá aparecer en Google News, o el índice de noticias de Google España. Además, ambos servicios de Google ofrecen información abierta y gratuita para los usuarios (Hererro-Solana, et al., 2014).

Sin embargo, ya hemos señalado que existe también diferencias entre ambos índices. Las más destacadas son:

- Google News es un servicio gratuito de noticias que recopila diariamente titulares de miles de fuentes informativas de todo el mundo y las muestra de una forma similar a la de una portada de periódico, mientras que el índice de noticias 
de Google España ofrece los resultados de búsqueda en forma de título y metadescripción alejándose así del diseño de portada periodística.

- Asimismo, Google News se caracteriza por redistribuir noticias extraídas de miles de fuentes (medios de comunicación) seleccionadas, y aceptadas como tal por la propia Google, ya que para poder aparecer en Google News como fuente de información hay que solicitar formalmente su inclusión, mientras que el índice de noticias de Google España no prioriza ninguna fuente de información específica. Por lo tanto, Google News ofrece resultados de búsqueda únicamente de los medios de comunicación que han pasado a formar parte de la base de datos de Google News, es decir, si un cibermedio no ha sido aceptado en la base de datos de Google News como fuente de información, sus noticias no podrán aparecer en este servicio, en cambio, el índice de noticias de Google España acepta todo tipo de webs que estén consideradas como cibermedio.

Los buscadores tratan de filtrar de manera eficaz las noticias, aunque ante la ingente cantidad de información, ofrecer los mejores resultados para los usuarios se ha convertido en una tarea compleja (Zhang et al, 2016).

Según recogen algunos estudios (Nechushtai y Lewis, 2019) Google News replica las estructuras tradicionales de los grandes medios como difusores de noticias ya que los grandes grupos de comunicación representan el 69\% de concentración de las noticias de Google News.

Aun así, los agregadores de noticias como Google News benefician a los medios de comunicación ya que les ayuda a atraer más tráfico web y por tanto más ingresos publicitarios (Wilson y Maceviciute, 2013; Colangelo y Tortit, 2019). De hecho, el poder formar parte de Google News como fuente de información es un gran valor añadido, ya que este servicio envía 6 millones de clics mensuales a editores de todo el mundo (Neil Patel, 2019) y, además, el $60 \%$ de las personas confían en esta herramienta para informarse (Wilson, 2016; Osman, 2017). Esto implica que se puede obtener miles de clics provenientes de Google News si se consigue formar parte de su índice (Patel, 2019).

Por otro lado, existe una relación compleja entre los medios de comunicación y Google. Se trata de una relación de amor y odio por parte de los medios de comunicación agregados a Google News, y no tanto por parte de Google. Ante esta circunstancia, los medios de comunicación plantean compensaciones, en muchos casos económicas, y en otras ocasiones en forma de soluciones tecnológicas y de acuerdos de colaboración con el propio Google (Cobos, 2018) para favorecer esta relación entre ambas partes.

Este conflicto viene motivado principalmente porque los agregadores de noticias en línea, como Google News, Yahoo! News, etc., se han convertido en las principales fuentes de noticias para el público (Lee y Chyi, 2015; Recio et al. 2015), y porque muchos 
medios de comunicación consideran que los lectores leen desde estos servicios el titular y la descripción, pero no hacen clic en la noticia (Chrysanthos, et al., 2015), y por tanto no la leen dentro de la web del cibermedio.

Sin embargo, existen estudios que analizan el problema de clic del usuario, una vez que éste ve el resultado de búsqueda de la noticia en Google y que confirman que los usuarios prestan atención a las fuentes y los titulares y, con base en estos elementos, hacen clic en el hipervínculo (Rovira y Marcos, 2014) y acaban leyendo la noticia.

Esta relación de conflicto y necesidad entre los medios de comunicación y Google se lleva produciendo desde 2007. De hecho, de 2007 a 2010 los medios de comunicación estadounidenses llevaron a cabo una mala cobertura con informaciones sensacionalistas para desacreditar el servicio Google News (Chyi et al. 2016). Durante este periodo, se trataba a Google como un enemigo, con publicación de informaciones muchas veces sesgadas, sin tener en cuenta las opiniones de lectores y sin mencionar que Google News es un servicio gratuito del que Google no se beneficia comercialmente (Chyi et al. 2016).

En España, en concreto, el conflicto entre medios de comunicación y Google terminó con la salida de Google News España y la consecuente creación de un nuevo índice de noticias adaptado al contexto español, el índice de noticias de Google España.

Los últimos meses de 2014 se vivió una gran polémica entre motores de búsqueda y agregadores, contra los medios de comunicación por la aprobación en enero de 2015 del canon AEDE o tasa Google (Guallar, 2015).

El canon AEDE supone la obligatoriedad de una compensación económica a los diarios por parte de los motores de búsqueda y agregadores de noticias por utilizar su contenido, motivo por el cual Google canceló el servicio de Google News en España. Los grandes medios estaban a favor del Canon mientras que la gran mayoría de los pequeños medios no. Se toma el nombre de Canon AEDE por las siglas de (Asociación de Editores de Diarios Españoles).

El 16 de diciembre de 2014 Google News salió de España y retiró los medios de comunicación españoles de su servicio porque se le exigía a Google el pago de dicha tasa a los medios de comunicación. Google consideró que no debía pagarles porque el servicio de Google News no les generaba beneficios económicos al tratarse de un servicio gratuito para los usuarios. Ante esta disyuntiva, la decisión fue abandonar su servicio en este país (Wall Street Journal, 2014). La noticia de la salida de Google News en España fue anunciada por el director de Google News, Richard Gingras a través del blog de Google (The Guardian, 2014). 
El fin del servicio de Google News España confirmó que:

- se producía una disminución de lectores en los medios de comunicación pequeños y medianos, en cambio en los grandes medios de comunicación esta disminución no se notó (Athey, et al. 2017).

- Nacía el índice de noticias de Google España que recogería resultados de búsqueda en forma de noticias, pero, como hemos visto, no seguiría el mismo planteamiento ni funcionamiento que Google News.

En resumen, las noticias pueden aparecer en los resultados de búsqueda del índice general de Google, en Google News siempre y cuando las noticias se publiquen en países que todavía cuentan con este servicio y en el índice de noticias de Google España. Por lo tanto, resulta esencial que los cibermedios sean capaces de aprovechar, a través de estrategias de posicionamiento, la visibilidad que les puede suponer el aparecer en los primeros resultados de estos buscadores.

\subsection{SEO como parte de la sostenibilidad}

Con el auge del SEO, algunos medios de comunicación han abierto una nueva línea de ingresos que incluye la venta de enlaces de autoridad. Estos enlaces de terceros se publican como parte del contenido de estos medios digitales a cambio de una contraprestación económica. El propósito de este nuevo modelo de negocio es el de mejorar la autoridad web y por consiguiente las posiciones en los resultados de búsqueda de estos anunciantes.

Es importante resaltar que Google y otros motores de búsqueda cuentan con una métrica basada en el análisis de enlaces externos que apuntan a una web y que permite determinar la importancia de estas páginas. Es lo que se conoce como PageRank (Brin; Page, 2000).

La dinámica es la siguiente: una página se posiciona con base en su relevancia y características intrínsecas, pero también extrínsecas, es decir se analiza una página con base en una palabra clave, su disposición en el texto, pero también la calidad y cantidad de enlaces que recibe un contenido/página de otras webs (Lewandowski, 2012; Harry, 2013; Giomelakis; Veglis, 2015; Codina; Rovira, 2015).

Esto implica, por tanto, que si hay dos páginas que tratan el mismo tema y quieren aparecer en los resultados de búsqueda por la misma palabra clave (palabra consultada por el usuario desde el buscador) se posicionará mejor, a priori, aquella que reciba un mayor número de enlaces (también llamados comúnmente back links) desde otras páginas web, que al mismo tiempo, también recibirán enlaces desde otros sitios web, y así sucesivamente (Brin; Page, 2000; Thelwall, 2004; Gonzalo-Penela, 2006). 
De esta manera, el objetivo de estos enlaces es el de traspasar su autoridad a la página que está enlazando, lo que repercute positivamente en los resultados de búsqueda y por tanto a una mejor posición en estos resultados (Crowe, 2017; Giomelakis; Veglis, 2016).

Por lo tanto, la cantidad y la calidad de los backs links que apuntan a una web, es uno de los factores de posicionamiento más importantes y tenidos en cuenta por motores de búsqueda como Google (Fishkin, 2016; García-Carretero et al., 2016).

Ante esta circunstancia, es natural encontrarnos con que muchos SEOs se han profesionalizado en la construcción de enlaces, es decir, en la creación de estrategias para conseguir que webs de terceros enlacen las webs de sus clientes, es lo que se conoce como comúnmente como link building (Gonzalo-Penela, 2006; Serrano-Cobos, 2015).

Existen diferentes maneras de realizar los procesos de link building (Monterde, 2016; Publisuites, 2018). A continuación, se destacan los más habituales:

\begin{tabular}{|l|l|}
\hline Tipo & Descripción \\
\hline $\begin{array}{l}\text { Link building } \\
\text { natural o } \\
\text { editorial }\end{array}$ & $\begin{array}{l}\text { Se trata de una estrategia en donde el contenido de calidad de la web } \\
\text { es el elemento principal para obtener enlaces externos que citen ese } \\
\text { contenido. La filosofía es la siguiente: a mayor calidad de un artículo, } \\
\text { mayor probabilidad de que sea citado, esto es, enlazado. }\end{array}$ \\
\hline $\begin{array}{l}\text { Link building } \\
\text { estratégico }\end{array}$ & $\begin{array}{l}\text { Consiste en actuar de manera proactiva para conseguir enlaces de } \\
\text { webs de terceros. Para ello se publican enlaces en foros, wikis, blogs } \\
\text { 2.0, etc., o incluso se llevan a cabo campañas por correo electrónico } \\
\text { contactando a responsables de sitios para solicitar enlaces. Se trata } \\
\text { de todo un arte porque si se enlaza en este tipo de web de manera } \\
\text { masiva, o siguiendo algún tipo de patrón, los motores de búsqueda } \\
\text { son capaces de identificar que estos enlaces se han conseguido } \\
\text { artificialmente y por lo tanto pueden penalizarlo eliminándolo de sus } \\
\text { índices o bajándolo de posición en sus resultados de búsqueda. }\end{array}$ \\
\hline
\end{tabular}

Tabla 1: Principales tipos de estrategias de Link building

Los profesionales del link building más estratégico, por tanto, tienen como principal objetivo (Cámaras-León, 2018; Rowe, 2018) obtener enlaces externos, para ello pueden buscarlos de manera gratuita a través de perfiles web, redes sociales, foros, wikis, blogs 2.0, directorios, etc. (Cooper, 2012; Dean, 2018), o pagando a webs de terceros o medios digitales (caso que nos ocupa) para que incluyan sus enlaces en sus páginas. 
Ante esta necesidad de traspaso de autoridad para mejorar las posiciones en los buscadores, los medios de comunicación han encontrado un nicho de negocio. Era de esperar, más pronto que tarde, que los responsables SEO de las empresas se preguntaran por la posibilidad de comprar enlaces en diarios digitales.

Sin embargo, ante la falta de acceso a los responsables de los medios de comunicación online por parte de empresas y SEO de la empresa privada, han surgido plataformas que funcionan como empresas intermediarias entre los responsables de las webs que necesitan back links y los cibermedios, algunas de estas son Prensarank, Publisuites, Unancor, RT Go Press o Dofollow.es, entre otras.

En definitiva, el SEO como modelo de negocio es una realidad que debe tener su propia regulación, ya que, dado este cambio en el ecosistema informativo con la venta de enlaces, todavía no existe un consenso de cómo publicar e identificar este contenido dentro de los medios digitales, hecho expresamente para enlazar a la web que paga por ello. Se han encontrado casos de medios de comunicación online que indican que se trata de contenido patrocinado, y otros en cambio lo publican como contenido editorial de calidad y original. 


\section{SEGUNDA PARTE \\ MARCO DE OPTIMIZACIÓN GLOBAL DEL SEO EN \\ PERIODISMO}

\section{Marco metodológico}

A continuación, señalamos las metodologías cualitativas empleadas a lo largo de esta parte de la investigación, a saber, revisiones sistematizadas y entrevistas semiestructuradas aplicadas a expertos en consultoría SEO.

\subsection{Revisiones sistematizadas}

Para llevar a cabo esta investigación hemos realizado una revisión sistematizada (Pujol, 1995; Bambra, 2005; Hart, 2008; Urrutia, Bofill, 2010; Booth et al., 2012; Codina, 2018) de la producción académica y profesional sobre la intersección de los siguientes campos:

- SEO semántico

- Search Experience Optimization

- SEO en medios audiovisuales

- SEO y Google News

A continuación, proporcionamos los parámetros principales de las revisiones sistematizadas que han sido llevadas a cabo para esta investigación. Para ello realizamos una tabla sistemática que recoge los principales parámetros utilizados para el estudio de las diferentes revisiones sistematizada trabajadas:

\begin{tabular}{|c|c|c|c|c|c|c|c|}
\hline \multicolumn{8}{|c|}{ PRINCIPALES PARÁMETROS DE LAS REVISIONES SISTEMATIZADAS } \\
\hline ID & Tema & $\begin{array}{c}\text { Bases de datos } \\
\text { consultadas }\end{array}$ & $\begin{array}{l}\text { Fecha de } \\
\text { búsqueda }\end{array}$ & $\begin{array}{l}\text { Ecuaciones de } \\
\text { búsqueda } \\
\text { utilizadas }\end{array}$ & $\begin{array}{l}\text { Criterios de } \\
\text { inclusión }\end{array}$ & $\begin{array}{l}\text { Criterios } \\
\text { de } \\
\text { exclusión }\end{array}$ & Resultados \\
\hline 1 & SEO semántico & $\begin{array}{l}\text { - Scopus, } \\
\text { - Web of } \\
\text { Sciences } \\
\text { - AMC } \\
\text { - Google Scholar }\end{array}$ & Enero 2018 & $\begin{array}{l}\text { - "Semantic web" } \\
\text { OR "Schema.org" } \\
\text { OR "SEO" AND } \\
\text { "Semantic web" } \\
\text { - "Semantic SEO" } \\
\text { OR "SEO" AND } \\
\text { "web", } \\
\text { - "Search engine" } \\
\text { AND “web", y } \\
\text { diversas } \\
\text { variaciones de }\end{array}$ & $\begin{array}{l}\text { - Artículos } \\
\text { académicos } \\
\text { relevantes de } \\
\text { los últimos seis } \\
\text { años, en } \\
\text { castellano, } \\
\text { inglés, y } \\
\text { catalán } \\
\text { - Trabajos } \\
\text { seminales muy } \\
\text { citados, }\end{array}$ & $\begin{array}{l}\text {-Artículos } \\
\text { no } \\
\text { escritos } \\
\text { en } \\
\text { castella- } \\
\text { no, in- } \\
\text { glés o } \\
\text { catalán } \\
\text { - Falsos } \\
\text { positivos }\end{array}$ & $\begin{array}{l}43 \\
\text { documentos }\end{array}$ \\
\hline
\end{tabular}




\begin{tabular}{|c|c|c|c|c|c|c|c|}
\hline & & & & $\begin{array}{l}\text { idiomas y } \\
\text { sinónimos. }\end{array}$ & $\begin{array}{l}\text { independiente } \\
\text { mente de su } \\
\text { fecha de } \\
\text { publicación. } \\
\text { - Literatura } \\
\text { Gris. }\end{array}$ & & \\
\hline 2 & SXO & $\begin{array}{l}\text { - Scopus, } \\
\text { - Web of } \\
\text { Sciences } \\
\text { - LISTA } \\
\text {-Communication } \\
\text { Sources } \\
\text { - Google Scholar } \\
\text { - webs de } \\
\text { referencia en el } \\
\text { sector del } \\
\text { posicionamiento } \\
\text { web }\end{array}$ & $\begin{array}{l}\text { Noviembre y } \\
\text { Diciembre de } \\
2018\end{array}$ & $\begin{array}{l}\text { (“User } \\
\text { experience" OR } \\
\text { UX OR “User } \\
\text { Interface” OR UI } \\
\text { OR “information } \\
\text { architecture" OR } \\
\text { “User } \\
\text { interaction”) AND } \\
\text { (SXO OR “Search } \\
\text { Experience } \\
\text { Optimization” OR } \\
\text { SEO OR “web } \\
\text { positioning” OR } \\
\text { "Search Engine } \\
\text { Optimization”) }\end{array}$ & $\begin{array}{l}\text { - Artículos } \\
\text { académicos } \\
\text { relevantes de } \\
\text { los últimos seis } \\
\text { años, en } \\
\text { castellano, } \\
\text { inglés, y } \\
\text { catalán } \\
\text { - Trabajos } \\
\text { seminales muy } \\
\text { citados, } \\
\text { independiente } \\
\text { mente de su } \\
\text { fecha de } \\
\text { publicación. } \\
\text { - Literatura } \\
\text { Gris. }\end{array}$ & $\begin{array}{l}\text {-Artículos } \\
\text { no } \\
\text { escritos } \\
\text { en caste- } \\
\text { llano, } \\
\text { inglés o } \\
\text { catalán } \\
\text { - Falsos } \\
\text { positivos }\end{array}$ & $\begin{array}{l}20 \\
\text { documentos }\end{array}$ \\
\hline 3 & $\begin{array}{l}\text { SEO en } \\
\text { medios } \\
\text { audiovisuales }\end{array}$ & $\begin{array}{l}\text { Scopus, } \\
\text { Web of Sciences } \\
\text { LISTA } \\
\text { Communication } \\
\text { Sources } \\
\text { Google Scholar } \\
\text { webs de } \\
\text { referencia en el } \\
\text { sector del } \\
\text { posicionamiento } \\
\text { web }\end{array}$ & $\begin{array}{l}\text { Septiembre y } \\
\text { octubre de } \\
2018\end{array}$ & $\begin{array}{l}\text { - (Radio OR } \\
\text { Television OR tv) } \\
\text { AND (web or } \\
\text { website AND seo } \\
\text { OR web } \\
\text { positioning OR } \\
\text { Search Engine } \\
\text { Optimization) } \\
\text { - (Journalism OR } \\
\text { Cybermedia) } \\
\text { AND( web or } \\
\text { website) AND } \\
\text { (seo OR web } \\
\text { positioning OR } \\
\text { Search Engine } \\
\text { Optimization) }\end{array}$ & $\begin{array}{l}\text { - Artículos } \\
\text { académicos } \\
\text { relevantes de } \\
\text { los últimos seis } \\
\text { años, en } \\
\text { castellano, } \\
\text { inglés, y } \\
\text { catalán } \\
\text { - Trabajos } \\
\text { seminales muy } \\
\text { citados, } \\
\text { independiente } \\
\text { mente de su } \\
\text { fecha de } \\
\text { publicación. } \\
\text { - Literatura } \\
\text { Gris. }\end{array}$ & $\begin{array}{l}\text {-Artículos } \\
\text { no } \\
\text { escritos } \\
\text { en caste- } \\
\text { llano, } \\
\text { inglés o } \\
\text { catalán } \\
\text { - Falsos } \\
\text { positivos }\end{array}$ & $\begin{array}{l}20 \\
\text { documentos }\end{array}$ \\
\hline 4 & $\begin{array}{l}\text { SEO y Google } \\
\text { News }\end{array}$ & $\begin{array}{l}\text { Scopus, } \\
\text { Web of Sciences } \\
\text { LISTA } \\
\text { Communication } \\
\text { Sources } \\
\text { Google Scholar } \\
\text { webs de } \\
\text { referencia en el } \\
\text { sector del } \\
\text { posicionamiento } \\
\text { web }\end{array}$ & $\begin{array}{l}\text { Marzo-mayo } \\
\text { de } 2019\end{array}$ & $\begin{array}{l}\text { (“Google News”) } \\
\text { AND (“News } \\
\text { Media" OR } \\
\text { “Digital News } \\
\text { Media" OR } \\
\text { "Journalism” OR } \\
\text { “Online News } \\
\text { paper" OR "SEO” } \\
\text { OR “web") }\end{array}$ & $\begin{array}{l}\text { - Artículos } \\
\text { académicos } \\
\text { relevantes de } \\
\text { los últimos seis } \\
\text { años, en } \\
\text { castellano, } \\
\text { inglés, y } \\
\text { catalán } \\
\text { - Trabajos } \\
\text { seminales muy } \\
\text { citados, } \\
\text { independiente- } \\
\text { mente de su }\end{array}$ & $\begin{array}{l}\text {-Artículos } \\
\text { no } \\
\text { escritos } \\
\text { en caste- } \\
\text { llano, } \\
\text { inglés o } \\
\text { catalán } \\
\text { - Falsos } \\
\text { positivos }\end{array}$ & $\begin{array}{l}29 \\
\text { documentos }\end{array}$ \\
\hline
\end{tabular}




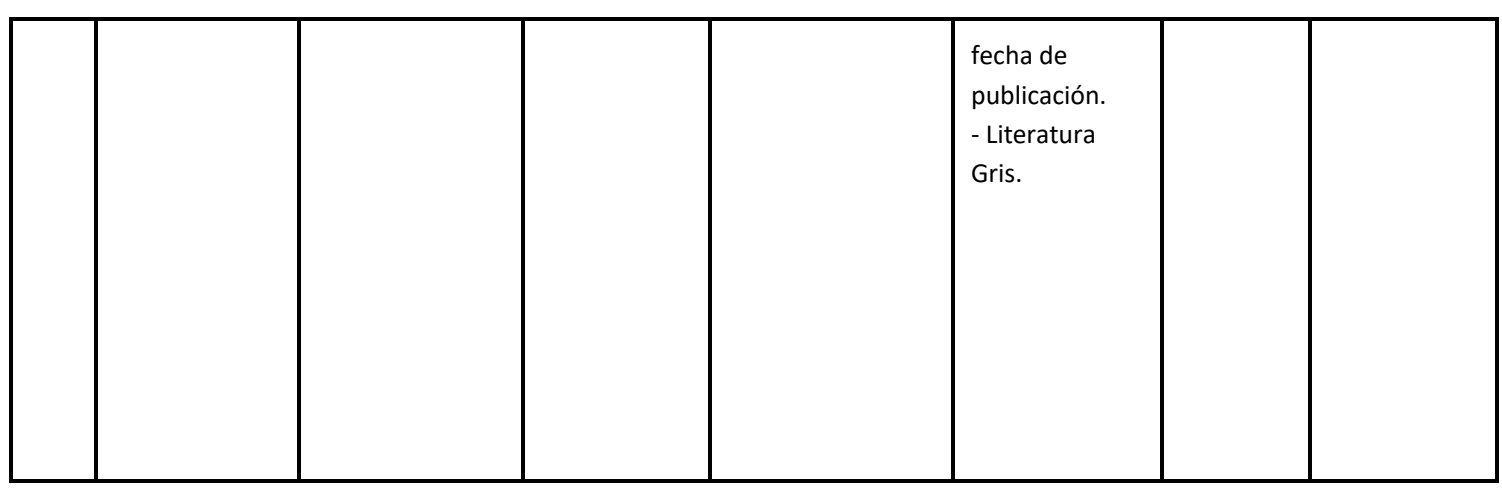

Tabla 2: Revisiones sistematizadas desarrolladas y sus principales parámetros de búsqueda

\subsection{Entrevistas semiestructuradas}

Para el desarrollo de este trabajo se han llevado a cabo 10 entrevistas semiestructuradas (Coller, 2000; Valles, 2002; Alves y Díaz-Noci, 2014) durante 2018 y 2019 a profesionales relacionados con SEO de consultoría.

Los 10 participantes han sido seleccionados con base en las así llamadas preguntas criterio (Valles, 2002) en donde nos planteamos quiénes tenían la información relevante, eran más accesibles social y físicamente, estaban más dispuestos a informar, y eran más capaces de comunicar con precisión la información. A continuación, mostramos los principales elementos que formaron parte de las preguntas de la entrevista, los objetivos concretos relacionados que queríamos identificar y los diferentes participantes de las entrevistas semiestructuradas.

Modelo de entrevista semiestructurada por perfil: categorías, objetivos y preguntas

Entrevista aplicada a expertos de la consultoría SEO

\begin{tabular}{|l|l|l|}
\hline Cat. & Objetivo & Temas que plantear \\
\hline $\begin{array}{l}\text { Opiniones y } \\
\text { visiones SEO }\end{array}$ & $\begin{array}{l}\text { Analizar cuáles son las tendencias } \\
\text { de posicionamiento en } \\
\text { buscadores a medio plazo. } \\
\text { Entender cómo los expertos en } \\
\text { SEO se enfrentan a los nuevos } \\
\text { escenarios surgidos en la } \\
\text { recuperación de información } \\
\text { como son las búsquedas } \\
\text { semánticas, la búsqueda por voz, } \\
\text { etc. }\end{array}$ & $\begin{array}{l}\text { ¿Puatro de los } \\
\text { ¿Puncipales factores SEO para 2019? } \\
\text { sobre cómo deberá abordar el } \\
\text { profesional del SEO los nuevos } \\
\text { escenarios siguientes: búsquedas } \\
\text { semánticas, búsquedas por voz, } \\
\text { ¿intención de búsqueda? }\end{array}$ \\
\hline Técnicas SEO & $\begin{array}{l}\text { Averiguar hacia qué tipo de } \\
\text { trabajo SEO se enfocan más los } \\
\text { expertos en posicionamiento web }\end{array}$ & $\begin{array}{l}\text { ¿Qué tipo de SEO cree que tendrá } \\
\text { mayor peso e importancia, el SEO } \\
\text { técnico, el SEO On-page o el SEO Off- }\end{array}$ \\
\hline
\end{tabular}




\begin{tabular}{|l|l|l|}
\hline & y por qué. & page? \\
\hline $\begin{array}{l}\text { Herramientas } \\
\text { SEO }\end{array}$ & $\begin{array}{l}\text { Confirmar cuál o cuáles son las } \\
\text { herramientas de auditoría SEO } \\
\text { más utilizadas por los expertos en } \\
\text { posicionamiento web. }\end{array}$ & $\begin{array}{l}\text { De este listado ¿Cuál es la herramienta } \\
\text { SEO que más utiliza? }\end{array}$ \\
\hline $\begin{array}{l}\text { Percepción del } \\
\text { SEO }\end{array}$ & $\begin{array}{l}\text { Conocer cuál es la percepción } \\
\text { que los expertos en SEO tienen } \\
\text { sobre el trabajo en visibilidad } \\
\text { web llevado a cabo por los diarios } \\
\text { digitales. }\end{array}$ & $\begin{array}{l}\text { Cómo experto en SEO ¿considera que } \\
\text { los diarios digitales están aplicando } \\
\text { buenas, malas o nulas estrategias SEO? }\end{array}$ \\
\hline $\begin{array}{l}\text { Rutinas } \\
\text { productivas }\end{array}$ & $\begin{array}{l}\text { Reconocer qué estrategia o } \\
\text { estrategias llevaría a cabo un } \\
\text { experto en SEO para mejorar el } \\
\text { posicionamiento web de un diario } \\
\text { digital sin que por ello afectase a } \\
\text { la calidad de las noticias. }\end{array}$ & $\begin{array}{l}\text { En caso de que tenga alguna } \\
\text { experiencia como experto SEO en } \\
\text { medios de comunicación digitales } \\
\text { ¿existe alguna recomendación muy } \\
\text { general que haría llegar a los medios } \\
\text { para que fueran capaces de } \\
\text { posicionarse mejor sin que por ello } \\
\text { afectase a la calidad de la información } \\
\text { de las noticias? }\end{array}$ \\
\hline
\end{tabular}

Tabla 3: Modelo de entrevista semiestructurada por perfil: categorías, objetivos y preguntas

\begin{tabular}{|l|l|l|}
\hline \multicolumn{2}{|l}{ Participantes expertos en SEO del campo de la consultoría } \\
\hline Nombre & Empresa/web & URL \\
\hline Bruno Ramos & Agenciaseo.eu & brunoramos.es \\
\hline Emilio García Garrido & Campamento web & campamentoweb.com \\
\hline David Ayala & Soy Webmaster & soywebmaster.com \\
\hline Alex Navarro & Dropalia & dropalia.com \\
\hline Esteve Castells & Estevecastells & Estevecastells.com \\
\hline Luis Villanueva & Webpositer & webpositer.com \\
\hline Natzir Turrado & Analista SEO & analistaseo.es \\
\hline César Aparicio & Craneo Digital & craneo.digital \\
\hline Fernando Muñoz & Señor Muñoz & raiz.es/nosotros/fernando-munoz \\
\hline Sergio Castelo & Sergio Castelo & sergiocastelo.com \\
\hline
\end{tabular}




\section{Estrategias y protocolos}

En este apartado analizaremos y discutiremos el uso de técnicas SEO en cibermedios desde las diferentes perspectivas estudiadas, es decir desde el SEO semántico, el SXO y la optimización integral de noticias y cibermedios para los índices de Google, Google News e índice de noticias de España.

A lo largo de nuestra investigación, hemos podido abordar los principales elementos necesarios para implantar un modelo integral del SEO en un cibermedio, tanto desde el punto de vista del redactor/periodista como del experto en posicionamiento en buscadores.

Para ello, ha sido necesario investigar primero estos elementos por separado, para así entender cada una de las necesidades propias del SEO y del periodismo y después unirlas de una forma armónica para que actúen de manera adecuada dentro de una empresa periodística.

A continuación, presentamos de manera desagregada cada elemento y lo ubicamos de manera descriptiva.

\subsection{Framework de SEO semántico para cibermedios}

EI SEO semántico es una estrategia para optimizar la intención de búsqueda de los usuarios en la que intervienen diferentes elementos, principalmente el RankBrain y LSI (Latent Semantic Indexing) ya que son actores esenciales para obtener resultados en la búsqueda semántica, y también la tecnología Schema.org, considerada paradigma del SEO semántico y lenguaje estandarizado elegido por los principales motores de búsqueda para favorecer los resultados enriquecidos. A continuación, mostramos el Framework Integral de SEO semántico (por sus siglas ISS) y proponemos las principales técnicas para optimizar la intención de búsqueda. 


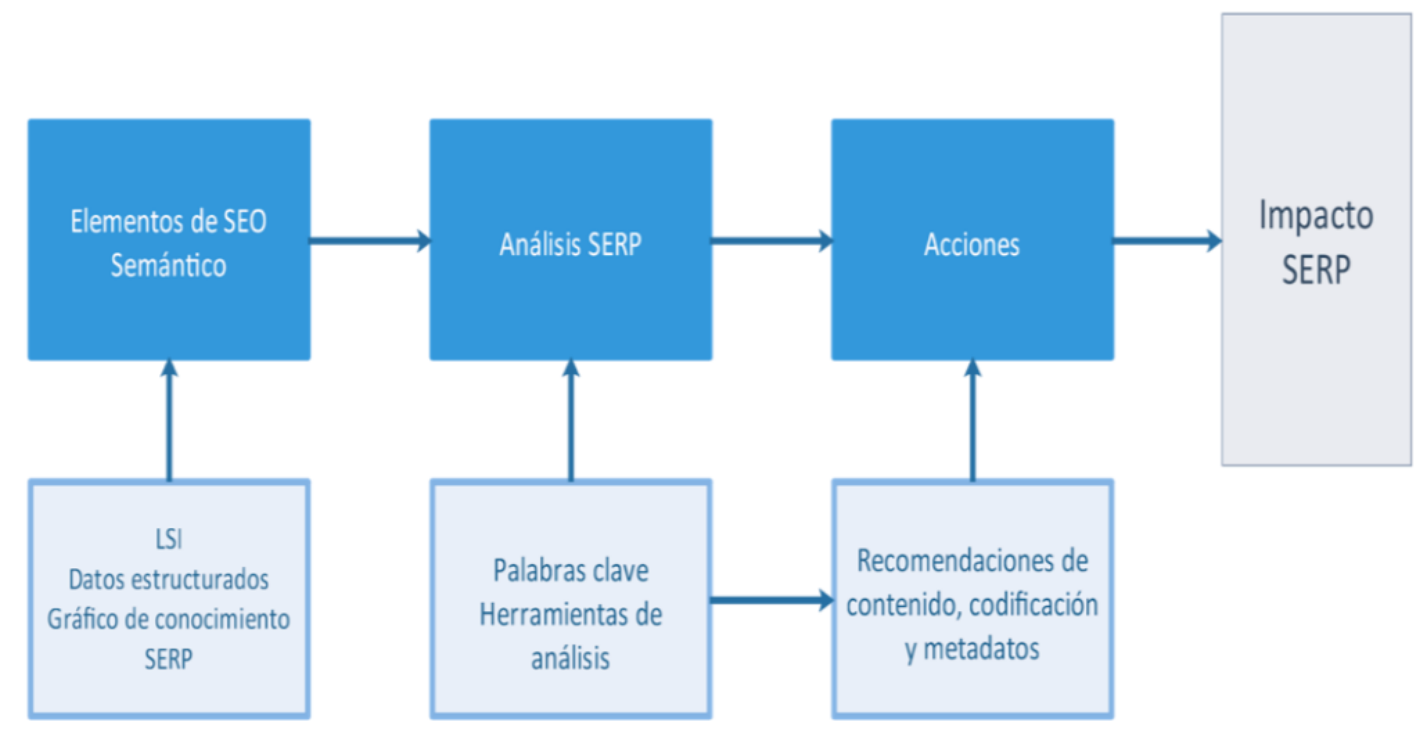

Figura 8: Diagrama de procesos para la implementación del SEO semántico.

En lo que sigue, presentamos algunos de los principales pasos a seguir en relación con una estrategia de optimización del SEO semántico en un medio de comunicación:

- Enriquecer el código fuente de los contenidos con Schema.org mediante el uso de CMS especializados o debidamente configurados.

- Desarrollar y aplicar una adecuada arquitectura de la información.

- Supervisar y resolver de forma adecuada aspecto de SEO técnico relacionados con el mapa de la web, la indexabilidad, etc.

- Evitar contenido de baja calidad: textos no originales, sin citar fuentes, sin enlaces de salida, etc.

- Producir contenido utilizando diferentes formatos: texto, imagen, vídeo, etc.

- Optimizar el marcado semántico de las noticias, en general con el uso de metadatos y de un CMS especializado o adecuadamente configurado.

- Analizar los resultados enriquecidos obtenidos y aplicar estrategias de mejora en función de los mismos. 


\subsection{Protocolo de análisis SXO para cibermedios}

Para que los cibermedios puedan optimizar la experiencia del usuario, o lo que es lo mismo para poder aplicar de manera eficaz estrategias de Search eXperience Optimization, es preciso prestar atención a los parámetros arquitectura de la información, el SEO de contenidos, el SEO técnico, los metadatos, las señales de usuario, la autoridad web y la buscabilidad.

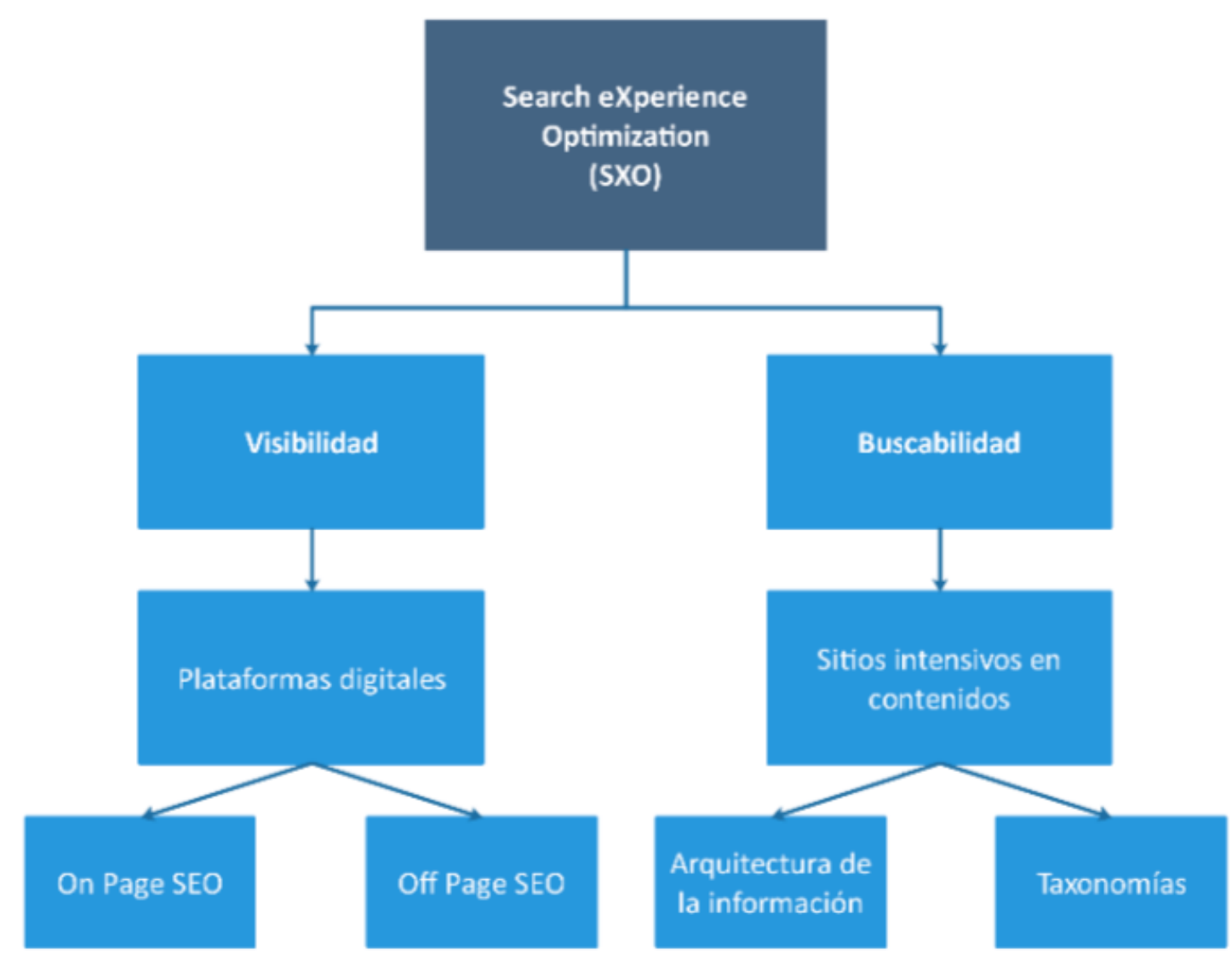

Figura 9: Diagrama de los principales elementos que componen el Search Experience Optimization

Estos parámetros contemplan, a su vez, 26 indicadores de aplicación. Estos parámetros con sus correspondientes indicadores se han materializado en El Protocolo de Análisis de la eXperiencia de Búsqueda en Cibermedios (PAXBCM).

Algunas de las principales recomendaciones de optimización de SXO, que puedan ser aplicables a medios de comunicación digitales, surgidos del PAXBCM son:

- Aplicar siempre que sea adecuado, enlazado interno en el cuerpo de las noticias. 
- Redactar noticias de un mínimo de 400 palabras, con imágenes y contenido audiovisual, siempre que no contradiga las especificaciones concretas del género periodístico del que se trate.

- Contar con un mapa del sitio web, así como un archivo robot.txt debidamente configurados.

- Usar metadatos para imágenes y en especial el atributo ALT en las imágenes de las noticias.

- Crear contenido de calidad con mención a fuentes externas y enlaces internos (en su caso) que completen la información creada

- Utilizar marcado semántico Schema.org recomendado por los principales buscadores.

- Optimizar el denominado título SEO, que coincide con la etiqueta title del código fuente (HTML)

- Optimizar la metadescripción de cada noticia, también parte del código fuente, no visible para los lectores de la noticia, pero utilizado por los buscadores para representar la noticia en sus páginas de resultados.

- Adoptar políticas de difusión de contenidos a través de las redes sociales.

- Disponer de un buscador interno de noticias que aporte resultados adecuados a las consultas de los usuarios.

- Adaptar la web a la versión móvil.

- Optimizar la velocidad de carga de la web.

- Crear y aplicar una óptima arquitectura web.

\subsection{Google, Google News e Índice de Noticias de Google}

Es posible plantear una serie de estrategias SEO para cibermedios analizando los principales elementos que intervienen en el proceso de optimización de noticias para aparecer en los principales resultados de búsqueda de Google general, Google News y el índice de noticias de Google España. 


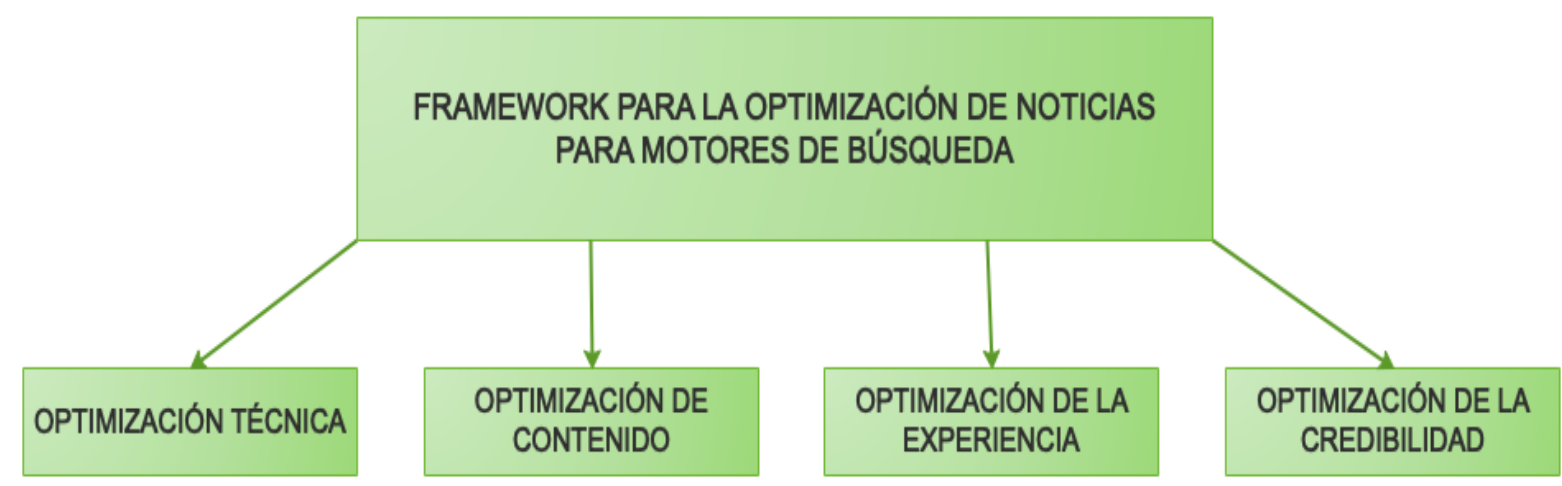

Figura 10: Diagrama de propuesta de optimización de noticias para el índice general de Google, Google News e índice de noticias de Google España

Este framework (marco de trabajo) incorpora los principales elementos que se estudian tanto desde la academia como desde las fuentes empresariales de referencia sobre visibilidad web y cibermedios.

Estos elementos son la optimización del SEO técnico de los cibermedios, la optimización del contenido de sus noticias, la optimización de la experiencia de sus lectores y la optimización de su credibilidad como servicio al ciudadano. A continuación, desglasamos cada una de ellas.

\section{Optimización técnica:}

- Usar el sitemap especia de Google Noticias.

- Usar la metaetiqueta "News_Keyword" en cada noticia.

- Usar el atributo alt para la imagen.

- Utilizar schema.org, mínimo "newsArticle".

- Publicar noticias con un código fuente HTML bien estructurado.

- El dominio y las páginas deben ser accesibles para los robots de Google. Permitir acceso al archivo robots.txt.

- Proporcionar las fechas y horas de publicación exactas de las noticias. Para ello debemos utilizar los esquemas schema.org "dataPublished" y "DataModified"

- Proteger a los usuarios y sus datos con el protocolo de seguridad https.

- Utilizar la tecnología AMP para facilitar el acceso desde el móvil.

\section{Optimización de contenido:}

- Crear contenido original, de calidad y de fácil lectura. En general, los criterios de calidad periodística son también criterios de calidad para los buscadores.

- Publicar sobre temas de actualidad que generen búsquedas de los lectores. 
- El cuerpo de la noticia debe contener un mínimo de 300 palabras, así como contenido multimedia.

- Apoyar el contenido con palabras semánticamente relacionadas con uso de entidades.

- Escribir titulares claros y precisos con encabezados $(\mathrm{h} 1, \mathrm{~h} 2)$ compactos, concisos y con la palabra clave principal lo más a la izquierda posible.

- Realizar un enlazado interno de valor para los lectores en forma de enlaces, categorías o etiquetas que amplíen la lectura de los usuarios.

- Desarrollar un enlazado externo con urls y textos ancla que sean únicos, permanentes y completen noticias.

- Promocionar el contenido en redes sociales para llegar a más lectores.

\section{Optimización de la experiencia:}

- Incluir iconos sociales para que los usuarios compartan noticias.

- Proporcionar enlaces a contenido relacionado y que dichos enlaces sean fácilmente identificables.

- Incluir tiempo estimado de lectura.

- Estimular acciones de seguir leyendo nuevas noticias.

- Favorecer la buena velocidad de carga con el uso de AMP o combinando AMP y PWA.

\section{Optimización de la credibilidad:}

- Identificar claramente los principios del medio de comunicación, su misión, su código ético y quién lo financia.

- Identificar claramente al periodista que escribió la noticia.

- Reconocer las fuentes y citarlas. Favorecer la diversidad de fuentes.

- Dar espacio al lector para fomentar su participación y puedan dar su opinión.

- Dar acceso abierto a los lectores de la información de contacto completa. 


\section{Marco global: el Departamento de SEO y la Redacción}

A continuación, y apoyándonos en los estudios precedentes, presentamos una propuesta para un marco de optimización global del SEO en un cibermedio. Esta propuesta se basa en la articulación del SEO en un cibermedio en dos niveles: Departamento de SEO y Redacción.

Dicho de otro modo, para implantar de manera integral el SEO de una redacción es preciso separar claramente el trabajo de los periodistas/redactores y el de los expertos o responsables SEO a nivel de todo el medio. Esta diferencia corresponde entonces no solo a dos funciones sino a dos ámbitos:

- el del Departamento de SEO -lo llamamos así aunque en pequeños cibermedios el Departamento puede ser una sola persona-;

- el de la Redacción del medio.

Al Departamento de SEO le corresponde una función estratégica de análisis y de generación de orientaciones para los redactores. A la redacción le corresponde aplicar las recomendaciones de optimización SEO sin que las mismas afecten a la calidad periodística de las noticias (esto es algo en lo que seremos muy insistentes). Otra forma de entender esta distribución es la siguiente:

\begin{tabular}{|c|c|}
\hline Departamento de SEO & Redacción \\
\hline - & Estrategia general de visibilidad \\
del medio, & - \\
- Análisis continuado del & digitales en la distribución de las \\
rendimiento del medio en & noticias. \\
buscadores. & Entender el funcionamiento \\
- Monitorización de tendencias en & básico de los buscadores. \\
redes sociales y en tendencias de & Conocer las recomendaciones de \\
búsqueda. & visibilidad preparadas por el \\
- Formación SEO para redactores. & Departamento de SEO. \\
Consultoría SEO para la & Conocer los principios del SEO de \\
redacción. & contenidos y aplicarlos en la \\
SEO técnico en general., & producción de las noticias, tanto \\
& de texto como en otros formatos \\
& (imagen, p.e.). \\
\hline
\end{tabular}

En los siguientes apartados desarrollamos las ideas mostradas de forma sintética en este apartado. 


\subsection{Función del Departamento de SEO}

El Departamento de SEO debe elaborar la estrategia de SEO de todo el medio. Además, debe explicar a la redacción en qué consiste el SEO y por lo tanto las razones por las cuales debe aplicarse determinadas formas de trabajo. Debe crear manuales básicos de procedimiento para los periodistas, así como buscar las fórmulas que ayuden a estimular una cultura del SEO dentro de la redacción.

Es importante destacar, como ya hemos visto a lo largo de este informe, que Google, Google News y el índice de noticias de Google España son índices diferentes, por lo que los responsables del SEO de un cibermedios deben ser capaces de entender cómo enfocarse estratégicamente a cada uno de ellos. La elaboración de un proceso de trabajo, como el Framework News aquí identificado, que permita aparecer en los tres buscadores (en el caso de España está desactivado) es esencial para poder optimizar los tiempos y productividad del trabajo periodístico.

Además de estas cuestiones generales, las diferentes labores estratégicas del Departamento de SEO se pueden articular alrededor de los puntos que presentamos a continuación.

\subsubsection{Tipos de SEO}

Este bloque incluye el SEO semántico, el SXO (Search eXperience Optimization) y el VSO (SEO para YouTube), en este último caso si el medio (como es recomendable) produce material audiovisuales y dispone de canal propio en YouTube. Los examinamos a continuación.

- El SEO semántico se enfoca en obtener resultados de búsqueda enriquecidos, mejorar los contenidos con relación a la intención de búsqueda de los usuarios y en crear contenido que incluya entidades y elementos semánticos afines al titular (o palabra clave) de la noticia que se quiera posicionar en Google. En este caso, el redactor debe trabajar en el SEO semántico desde el contenido de sus noticias, a fin de que incluyan fuentes de información, noticias relacionadas y sinónimos de las palabra clave principal. Por su parte, el experto SEO debe trabajar en el SEO semántico aplicando los esquemas del lenguaje Schema.org, la tecnología AMP (Accelerated Mobile Pages) y analizando el comportamiento de los resultados de búsqueda obtenidos diariamente a través de herramientas de auditoría SEO. 
- EL SXO optimiza la experiencia del usuario cuando visita un cibermedio, de este modo se consigue no solo que el lector navegue por más número de noticias del medio, sino que además vuelva a visitar la web en futuras ocasiones. Para la aplicación del SXO en un cibermedio, el periodista debe publicar noticias que cubran los estándares de calidad (extensión, citación de fuentes, uso de imágenes y contenido audiovisual, etc.). Por otra parte, para que el departamento SEO de un cibermedio practique el SXO deberá mejorar la velocidad de carga de la web y convertirla en responsive en caso de que no esté adaptada a los dispositivos móviles, mejorar la accesibilidad de la web para todo tipo de usuarios y refinar sus buscadores internos para que los usuarios puedan realizar tanto búsquedas simples como avanzadas dentro de la web.

- EI VSO es el conjunto de estrategias que se realizan en los vídeos que se publican en YouTube para que éstos puedan aparecer en sus resultados de búsquedas en posiciones preferentes. Corresponde al periodista realizar las piezas periodísticas con contenido de calidad, mientras que corre a cargo del departamento SEO optimizarlo una vez está publicado en YouTube. Dicha optimización se centra principalmente en el uso adecuado y estratégico de las descripciones, etiquetas y categorías que nos permite rellenar esta plataforma.

\subsubsection{Uso de herramientas SEO}

Este apartado incluye la utilización de herramientas como Sistrix, SEMrush, Ahrefs o Vidlq por lo que hace al SEO, sin perjuicio de otras herramientas de seguimiento y monitorización de redes sociales como Chartbeat u otras.

El uso de herramientas SEO en una redacción periodística no solo ayuda a comparar sus resultados con los de su competencia a nivel de palabras clave posicionadas y número de enlaces externos obtenidos, sino que, además, permite identificar oportunidades para crear nuevas noticias que incorporen tendencias de búsqueda y, por tanto, mejorar la visibilidad web del cibermedio.

\subsubsection{Política de enlaces patrocinados}

Si se lleva a cabo esta esta práctica para mejorar los ingresos del medio, debe hacerse bajo condiciones estrictas de buenas prácticas. La principal es separar contenido editorial de contenido patrocinado. En todo caso, la gestión de este servicio no puede depender únicamente del departamento comercial, sino también de los responsables de la redacción del cibermedio, ya que hay que regularlo adecuadamente para que no se vean afectadas la calidad de las noticias. 
También es importante que la gestión de este servicio se lleve a cabo en coordinación con el departamento SEO porque es necesario que la venta de enlaces patrocinados sea coherente y no masiva para que no afecte ni a la salud ni a la credibilidad del cibermedio.

\subsubsection{Formación SEO}

La formación en posicionamiento en buscadores es esencial para todos los perfiles profesionales de la redacción y debe consistir en una formación continua. La formación en SEO ayudará a los periodistas a entender la importancia de aparecer en los resultados de búsqueda, porque hará que los lectores aumenten. Asimismo, favorecerá, también, la adecuada integración del SEO en las rutinas productivas del cibermedio.

Por otro lado, el propio departamento SEO también debe recibir formación constante ya que los buscadores van evolucionando, por lo que las técnicas de SEO deben evolucionar también.

Esto implica que una técnica que funciona bien hoy, es posible que no funcione igual de bien en un futuro. El experto SEO de un cibermedio debe tener una formación avanzada que incluya no solo labores técnicas de optimización (schema.org, AMP, arquitectura web, usabilidad, etc.) sino también debe aprender a analizar e identifica tendencias de búsqueda y poder plantear temas a los redactores para atraer tráfico web siguiendo tendencias observadas en plataformas digitales.

\subsection{La redacción}

Este es el nivel que afecta a la producción y la redacción de los contenidos periodísticos en sus diversos géneros, aunque el más afectado por el SEO es el de la producción de noticias sobre hechos de actualidad.

Debido a la producción de trabajos anteriores del Grupo DigiDoc sobre el tema, para presentar los apartados que corresponden al nivel redaccional seguiremos principalmente el Framework SEO-RCP (Codina et al., 2016) con algunas actualizaciones para esta edición. 
Como sea, de acuerdo con el Framework SEO-RCP, la optimización de la producción periodística de un cibermedio, de cara a su máxima viabilidad web, se puede articular en tres fases:

- Redacción: que corresponde a la producción convencional de la producción periodística (noticias, p.e.).

- Chequeo SEO: corresponde al chequeo SEO y la optimización de la visibilidad de los contenidos.

- Programación: corresponde a la publicación, que puede ser inmediata o programada, en su caso en función de criterios de oportunidad, así como la programación de publicación en las diversas plataformas del medio.

\section{Principios periodísticos y principios SEO}

Una vez consideradas las fases, veamos a continuación con más detalla la distribución de los grupos de principios que deben combinarse en el SEO periodístico:

- En la fase de Redacción de la noticia siempre debe obedecer y respetar los principios periodísticos.

- En la fase de Chequeo SEO, en cambio, se aplican criterios de visibilidad en buscadores y en redes sociales. En esta fase aparecen dos componentes principales:

- el principio de la doble titulación,

- la distribución óptima de conceptos clave (palabras y frases clave).

- Las posibles contradicciones deben resolverse a favor de los criterios periodísticos (de aquí la primacía de los principios periodísticos).

- Una vez la noticia se ha beneficiado de una redacción eminentemente periodística y de una optimización SEO, puede procederse a la Programación o a su publicación inmediata través de diversas plataformas: la del propio medio, en primer lugar, y la de otros canales, en especial redes sociales.

\subsubsection{Principio de la doble titulación}

La doble titulación se refiere a la práctica observada por algunos de los mejores medios de comunicación y que consiste en:

- aplicar criterios periodísticos al denominado, por este motivo, título periodístico (que en el lenguaje HTML corresponde a la etiqueta $<$ h1 $>$ );

- mientras corresponde aplicar criterios SEO al denominado, por este motivo, título SEO (que en el lenguaje HTML corresponde a la etiqueta $<$ title>). 
El título periodístico es el que el lector verá como titular de la noticia cuando accede al cibermedio. Por eso corresponde aplicar criterios periodísticos y del libro de estilo del medio.

El título SEO consiste es el que el lector verá en la página del buscador o en las redes sociales. Corresponde a uno de los metadatos principales que se utilizan en el SEO (el otro es el metadato description) y está destinado a las plataformas digitales, con el fin de mejorar su comprensión de la noticia.

El CMS o gestor de contenidos del medio debe entonces proporcionar a los redactores una forma de aplicar ambos títulos de una forma diferenciada en el momento de redactar la noticia.

Ambos títulos (periodístico vs SEO) pueden coincidir en algunos casos, pero en muchas ocasiones es necesario establecer diferencias entre el título periodístico y el título SEO. Un primer motivo de estas diferencias (pero enseguida veremos otros), es que el título SEO es el que aparece en las páginas de resultados de los buscadores. Por un lado, esto implica la necesidad de añadir contexto y por otro la de delimitar su extensión.

Con mayor detalle, los motivos de la necesidad de diferentes títulos periodísticos y SEO se pueden articular así en base al contexto de la noticia y en base a las divergencias más características. Vamos a verlos a continuación.

En el primer sentido, debemos recordar que las noticias generadas por los cibermedios aparecen en diferentes plataformas. En concreto:

- Como parte de web del cibermedio

- Como parte de la página de resultados de un buscador

- Como parte del feed o del timeline de una red social

Los diferentes contextos anteriores, nos lleva a las divergencias de titulación que suelen ser más habituales, que intenta recoger los puntos siguientes:

- Sección y cabecera explícita en el sitio del medio vs contexto de la página de resultados de un buscador. Esto implica la necesidad de añadir, por ejemplo, el nombre de la sección en el caso del titulo SEO, mientras que en el título periodístico sería redundante.

- Apellidos vs Nombres completos. En la noticia aparecida en la plataforma del medio no es necesario poner el nombre y los apellidos de los personajes que protagonizan la noticia ya que el contexto (p.e. las imágenes) lo hacen innecesario. En cambio, es importante poner nombre y apellidos en el caso del título SEO para que Google entienda la noticia. 
- Recomendaciones del libro de estilo vs tendencias de búsqueda. Los usuarios pueden buscar un tema determinado usando expresiones que prohíbe el libro de estilo por incorrectas. En el título periodístico es imprescindible utilizar los términos correctos. En cambio, en el título SEO se pueden usar las formas de expresión más frecuentes.

Todo lo anterior nos dice que, gracias al uso de metadatos, en concreto los metadatos $<$ title> y <description>, cuyo uso debe facilitar el CMS del medio, hace posible compatibilizar los criterios periodísticos y los criterios de posicionamiento SEO.

Por ejemplo, puede ser una norma en un cibermedio que el título SEO (etiqueta $<$ title $>$ ) incluya siempre el nombre del medio (branding) así como el título de la sección. Dos datos útiles para el SEO, pero innecesarios desde el punto de vista de los criterios periodísticos (etiqueta $<\mathrm{h} 1>$ ). Por eso tienen sentido aplicar estos criterios en el título SEO, pero no en el título periodístico.

\subsubsection{Plataformas}

El sitio de un cibermedio es su lugar de publicación natural. Sin embargo, el término "natural" no implica que la página web del cibermedio sea el lugar donde la noticia vaya a ser vista por primera vez ni siquiera donde vaya a ser vista más veces.

En este sentido, entendemos que actualmente una noticia o información periodística es susceptible de ser vista en las siguientes plataformas:

- Página de resultados de un buscador, donde la noticia será vista a través de un snippet en el que el título será tomado del metadato <title> (no del contenido de la etiqueta h1) y la descripción será tomada también de otro metadato, en este caso denominado <description>.

- Redes sociales como Facebook y Twitter que utilizan también sus propios metadatos, de manera que será vista posiblemente con otro título y una descripción distinta, si así se hizo al redactar la noticia en el CMS correspondiente.

- Por último, aunque es la más importante, en el sitio web del cibermedio, donde aparecerá en un contexto determinado según la forma de acceder por navegación o mediante una URL directa. 


\subsubsection{Palabras clave, frases clave y conceptos}

La palabra clave es el término por el cual esperamos que nuestra noticia sea buscada o por la cual nos gustaría que nuestra noticia tuviera la máxima visibilidad posible como resultado de una búsqueda en Google (o en otros buscadores).

Normalmente, se optimizan las noticias para una palabra clave. Si queremos optimizarlas para dos o más, habrá que reiterar los chequeos que se presentan más adelante, así como considerar una mayor extensión de la noticia.

Por último, cabe tener presente que los buscadores cada vez utilizan más los conceptos y no solo las palabras clave para determinar la idoneidad de una noticia en respuesta a una búsqueda.

Pero los conceptos siempre se expresan mediante palabras y expresiones concretas, por este motivo, mantenemos la idea de las palabras clave en lo que seguirá. A continuación, por tanto, veremos una serie de consideraciones y de dimensiones que afectan al SEO y al tratamiento de las palabras clave en las noticias.

\section{Densidad de palabra clave}

Es el número de veces que aparece la palabra clave en relación con el número total de palabras que tiene la noticia. Se calcula dividendo el número de veces que aparece la palabra clave por el número total de palabras y multiplicando por cien. Por ejemplo, si en una noticia la palabra clave aparece en 9 de las 600 palabras en total, esto nos dice que la densidad es del 1,5 por ciento.

\section{Densidad óptima de palabra clave}

¿Existe una densidad óptima? Oficialmente, Google asegura que no la hay. La recomendación oficial es que se debe escribir para seres humanos, no para Google, de modo que la mejor densidad es la que produce de manera espontánea el lenguaje natural. No obstante, aunque no exista una densidad óptima, los análisis de algunos expertos señalan claramente la existencia de un rango óptimo que se suele situar entre el 0,5 y 2,5 por ciento, aunque este último nivel seguramente es mejor evitarlo y considerar que al menos la palabras clave debe estar en un 1 por ciento y no superar el 2 por ciento. 


\section{Infraoptimización SEO}

Es un hecho que los seres humanos no somos siempre consistentes. Podemos escribir un largo artículo con la idea de que estamos hablando sobre un determinado tema sin apenas haber usado la palabra clave que mejor lo identifica. En este caso, un bajo número de repeticiones de la palabra clave impedirá que Google considere relevante esa noticia dando lugar a un caso de infra optimización SEO, tan inadecuado como una sobre optimización.

\section{Sobreoptimización SEO}

Los algoritmos de análisis de Google penalizan la sobre optimización SEO. Se define como la repetición anti natural, más allá de la frecuencia habitual para una lengua, de una misma palabra o frase en un mismo texto. Es evidente que una buena escritura combina sinónimos y evita expresamente repetir demasiadas veces la misma palabra en una misma frase. Esta naturalidad y calidad de escritura es la que busca promover Google mediante la penalización de textos sobre optimizados para el SEO.

\section{Rango óptimo}

Si bien es cierto que no hay una densidad óptima, al menos parece que hay un rango óptimo. Sería aquel que nos indica cuál es la densidad mínima y máxima deseables. Conviene evitar la densidad mínima por peligro de infra optimización y la máxima por su contrario, la sobre optimización. Según diversos análisis parece que el rango óptimo es relativamente amplio, porque iría del 0,5 al 2,5 por ciento, al menos en el contexto de texto relativamente extensos (900 palabras o más). No obstante, en general parece que hay que evitar los extremos. Esto nos situaría en un rango de entre el 1 y el 2 por ciento.

\section{Distribución óptima}

Muchos profesionales del SEO prefieren pensar en una distribución óptima en lugar de una densidad óptima. Según esto, lo que se valora es dónde aparece la palabra clave, en qué lugares de la página y no cuántas veces. Mientras no superemos el rango óptimo, la idea de la distribución es más eficiente porque permite presentar una estructura de entrada convincente y sin forzar el lenguaje natural.

\section{Análisis semántico}

El análisis semántico esta siendo cada vez más incorporado por los buscadores, tanto para entender las preguntas de los usuarios e interpretar bien su intención de búsqueda, como para interpretar el tema o contenido de las páginas. El análisis semántico no toma 
en cuenta cadenas de caracteres, sino conceptos y temas relacionados. Según esto, para saber si una página es adecuada para una cierta palabra clave, debe considerarse los sinónimos y los términos relacionados de esa palabra determinada. Para saber si una página es adecuada para una búsqueda que utilice la expresión "derechos humanos", el buscador considerará más relevantes las páginas que además de la anterior, también contengan términos como "democracia", "libertad", "justicia", etc.

\section{Intención de búsqueda}

Los buscadores cada vez más tienen en cuenta la intención de búsqueda y no solamente las palabras clave. Esto significa que la selección de las palabras clave debe tener en cuenta también la intención de búsqueda que quiera solucionar la noticia o el contenido producido por el medio. Un ejemplo fácil puede ser añadir palabras clave como "consejo" o "guía" cuando el medio publique informaciones para ayudar a los lectores en la campaña de la declaración de renta de cada año. O utilizar palabras como "análisis", "crítica", etc., en artículos sobre libros, películas o estrenos de teatro, etc. Igualmente, se pueden utilizar frases como "Para entender $x x^{\prime}$ ", si se publican contenidos para aclarar temas de actualidad de cierta complejidad.

\section{Entidades}

Personas, organismos, ciudades, empresas, etc., constituyen lo que en búsqueda semántica se denominan entidades. Más concretamente, estamos hablando de nombres de entidades. La aparición de tales nombres, y por tanto, la aparición de nombre propios, topónimos, etc., otorga credibilidad a una noticia, porque se interpreta a la vez como una referencia a hechos de actualidad y una referencia también a posibles fuentes. En este sentido, las entidades constituyen otra forma de interpretar las necesidades de palabras clave que deben aparecer en una noticia.

\subsubsection{Chequeo y optimización SEO de la noticia}

Señalemos de entrada, que algunos de los puntos este chequeo SEO pueden obligar a editar o reescribir partes de la noticia. Debe procederse siempre a esta edición salvo si afecta a la calidad periodística.

En caso de contradicción entre el imperativo SEO y el imperativo Periodístico, el SEO debe ceder. El periodismo está al servicio de las personas, no de Google. Por ejemplo, como se verá enseguida, el punto de chequeo 1 propone una extensión mínima de 300 palabras, pero esto debe aplicarse cuando no vaya contra el género periodístico concreto. 
En todo caso, los puntos de optimización de la noticia que el periodista-redactor debe considerar de acuerdo con este marco de trabajo son los que se indicarán a continuación.

Damos por supuesto el uso de un CMS que permite editar y asignar metadatos a los contenidos, concretamente que permita editar los metadatos <title> y <description>. Igualmente, sería deseable un CMS (o un plugin) que permita también editar los metadatos de las dos redes más importantes: Facebook y Twitter.

01. Extensión. Al menos 300 palabras y mucho mejor si supera esa cifra. De ser posible, y si está justificado, más palabras, p.e. 900 o 1.000 posicionan mejor.

02. Multimedia. Añada siempre algún componente multimedia, al menos una fotografía.

03. Palabra clave. Decida cuál es la palabra clave o concepto principal de su entrada. A partir de aquí debe aplicar los puntos siguientes en consonancia.

04. Distribución óptima de la palabra clave, de sus sinónimos y/o de términos directamente relacionados:

- En el título periodístico (etiqueta $<\mathrm{h} 1>$ )

- En la URL de la entrada. Edite la URL si es necesario para evitar palabras vacías y limitar la extensión. Es preferible títulos cortos y fácilmente manejables.

- En el título SEO (etiqueta <title>). Máximo 70 caracteres

- En el metadato <description>. Máximo 156 caracteres

- En uno de los titulares del cuerpo de la noticia (etiqueta h2)

- En el primer párrafo.

- En alguno(s) de los párrafos centrales.

- En alguno(s) de los párrafos finales.

- En al menos una de las imágenes: en el pie de foto y en los metadatos (etiqueta <alt $>$ )

05. Énfasis. En alguna de sus ocurrencias, la palabra clave debe estar marcada en negrita o cursiva si lo permite el libro de estilo.

06. Apoyo semántico. Recuerde utilizar sinónimos y términos relacionados con la palabra clave en el cuerpo y/o en los titulares de la entrada para apoyar la fortaleza de la palabra clave.

07. Credibilidad. Mencione entidades en forma de nombre de personas, lugares o instituciones y añada enlaces a las entidades si es el caso.

08. Enlaces internos. Siempre que sea posible, establezca enlaces con otras entradas relacionadas temáticamente, utilizando la taxonomía o el sistema de etiquetas o categorías de su sitio web. 
09. Web social y contenido adaptativo. Asegúrese de configurar la entrada de modo que se publique en redes sociales, así como de disponer de botones de (re) difusión en redes sociales activados y configurados. En caso de disponer de la posibilidad con su CMS, considere títulos, descripciones e imágenes específicas para redes como Facebook y Twitter.

10. Programación. Programe la entrada, si es el caso, para que se publique en el momento óptimo según su consideración y naturaleza. Esto incluye no solamente el sitio web del medio, sino también otras plataformas del medio, como Facebook y Twitter.

\subsection{Conclusiones}

Como conclusión de este apartado, cabe reforzar la idea de que el procedimiento debe poner el énfasis en el mejor periodismo, para luego añadir una optimización SEO que puede basarse en los 10 puntos precedentes, siempre que ninguno de ellos entre en contradicción con los principios periodísticos.

Igualmente, cabe reformar la idea de que cuando utilizamos la expresión palabra clave nos referimos tanto a un término concreto como a sus sinónimos y conceptos relacionados, si fuera el caso. La buena escritura periodística ya tiene tendencia a utilizar una vocabulario rico, pero los puntos anteriores nos recuerdan también que hemos de ser consistentes.

Si queremos que una noticia, por ejemplo, sobre "turismo en Barcelona" sea muy visible para búsquedas de esta palara clave, lo que no podemos hacer es ignorar la necesidad de que esta misma frase clave (sin olvidar sinónimos y términos relacionados) tenga una densidad y una distribución óptimas según indican los puntos anteriores.

En el momento en que, para una misma noticia deseamos que su visibilidad se amplíe a una segunda o incluso una tercera palabras (o frases) clave, deberemos reiterar los puntos de chequeo anteriores para cada una de ellas, y seguramente deberemos ampliar su extensión en consecuencia. 


\section{TERCERA PARTE \\ ENTREVISTAS Y CONCLUSIONES}

\section{Entrevistas: el SEO según sus profesionales y expertos}

A continuación, se incluyen las respuestas proporcionadas por el grupo de profesionales y expertos SEO que aceptaron responder una encuesta enviada por correo con motivo de esta investigación. Es costumbre situar esta clase de materiales en un anexo. En cambio, nosotros creemos que merecen un apartado específico en el cuerpo de este informe por el valor que tienen dada la autoridad de quienes participaron.

\section{Experto: Bruno Ramos}

Brunoramos.es

\section{Pregunta}

¿Puede señalar cuatro de los principales factores SEO para 2019?

Enlaces entrantes de autoridad referentes del sector y que envíen tráfico. Contenido de calidad enfocado a resolver querys concretas. SEO on page, experiencia de usuario, velocidad de carga y usabilidad. Generación de marca propia y citaciones.

\section{Pregunta}

¿Puede indicar algunos aspectos clave sobre cómo deberá abordar el profesional del SEO los nuevos escenarios siguientes: búsquedas semánticas, búsquedas por voz, intención de búsqueda?

Búsquedas semánticas: enriqueciendo el contenido con variaciones, long tail, LSI, y mapas de entidades.

Búsquedas por voz: generar contenido en formato pregunta, que ataque long long tail y estructurar el contenido de forma precisa con listas ordenadas encabezadas por títulos específicos. 
Intención de búsqueda: ofrecer el resultado lo más arriba posible con contenido específico para la keyword, generando clústeres para las keywords más ambiguas que balanceen el tráfico hacia uno u otro contenido.

\section{Pregunta}

¿Qué tipo de SEO cree que tendrá mayor peso e importancia: el SEO técnico, el SEO On-page o el SEO Off-page? ¿Desea añadir alguna motivación para su elección?

Todos los tipos de SEO tienen su importancia, decantarse solo por uno sería una temeridad, ya que el posicionamiento se logra con la conjunción de centenares de factores que deben pulirse para superar a la competencia. Así pues, el SEO activo sería la actitud más importante.

\section{Pregunta}

De este listado ¿Cuál es la herramienta SEO que más utiliza? SEMrush, Ahrefs, Majestic, Sistrix, Xovi, MOZ y Woornak. ¿Desea añadir alguna motivación para su elección?

Las uso todas, pero SEMrush con mayor frecuencia y por ser la más completa en funcionalidades y países en su base de datos, aunque no es la más especializada para ciertas tareas como link building o gestión de canibalización.

\section{Pregunta}

Cómo experto en SEO y en líneas generales ¿considera que los diarios digitales están aplicando buenas, malas o nulas estrategias SEO? ¿Desea argumentar su respuesta?

Sí. El primer gran cambio ha sido la integración de AMP e Instant Articles de Facebook. Ok Diario acaba de realizar una compra masiva de webs verticales para ampliar su contenido para acaparar más tráfico orgánico y autoridad en todas sus líneas de contenido. 


\section{Pregunta}

En caso de que tenga alguna experiencia como experto SEO en medios de comunicación digitales ¿ existe alguna recomendación muy general que haría llegar a los medios para que fueran capaces de posicionarse mejor sin que por ello afectase a la calidad de la información de las noticias?

La respuesta está en el mundo off line. Los grandes grupos editoriales no solo tienen periódicos para alcanzar a la gran audiencia: generan productos verticales en formato revista para atacar nichos de mercado concretos y acaparar anunciantes especializados dispuestos a pagar más por una audiencia segmentada.

Ese es el camino a seguir (recuerdo el caso de Ok Diario o la adquisición de blogs temáticos del resto de medios generalistas, como Microsiervos por Economía Digital).

Generar contenido inbound que atraiga lectores, ayude a posicionar contenidos que resuelvan intenciones de compra, que atraigan anunciantes y mejoren las cuentas anuales.

\section{Experto: Emilio García Garrido}

campamentoweb.com

\section{Pregunta}

¿Puede señalar cuatro de los principales factores SEO para 2019?

- Intención de búsqueda (la concordancia de lo que un usuario espera de un resultado web, con el tipo de contenido que ofrece la misma). Para esto es importante delimitar qué es una keyword informativa o transaccional y qué está buscando específicamente cada usuario.

- Autoridad (número y calidad de los enlaces entrantes hacia la web).

- Búsquedas de marca (asociar una keyword con una marca en concreto)

- Estructura web (tener una URL para cada objetivo o keyword, con el objetivo de contextualizar al máximo, aportando la palabra clave principal en el título y contenido principal). 


\section{Pregunta}

¿Puede indicar algunos aspectos clave sobre cómo deberá abordar el profesional del SEO los nuevos escenarios siguientes: búsquedas semánticas, búsquedas por voz, intención de búsqueda?

- Búsquedas semánticas

- Mayor cantidad de contenido con palabras clave secundarias potenciadas en encabezados o negritas.

- Texto mejor maquetado para que invite a la lectura, y que dicha extensión no sea contraproducente para que el usuario lo lea.

- Aprovechar inserciones audiovisuales. No solo de YouTube e imágenes, sino de otras redes sociales (tweets, publicaciones de Facebook, Instagram...).

- Búsquedas de voz

- Respuestas simples en el primer párrafo del contenido.

- Concordancia exacta con las keywords, incluyendo pronombres interrogativos en caso de ser necesarios. Por ejemplo: para "qué es la plata 925" se debería incluir toda la oración interrogativa en lugar de solo "plata 925".

- Apoyarse en elementos como tablas y listados, dependiendo de la intención de búsqueda (comparativas, listado de recetas o características...).

- Intención de búsqueda

- Estudio de lo que está posicionando actualmente Google para cada consulta. Así sabremos con certeza qué tipo de contenido quiere posicionar para cada keyword.

- No obsesionarse con las palabras, sino aprovechar otros elementos como los mencionados anteriormente: tablas, listados, imágenes, videos, enlaces externos que sean de utilidad... Investigar si estamos tratando con una keyword informativa o transaccional.

\section{Pregunta}

¿Qué tipo de SEO cree que tendrá mayor peso e importancia: el SEO técnico, el SEO Onpage o el SEO Off-page? ¿Desea añadir alguna motivación para su elección?

SEO On-Page, ya que la experiencia de usuario reside en ella y es una tendencia desde hace años. En cuanto al SEO Técnico, considero que Google tendrá cada vez más recursos y facilidades para solventar por sí mismo problemas técnicos que encuentre en 
la web. A no ser que afecte al usuario directamente (SEO On-Page), considero que no tendrán impacto en los rankings.

\section{Pregunta}

De este listado ¿Cuál es la herramienta SEO que más utiliza? SEMrush, Ahrefs, Majestic, Sistrix, Xovi, MOZ, y Woornak. ¿Desea añadir alguna motivación para su elección?

Ahrefs, sin duda. Es la que tiene una base de datos más amplia (por lo que los datos son más fiables y de mayor cantidad que el resto de herramientas). Además, ofrece un abanico de herramientas que ayudan tanto en SEO On Page (análisis en forma de auditoría), SEO Off Page (la de siempre, con análisis de enlaces) y de Keyword Research (para analizar palabras clave).

\section{Pregunta}

Cómo experto en SEO, y en líneas generales ¿considera que los diarios digitales están aplicando buenas, malas o nulas estrategias SEO? ¿Desea argumentar su respuesta?

Buenas estrategias. Conozco a varios SEOs de dicho sector y se centran mucho en ofrecer el mejor contenido al usuario (por ejemplo, mostrar la mayor información posible en eventos en directo), así como tratar aspectos de SEO Técnico como el crawl Budget (fundamental para proyectos tan grandes como los periódicos).

\section{Pregunta}

En caso de que tenga alguna experiencia como experto SEO en medios de comunicación digitales ¿existe alguna recomendación muy general que haría llegar a los medios para que fueran capaces de posicionarse mejor sin que por ello afectase a la calidad de la información de las noticias?

No tengo experiencia directa en medios, pero recomendaría hacer titulares atractivos pero sin olvidar las keywords, hacer enlaces internos con palabras clave que sean tendencia cada día, trabajar el perfil de indexación, además del crawl Budget (por ejemplo, eliminando la paginación de las categorías para evitar que haya miles de páginas que rastrear). 


\section{Experto: David Ayala}

soywebmaster.com

\section{Pregunta}

¿Puede señalar cuatro de los principales factores SEO para 2019?

- Experiencia de Usuario

- CTR

- Optimización On Page

- Link Building

\section{Pregunta}

¿Puede indicar algunos aspectos clave sobre cómo deberá abordar el profesional del SEO los nuevos escenarios siguientes: búsquedas semánticas, búsquedas por voz, intención de búsqueda?

- Búsquedas semánticas: Sin lugar a dudas hay que trabajar las variaciones de las palabras clave, los sinónimos, las palabras derivadas, las palabras relacionadas con la temática, palabras compuestas, etcétera.

- Búsquedas por voz: Habrá que trabajar para conseguir ser el primero ya que si no, no tendremos representación en estas búsquedas. Además habrá que trabajar las búsquedas tipo pregunta como: “¿Cómo llegar al lugar..." “¿Cuál es el restaurante más cercano a...?"... Este tipo de búsquedas serán las predominantes por voz.

- Intención de búsqueda: Hay que tener coherencia en las búsquedas respecto a lo que ofrecemos y siempre buscar palabras clave cuya intención de búsqueda sea coherente con el contenido o productos que ofrecemos para que así tengamos mayor porcentaje de éxito en nuestro objetivo final, ya sea conseguir ventas, conseguir leads o sea el que sea. 


\section{Pregunta}

¿Qué tipo de SEO cree que tendrá mayor peso e importancia: el SEO técnico, el SEO Onpage o el SEO Off-page? ¿Desea añadir alguna motivación para su elección?

El SEO On Page, ya que sin un buen SEO On Page, el SEO Off Page o el SEO técnico pierden fuerza.

\section{Pregunta}

De este listado ¿Cuál es la herramienta SEO que más utiliza? SEMrush, Ahrefs, Majestic, Sistrix, Xovi, MOZ, y Woornak. ¿Desea añadir alguna motivación para su elección?

SEMRush, ya que es una herramienta con la que trabajo muy cómodo para el keyword research. Otra herramienta con la que trabajo mucho es Screaming frog y además, me parece esencial para cualquier análisis web.

\section{Pregunta}

Como experto en SEO, y en líneas generales ¿considera que los diarios digitales están aplicando buenas, malas o nulas estrategias SEO? ¿Desea argumentar su respuesta?

Están aplicando buenas estrategias SEO pero, se quedan a veces cortos a la hora de optimizaciones On Page, aunque es entendible por las limitaciones que tiene llevar un negocio de ese calibre.

\section{Pregunta}

En caso de que tenga alguna experiencia como experto SEO en medios de comunicación digitales ¿existe alguna recomendación muy general que haría llegar a los medios para que fueran capaces de posicionarse mejor sin que por ello afectase a la calidad de la información de las noticias?

Una recomendación sería que hubiera un mayor consenso entre redactores y SEOs, ya que aunque es verdad que los contenidos y titulares se tienen que hacer según unas directivas, se podrían optimizar un poco más de cara a SEO en la gran mayoría de medios. 


\section{Experto: Álex Navarro}

Dropalia.com

\section{Pregunta}

¿Puede señalar cuatro de los principales SEO para 2019?

Experiencia de usuario, Enlaces externos, Seo On Page y luego ya vendría todo lo demás.

\section{Pregunta}

¿Qué tipo de SEO cree que tendrá mayor peso e importancia: el SEO técnico, el SEO Onpage o el SEO Off-page? ¿Desea añadir alguna motivación para su elección?

Yo creo que es una combinación de todos. Piensa que el algoritmo de Google está compuesto por cientos de factores y es la satisfacción de todos ellos (o de la mayoría posible), lo que te hará conseguir subir en posiciones. También es verdad que Google le da más peso a ciertos factores y menos a otros (por ejemplo un enlace de calidad ayudará más que un hosting con IP geolocalizada en el país), pero como esto es tan cambiante con las actualizaciones de algoritmo, lo mejor es intentar satisfacer la mayor cantidad posible de factores.

\section{Pregunta}

De este listado ¿Cuál es la herramienta SEO que más utiliza? SEMrush, Ahrefs, Majestic, Sistrix, Xovi, MOZ, y Woornak. ¿Desea añadir alguna motivación para su elección?

En mi caso, las dos que más uso son Ahrefs y Screaming Frog.

\section{Pregunta}

Cómo experto en SEO, y en líneas generales ¿considera que los diarios digitales están aplicando buenas, malas o nulas estrategias SEO? ¿Desea argumentar su respuesta?

No se puede generalizar. Hay ciertos diarios que están haciendo unas estrategias de SEO extraordinarias (ejemplo Elmundo.es, RT.com, etc.) mientras que otros se están 
prostituyendo con la venta de enlaces a lo loco. Existen decenas de formas de monetizar mejor un periódico que la venta de enlaces. Y más si lo haces de forma tan exagerada como algunos de ellos. Eso solo lleva a una penalización segura.

El gran problema que muchos periódicos tienen, aún a día de hoy, es la gran cantidad de contenido escaso y duplicado, indexando en Google.

\section{Pregunta}

En caso de que tenga alguna experiencia como experto SEO en medios de comunicación digitales ¿existe alguna recomendación muy general que haría llegar a los medios para que fueran capaces de posicionarse mejor sin que por ello afectase a la calidad de la información de las noticias?

Creo que cada medio es un mundo, y todos se tienen que analizar de forma individual para poder recomendar algo. Pero si los medios consiguiesen tener una mejor experiencia de usuario (como por ejemplo la estancia en página o los clics internos) ganarían mucho. Esto se consigue con pequeños trucos On Page que periódicos como RT.com hacen muy bien (los enlaces a otras noticias relacionadas bien visibles dentro del contenido, los comentarios en tiempo real, etc.) $Y$ por supuesto, arreglar los problemas de contenido escaso y duplicado. Simplemente trabajando más eficazmente con subdominios, se pueden arreglar varios de estos problemas.

\section{Experto: Esteve Castells}

estevecastells.com

\section{Pregunta}

¿Puede señalar cuatro de los principales factores SEO para 2019?

Por orden: referring domains (enlazado externo), internal linking, relevancia del contenido (vs. user intent), calidad del contenido.

\section{Pregunta}

¿Puede indicar algunos aspectos clave sobre cómo deberá abordar el profesional del SEO los nuevos escenarios siguientes: búsquedas semánticas, búsquedas por voz, intención de búsqueda? 
Al tratarse de una búsqueda mucho más semánticas los contenidos tienen que tratarse de manera mucho más ad hoc en la que en pocas palabras respondemos la pregunta, pero a la vez no formulamos las preguntas con excesivas keywords. La manera más fácil de trabajar ahora mismo las búsquedas por voz es mediante la consecución de featured snippets, ya que más del $40 \%$ de las búsquedas por voz provienen de estos snippets.

\section{Pregunta}

¿Qué tipo de SEO cree que tendrá mayor peso e importancia: el SEO técnico, el SEO Onpage o el SEO Off-page? ¿Desea añadir alguna motivación para su elección?

Todo es SEO al fin y al cabo y Google no distingue entre uno u otro. El SEO sigue siendo transversal y todas las patas deben ser trabajadas, si no, no se suelen conseguir resultados.

\section{Pregunta}

De este listado ¿Cuál es la herramienta SEO que más utiliza? SEMrush, Ahrefs, Majestic, Sistrix, Xovi, MOZ, y Woornak. ¿Desea añadir alguna motivación para su elección?

SEMrush, Ahrefs. Añadiría: Screaming Frog, Fandango SEO, Botify, Kibana y las de Google (Analytics, GSC, Trends, Data studio...).

\section{Pregunta}

Cómo experto en SEO, y en líneas generales ¿considera que los diarios digitales están aplicando buenas, malas o nulas estrategias SEO? ¿Desea argumentar su respuesta?

Depende del diario, pero en general algunos aplican estrategias SEO muy sólidas, otros bastante flojas y algunos nulas.

Un ejemplo de buena estrategia SEO es OKDiario, que hace un estudio muy exhaustivo de las tendencias y posiciona muy bien las keywords que se propone con contenido bien estructurados para SEO.

Otro que emplea un SEO real-time excelente es La Vanguardia, con un equipo de SEOs muy grande que les permite planificar y ejecutar todas las noticias con grandes resultados. 


\section{Pregunta}

En caso de que tenga alguna experiencia como experto SEO en medios de comunicación digitales cexiste alguna recomendación muy general que haría llegar a los medios para que fueran capaces de posicionarse mejor sin que por ello afectase a la calidad de la información de las noticias?

Trabajar el títulos para SEO (<title>) y la imagen que aparece en el carrusel, así como tener versión AMP.

\section{Experto: Luis Villanueva}

Webpositer.com

\section{Pregunta}

¿Puede señalar cuatro de los principales factores SEO para 2019?

Mobile First Index, Experiencia de usuario, relevancia y contenido (search intent, voz, etc.).

\section{Pregunta}

¿Puede indicar algunos aspectos clave sobre cómo deberá abordar el profesional del SEO los nuevos escenarios siguientes: búsquedas semánticas, búsquedas por voz, intención de búsqueda?

Enfocándonos mucho al usuario y teniendo muy en cuenta qué intenciones presentes y futuras debemos responder.

\section{Pregunta}

¿Qué tipo de SEO cree que tendrá mayor peso e importancia: el SEO técnico, el SEO Onpage o el SEO Off-page? ¿Desea añadir alguna motivación para su elección? 
Bajo mi punto de vista si lo técnico está bien lo demás es más sencillo por lo que siendo todos necesarios necesitaríamos tener la base, porque la técnica te da la buena indexación, y sin indexación no hay seo.

\section{Pregunta}

De este listado ¿Cuál es la herramienta SEO que más utiliza? SEMrush, Ahrefs, Majestic, Sistrix, Xovi, MOZ, y Woornak. ¿Desea añadir alguna motivación para su elección?

SEMrush, Ahrefs, Majestic, Sistrix, Xovi, MOZ, y Woornak. Sin duda AHREFS, es la mas completa de todas con diferencia, aunque las mejores bajo mi punto de vista no están aquí: Analytics, Search Console y Screaming Frog.

\section{Pregunta}

Como experto en SEO, y en líneas generales ¿considera que los diarios digitales están aplicando buenas, malas o nulas estrategias SEO? ¿Desea argumentar su respuesta?

Como todo, algunos buenas y otros no tan buenas, por ejemplo me gusta la implementación de AMP que han realizado en el $A B C$ o el trabajo de estrategia SEO que hacen en La Vanguardia.

\section{Experto: Natzir Turrado}

analistaseo.es

\section{Pregunta}

¿Puede señalar cuatro de los principales factores SEO para 2019?

Resolver la intención de búsqueda, velocidad, ser una autoridad en tu sector y ser accesible e indexable (no es un factor como tal pero es algo cada más necesario con el auge de nuevos frameworks y librerías JS para el desarrollo de sitios web). 


\section{Pregunta}

¿Puede indicar algunos aspectos clave sobre cómo deberá abordar el profesional del SEO los nuevos escenarios siguientes: búsquedas semánticas, búsquedas por voz, intención de búsqueda?

Siendo el proveedor de respuestas de tu sector y convirtiéndote en una autoridad reputada: Identificando las necesidades y los problemas de tu target, la intención detrás de la búsqueda (revisando CTRs, rebotes desde orgánico, analizando búsquedas internas, y haciendo encuestas on site), aportando soluciones y respuestas mediante el contenido. En la búsqueda semántica y por voz la autoridad es importante porque intenta no mostrar contenidos de sitios poco reputados para evitar dar respuestas erróneas.

- Escribir en lenguaje natural y estructurando los textos.

- Haciendo uso de entidades relacionadas para dar más relevancia al contenido.

- Utilizar microdatos como Schema.org y hacer uso Google Actions.

\section{Pregunta}

¿Qué tipo de SEO cree que tendrá mayor peso e importancia: el SEO técnico, el SEO Onpage o el SEO Off-page? ¿Desea añadir alguna motivación para su elección?

(Entiendo que el SEO On Page son los contenidos, porque para mi el SEO técnico está dentro del On Page) Cuanto más evolucione Google al final no harán falta enlaces para saber qué contenido es bueno o no, y a medida que también evoluciona Google, el SEO técnico debería ir quedando en segundo plano, puesto que será capaz de rastrear nuevas tecnologías más eficientemente. Así que, en un futuro, me decantaría por el contenido como lo más importante. Lo curioso es cada vez más recibo más proyectos de SEO técnico y cada año se está volviendo más importante por lo que comentaba al principio, pero si pensamos en cómo sería en el tiempo, sin duda, creo que no haría falta tanto esta figura.

\section{Pregunta}

De este listado ¿Cuál es la herramienta SEO que más utiliza? SEMrush, Ahrefs, Majestic, Sistrix, Xovi, MOZ, y Woornak. ¿Desea añadir alguna motivación para su elección?

SEMrush, Sistrix y Ahrefs a partes iguales. No podría decir una u otra. 


\section{Pregunta}

Cómo experto en SEO, y en líneas generales ¿considera que los diarios digitales están aplicando buenas, malas o nulas estrategias SEO? ¿Desea argumentar su respuesta?

Creo que en España tenemos a los mejores SEOs de medios de todo el mundo. Cuando viajo o veo charlas de lo que hacen en medios de otros países como EEUU, UK, Alemania, etc. veo que estamos bastante por delante. Y a la muestra está que los medios españoles están dentro del top portales con más viabilidad en España, algo que no ocurre en otros países

\section{Pregunta}

En caso de que tenga alguna experiencia como experto SEO en medios de comunicación digitales ¿existe alguna recomendación muy general que haría llegar a los medios para que fueran capaces de posicionarse mejor sin que por ello afectase a la calidad de la información de las noticias?

El consejo que doy siempre a los redactores de medios es que moderen la creatividad en los lugares clave. No hacerlo puede evitar que una noticia sea descubierta y no reciba tráfico a menos que la encuentren los usuarios desde portada.

\section{Experto: Cesar Aparicio}

Craneoprevilegiado.com

\section{Pregunta}

¿Puede señalar cuatro de los principales factores SEO para 2019?

Indico los factores que considero primordiales para el posicionamiento en 2019 (que coinciden con los de años anteriores)

- Enlaces (como es habitual.

- Arquitectura interna.

- Contenido.

- Limpieza y eficiencia del sitio web. 
Todos los factores anteriores están interrelacionados unos con otros en mayor o menor medida.

\section{Pregunta}

¿Puede indicar algunos aspectos clave sobre como deberá abordar el profesional del SEO los nuevos escenarios siguientes: búsquedas semánticas, búsquedas por voz, intención de búsqueda?

Una misma URL puede resolver diferentes intenciones de búsqueda, por tanto, es importante destacar que no es necesario generar URL del tipo "diccionario" para cada consulta del usuario. Es más conveniente crear URL completas que resuelvan varias consultas. De este modo, evitamos inconvenientes derivados de contenidos excesivamente similares dentro de un sitio web, URL innecesarias (y lo que acarrean), etc.

Por tanto, la semántica (desde la perspectiva del procesamiento de lenguaje natural) tiende a interpretar mejor el contenido y esto permite que no sean necesarias tantas URL como hasta la fecha.

Respecto a la búsqueda por voz, sucederá lo mismo que con la búsqueda de texto en el medio plazo una vez que se estandarice el uso. De hecho, el funcionamiento detrás de la comprensión de la búsqueda con voz por parte de los motores de búsqueda se basa en los mismos pilares que el análisis de textos común.

\section{Pregunta}

¿Qué tipo de SEO cree que tendrá mayor peso e importancia: el SEO técnico, el SEO Onpage o el SEO Off-page? ¿Desea añadir alguna motivación para su elección?

EI SEO es técnico por definición siempre que se entienda la realidad de cómo funciona un buscador. Es más, la generación de contenido o keywords research se derivan de una tecnología con una técnica avanzada. Su conocimiento permite una ventaja competitiva considerable. ¿Es posible hacer SEO sin ser técnico? Sí. ¿Ser técnico ofrece una ventaja competitiva? Sí.

Respecto a la relevancia del SEO On-page u Off-page, uno sobre otro, a mi parecer van ligados. Un buen SEO On-page permite que los efectos del SEO Off-page sean más que destacables. Un SEO Off-page, en tanto a relevancia a través de enlaces se refiere, permite que un SEO On-page mediocre (por los motivos que sea pues no siempre se 
puede actuar como se quiere en un sitio sobre todo si son grandes sites) no sea tan relevante como lo sería en un sitio pequeño.

\section{Pregunta}

De este listado ¿Cuál es la herramienta SEO que más utiliza? SEMrush, Ahrefs, Majestic, Sistrix, Xovi, MOZ, y Woornak. ¿Desea añadir alguna motivación para su elección?

- Safecont

- Ahrefs

- Sistrix

- Link Affinity

- Screaming Frog

\section{Pregunta}

Como experto en SEO, y en líneas generales ¿considera que los diarios digitales están aplicando buenas, malas o nulas estrategias SEO? ¿Desea argumentar su respuesta?

El nivel SEO de las grandes publicaciones de diarios digitales me parece muy bueno. En buena medida por la complejidad del sector. La relación necesaria entre SEO e IT, la previsión editorial, la competición en búsquedas muy estacionales me parece meritorio.

\section{Pregunta}

En caso de que tenga alguna experiencia como experto SEO en medios de comunicación digitales cexiste alguna recomendación muy general que haría llegar a los medios para que fueran capaces de posicionarse mejor sin que por ello afectase a la calidad de la información de las noticias?

Prestar atención a contenidos antiguos (cuyo mayor coste ya fue soportado) en tanto a renovación como enlazado interno (dependiente exclusivamente de la gestión del sitio) con el fin de mejorar el middle y long tail. 


\section{Experto: Fernando Muñoz}

raiz.es

\section{Pregunta}

¿Puede señalar cuatro de los principales factores SEO para 2019?

Arquitectura, contenido, rendimiento y enlaces.

\section{Pregunta}

¿Puede indicar algunos aspectos clave sobre cómo deberá abordar el profesional del SEO los nuevos escenarios siguientes: búsquedas semánticas, búsquedas por voz, intención de búsqueda?

Intención de búsqueda: Respondiendo al usuario siempre. Cada URL debe ser claramente identificable su intención. Así una URL que no sea transaccional será complicado que aparezca ante búsquedas transaccionales.

Búsquedas semánticas: Entiendo que se refieren a las búsquedas producidas mediante preguntas. Si no es eso, por favor, aclaradme a qué os referís. Si es eso: igual que en el tema de la intención, respondiendo fielmente a las preguntas del buscante, que deben ser leíbles y fácilmente entendibles por el oyente.

Búsqueda por voz: se trabajarán de la misma manera que las búsquedas semánticas.

\section{Pregunta}

¿Qué tipo de SEO cree que tendrá mayor peso e importancia: el SEO técnico, el SEO Onpage o el SEO Off-page? ¿Desea añadir alguna motivación para su elección?

Con enlaces entrantes puedes posicionar. Solo con SEO técnico y SEO on-page, a no ser que alguien te enlace, complicado.

\section{Pregunta}

De este listado ¿Cuál es la herramienta SEO que más utiliza? SEMrush, Ahrefs, Majestic, Sistrix, Xovi, MOZ, y Woornak. ¿Desea añadir alguna motivación para su elección? 
Sistrix y onCrawl, porque son muy buenos y soy embajador de ambas en España. Y también Safecont, porque es muy buena y soy inversor.

\section{Pregunta}

Como experto en SEO, y en líneas generales ¿considera que los diarios digitales están aplicando buenas, malas o nulas estrategias SEO? ¿Desea argumentar su respuesta?

Muchísimas, no hay nada mas que ver la lucha constante entre los equipos de Unidad Editorial (El Mundo) y los de Grupo Godó (La Vanguardia), PRISA (El País) o Vocento $(A B C)$. Las luchas son constantes y se gastan mucha pasta en contratar grandes profesionales. Después han salido medios a competir como OKDiario y El Español que están agregando tráfico de otras cabeceras y les está funcionando francamente bien. ¿La estrategia es mala o buena en base a qué? ¿En base a éxito? Pues hay que decir, que todos los medios tienen mucho éxito, pero El Mundo es, a día de hoy, el mas potente.

\section{Pregunta}

En caso de que tenga alguna experiencia como experto SEO en medios de comunicación digitales ¿existe alguna recomendación muy general que haría llegar a los medios para que fueran capaces de posicionarse mejor sin que por ello afectase a la calidad de la información de las noticias?

Que no se dejen llevar por el "tengo que ser el primero". Mejor tardar 1 minuto en revisar que todo el SEO básico esté bien puesto que tener que andar después toqueteando.

\section{Experto: Sergio Castelo}

sergiocastelo.com

\section{Pregunta}

¿Puede señalar cuatro de los principales factores SEO para 2019?

Bajo mi punto de vista el SEO evoluciona, pero los factores han de ser siempre los mismos, tratar de abordar de la mejor manera una solución óptima para el usuario. Es decir, hay mucha gente que comenta que el contenido es el rey, o que lo son los enlaces 
o que las optimizaciones On Page son las que de verdad van a dar visibilidad en los buscadores. Bajo mi punto de vista el usuario es el verdadero rey y todas las acciones se deben enfocar en tratar de resolver su intención de búsqueda. Bajo este criterio, los cuatro principales factores que se deben tener en cuenta en el SEO (en 2019 y entiendo que más todavía en 2091) serán los cuatro que más convenzan a la mayor parte de usuarios. Enlaces que doten tu web de tráfico (no solo enlaces para ganar autoridad, sino que puedan despertar la curiosidad del usuario que está leyendo ese contenido y quiera saber más sobre ese tema en concreto). Optimización técnica: está claro que año a año los usuarios tienen mejores dispositivos, con cargas más rápidas e invierten en ellos queriendo tener mejores respuestas de tiempos y calidad. Una web ha de evolucionar, tanto en diseño como en experiencia de usuario y por lo tanto se debe mejorar cualquier punto que se pueda, teniendo también en cuenta los tiempos de carga. El AB Testing es y será un gran aliado del SEO y de la optimización en la conversión de objetivos. Contenidos claros y concisos: no hay una extensión mínima ni tampoco una máxima. Un contenido simplemente se debe enfocar al interés de la búsqueda que se necesita resolver.

\section{Pregunta}

¿Puede indicar algunos aspectos clave sobre cómo deberá abordar el profesional del SEO los nuevos escenarios siguientes: búsquedas semánticas, búsquedas por voz, intención de búsqueda?

Va todo en función del punto anterior. Un SEO debe tener conocimientos técnicos para abordar de la mejor manera posible los cambios de código, conocimientos conceptuales de contenido para abordar las estructuras de un texto o del árbol de navegación de una web, pero sobre todo un buen SEO ha de saber extraer y analizar los datos importantes de navegación que será de donde se pueda sacar un buen análisis para forjar una estrategia que aumente la visibilidad de la página web. A partir de ahí, las búsquedas darán igual si vienen desde un teclado o desde un micrófono, lo que de verdad importa es saber que el contenido que estás ofreciendo a tus usuarios es el acertado. Una página de tu proyecto puede tener un alto rebote, o un tiempo de estancia bajo en tu página, o un alto porcentaje de salidas, pero en función del contenido que tenga no tiene que estar relacionado con baja calidad ya que muchas veces el objetivo es dar una información que se consume sin más. Otra cosa es que a partir de ella, estudies y consigas mejorar la interacción con el usuario y lo puedas "enganchar" para que consuma más información. Al final la estrategia SEO debe ser diferente en función del proyecto del que se hable. No es lo mismo posicionarse para "comprar quesos" que para 
"propiedades del queso" que para "recetas con queso". Y los KPIs a tener en cuenta en cada una de esas búsquedas han de ser diferentes.

Al margen de eso, está reciente la salida de "speakable", todavía en beta en la sección de noticias de Google en USA. Esto será un marcado de datos (schema.org) que permitirá al asistente de búsqueda por voz de Google lea parte del contenido de nuestra página (sino entero). No debemos pensar solo en pantallas de ordenador o Smartphone y tabletas, la información se consume cada vez desde más dispositivos (smartwatchs, coches, etc.) y hay que estar preparado para ello.

\section{Pregunta}

¿Qué tipo de SEO cree que tendrá mayor peso e importancia: el SEO técnico, el SEO Onpage o el SEO Off-page? ¿Desea añadir alguna motivación para su elección?

El conjunto de todos ellos enfocados al usuario.

\section{Pregunta}

De este listado ¿Cuál es la herramienta SEO que más utiliza? SEMrush, Ahrefs, Majestic, Sistrix, Xovi, MOZ, y Woornak. ¿Desea añadir alguna motivación para su elección?

Uso por igual SEMrush, Ahrefs y Sistrix. Además me gustaría añadir alguna más que es vital para mi día a día: Screaming frog log analyzer, Screaming frog spider y la suite de mangools. Además de, por supuesto, Search Console y Analytics para estudiar los comportamientos del usuario. Ya no me meto en herramientas de keyword research y demás porque la lista podría hacerse infinita.

\section{Pregunta}

Como experto en SEO, y en líneas generales ¿considera que los diarios digitales están aplicando buenas, malas o nulas estrategias SEO? ¿Desea argumentar su respuesta?

En general, y en la prensa que consumo, existe un gran trabajo en SEO y se nota que han apostado por entrar en la guerra del posicionamiento web con muy buenos profesionales detrás. No voy a negar que muchas veces me entristezco al encontrarme con noticias que buscan el click baiting, algo que no me gusta o el abuso de contenidos sobreoptimizados. Entiendo que el primer punto pueda estar dentro de la "sucia" línea 
editorial de algunos medios y que no solo lo hacen por motivos SEO sino que ya es algo habitual para "vender" más. No me gusta el sensacionalismo.

\section{Pregunta}

En caso de que tenga alguna experiencia como experto SEO en medios de comunicación digitales cexiste alguna recomendación muy general que haría llegar a los medios para que fueran capaces de posicionarse mejor sin que por ello afectase a la calidad de la información de las noticias?

No todos los contenidos deben ser indexables en todo momento. Cuantas más URLs tengan, más se pueden diluir los esfuerzos por lo que veo clave, además de optimizar todos los puntos citados o no con anterioridad, seguir muy de cerca cuales son las URLS que tienen sentido que sigan al alcance de los buscadores. 


\section{Conclusiones}

Esta investigación ha permitido plantear un marco de optimización global de SEO en Cibermedios que puede ayudar a los medios de comunicación online a implantar en sus redacciones una cultura del posicionamiento en buscadores. Este marco de optimización no solo está pensado para los nuevos medios o los medios que comienzan a plantearse el SEO de manera estratégica, sino que también puede ayudar a aquellas redacciones periodísticas que ya tienen integrado el SEO en su día a día y que quieren mejorar algún aspecto específico de su proceso de trabajo.

Presentaremos las conclusiones relacionándolas con los objetivos que guiaron el desarrollo de este informe. Seguidamente, haremos lo mismo con las preguntas de investigación. Por último, propondremos algunos posibles estudios que se pueden desarrollar a futuro para ampliar el conocimiento del SEO en el contexto de los medios de comunicación online

Objetivo 1. Caracterizar el SEO semántico, el VSEO, y el SXO, identificar sus principales componentes de acuerdo con la corriente principal entre académicos y profesionales de este ámbito y plantear, de este modo, metodologías y procesos de aplicación en medios de comunicación online.

Las revisiones sistematizadas desarrolladas aplicadas al SEO semántico, el SEO en YouTube (VSEO), y al Search Experience Optimization (SXO) nos ha permitido plantear metodologías de análisis y procedimientos de trabajo estratégico de posicionamiento en cibermedios.

Las metodologías nos han servido, por un lado, como sistemas de checklist para comprobar el grado de optimización desarrollado sobre medios de comunicación online específicos, y noticias específicas.

$\mathrm{Y}$, por otro lado, como procedimientos o frameworks que nos han ayudado a aglutinar, de manera coherente, las principales estrategias que deben aplicar los cibermedios si quieren tener mayores posibilidades de aparecer en los buscadores en zonas preferentes, o en forma de resultados enriquecidos.

Objetivo 2. Aportar una serie de recomendaciones de aplicación SEO en cibermedios tanto, en los ya existentes como en los nuevos proyectos de emprendimiento periodístico. 
De las entrevistas a los consultores SEO hemos podido confirmar que consideran esencial desarrollar estrategias de posicionamiento en buscadores dentro de una redacción periodística si quieren ser competitivos. Los entrevistados consideran que el SEO On Page, el SEO Off Page y el SEO técnico son las tres ramas que los medios de comunicación online deben trabajar para alcanzar las mejores posiciones en los buscadores.

Asimismo, los entrevistados consideran que es esencial el uso de herramientas de análisis SEO dentro de las redacciones para poder medir los resultados y aplicar medidas correctivas y de mejora en los casos que así se precisen.

Adicionalmente, los entrevistados consideran que el SEO y su relación con el periodismo se afianzará a lo largo de los años, y que los cambios tecnológicos y de los propios algoritmos provocará el surgimiento de nuevos retos que los cibermedios tendrán que superar para continuar ganando lectores desde los buscadores.

Los datos recogidos que se desprenden tanto de la revisión sistematizada como de las entrevistas nos han permitido conocer perfectamente, en el contexto de la visibilidad web, el funcionamiento de la redacción de un cibermedio y su enfoque con el SEO.

En este sentido, se constata que las estrategias SEO son esenciales para el éxito de los cibermedios, principalmente porque los usuarios web buscan la información a través de Google, y poder aparecer en los primeros resultados en los buscadores permite no solo competir por las mejores posiciones en los resultados de búsqueda, sino que permiten obtener mayor tráfico web en forma de nuevos lectores.

Una vez examinados los objetivos, corresponde hacer lo mismo con las preguntas de investigación que nos habíamos formulado, y que son las siguientes:

Pregunta 1. ¿Es posible identificar sin ambigüedad las características del SEO semántico, el VSEO, y el SXO y sus principales elementos como una estrategia eficaz de visibilidad y posicionamiento web real para medios de comunicación Online?

Los resultados obtenidos nos permiten confirmar esta pregunta de manera positiva. Nuestras revisiones sistematizadas en el campo del posicionamiento y la visibilidad web nos ha ayudado a conocer qué tipo de estrategias SEO se pueden desarrollar y aplicar en los medios de comunicación online.

En este sentido, se reconoce una necesidad esencial del desarrollo de estrategias de posicionamiento en buscadores por parte de los medios de comunicación online, ya que 
éstos necesitan obtener más lectores, dar mayor visibilidad a sus noticias y ofrecerlas a un público objetivo específico que se informa desde los motores de búsquedas, y no desde las portadas de los medios.

Para obtener un buen posicionamiento de las noticias se necesita desarrollar estrategias específicas centradas en diferentes esferas del SEO como pudiera ser desde el punto de vista de la semántica y de la experiencia de usuarios.

Asimismo, se reconoce el papel fundamental de posicionarse no solo en Google sino en plataformas como YouTube de ahí que se planteen estrategias de Video Search Optimization (VSO).

Pregunta 2. ¿Es factible aportar una serie de recomendaciones de aplicación SEO para una mayor visibilidad para proyectos periodísticos?

Como demuestra el estudio desarrollado existen óptimas posibilidades de integrar el SEO en una redacción periodística con amplía tradición en papel.

Nuestro estudio permite confirmar un claro interés por la optimización de las noticias en los buscadores por parte de los medios de comunicación y un claro ejercicio práctico del SEO aplicado a las noticias, en cuanto a planificación y rutinas productivas.

A continuación, mostramos algunas posibles nuevas líneas de investigación que han surgido gracias al desarrollo de esta investigación. Para ello distinguimos investigaciones relacionadas con:

- Herramientas de auditoría SEO para cibermedios.

- Estrategias de posicionamiento en buscadores.

- Formación en SEO.

- Visibilidad web.

En este sentido, podemos destacar que se pueden realizar estudios con herramientas de posicionamiento en buscadores todavía no probadas como Screaming Frog, Xovi, MOZ, Searchmetrics, SEOProfiler, etc.

Además, los estudios con herramientas SEO podrían comparar medios de comunicación online heterogéneos tanto nacionales como internacionales, analizar agregadores de noticias como Reddit, Digg, Menéame, etc., o incluso estudiar diferentes secciones específicas (política, economía, deportes, etc.) y comprobar su grado de visibilidad web. 
En cuanto al posicionamiento en YouTube se podrían analizar no solo los canales de YouTube de cibermedios generalistas, sino también los regionales, o un grupo de videos de noticias específico, y ver cuáles han obtenido mejores posiciones en los resultados de búsqueda y por qué.

Asimismo, creemos que es posible diseñar futuras investigaciones que extiendan la aplicación de los sistemas de análisis y estrategias SEO desarrollados, tanto a nivel semántico, como de experiencia de usuario, a otros sectores de la comunicación, o incluso caracterizar de manera más eficaz algunos de estos sectores para ayudar a su optimización continuada.

También podrían desarrollarse estudios sobre SEO técnico y de SEO de contendidos para medios de comunicación Online. A su vez, se podría plantear sistemas de análisis y estrategias SEO aplicados a búsquedas por voz, y posicionamiento de imágenes en el índice de Google Imágenes.

Por último, consideramos que podemos realizar nuevos análisis que ayuden a ampliar el cómo y el porqué del SEO a través de nuevas observaciones participantes a otros cibermedios nacionales e internaciones, uso de métodos Delphi, focus group, e incluso con paneles de expertos y otros métodos de consenso 


\section{Referencias}

\section{Bibliografía citada y consultada sobre SEO y periodismo y temas relacionados}

- Abadal, E., \& Guallar, J. (2008). Les hemeroteques digitals de la premsa catalana: anàlisi dels diaris catalans de més difusió. En: 11es Jornades catalanes d'informació i documentació, Barcelona, España, 22-23 mayo. http://eprints.rclis.org/11696

- Abadal, E. (2002). Elementos para la evaluación de interfaces de consulta de bases de datos web. El profesional de la información, v. 11, n. 5, pp. 349-360.

- Adams, B. (27 de mayo de 2019). How to Get Into Google News - Whiteboard Friday. Obtenido de Moz: https://moz.com/blog/how-to-get-into-google-news

- Almirón, N. (2009). Grupos privados propietarios de medios de comunicación en España: principales datos estructurales y financieros. Comunicación y Sociedad, vol. 23, n. 1, pp.243-273.

- Al-Nashmi, E., Michael, T., Cleary, J. (2017). Boots on the Ground?: How International News Channels Incorporate User-Generated Content into Their YouTube Presence. International Communication Gazette, 79 (8): 746-768. doi:10.1177\%2F1748048517707404.

- Amazeen, M., \& Muddiman, A. (2017). Saving media or trading on trust? The effects of native advertising on audience perceptions of legacy and online news publishers. Digital journalism, v. 6, n. 2, pp. 176-195.

- Amazeen, M., \& Wojdynski, B. (2018). The effects of disclosure format on native advertising recognition and audience perceptions of legacy and online news publishers. Journalism, pp. 1-20. https://doi.org/10.1177/1464884918754829

- Angela M. Lee, A.; Chyi, H (2015) The Rise of Online News Aggregators: Consumption and Competition, International Journal on Media Management, 17:1, 3-24, DOI: 10.1080/14241277.2014.997383

- Angrosino M. (2012) Etnografía y observación participante en Investigación Cualitativa. Colección Investigación Cualitativa. Madrid: Editorial Morata; 2012 
- Anton, L., \& Guallar, J. (2014). Análisis de los archivos audiovisuales en internet de las televisiones autonómicas españolas. Revista española de documentación científica, v. 37, n. 1. https://doi.org/10.3989/redc.2014.1.1044

- Arias-Robles, F. (2016). Teoría y práctica del lenguaje ciberperiodístico. SEO, redes e (hiper)textos. Revista mediterránea de comunicación, v. 7, n. 2, pp. 177194.

- $\quad$ https://doi.org/10.14198/MEDCOM2016.7.2.8

- Arora, L. (9 de noviembre de 2018). SEO: Search Experience Optimization. Obtenido en Envigo: https://www.envigo.co.uk/blog/search-engineoptimisation/seo-search-experience-optimization

- Artero, J., \& Sánchez-Tabernero, A. (2015). Media and telecomunications concentration in Spain. European Journal of Comunication, vol. 30 (3), pp. 319336. https://doi.org/10.1177/0267323115577307

- Asser, M. (15 de marzo de 2018). Search Engine Optimisation in BBC News. Obtenido de BBC: http://www.bbc.co.uk/blogs/internet/posts/search_engine_optimisation_in

- Bakker, P. (2014). Mr. Gates returns: Curation, community management and other new roles for journalists. Journalism studies, v. 15, n. 5, pp. 596-606.

- https://doi.org/10.1080/1461670X.2014.901783

- Barr, A. (27 de mayo de 2019). Google to Shut Google News in Spain in Response to New Law. Obtenido de The Wall Street Journal https://www.wsj.com/articles/google-shutting-google-news-in-spain1418265199

- Batsell, J. (23 de septiembre de 2018). 4 steps to bring ethical clarity to native advertising. Obtenido de Neiman Report: https://niemanreports.org/articles/4steps-to-bring-ethical-clarity-to-native-advertising

- Berners-Lee, T., Hendler, J., \& Lassila, O. (2002). The semantic Web: a new form of Web content that is meaningful to computers will unleash a revolution of new possibilities. Scientific American, 01-03

- Berners-Lee, T. (2010) Long live the web. Scientific American.80-85 
- Bing. (15 de enero de 2018) Marking up your site: Overview. Obtenido de Bing: https://www.bing.com/webmaster/help/marking-up-your-site-with-structureddata-3a93e731

- Boachie, P., \& Bench-Capon, S. (13 de mayo de 2018). How to Optimize Your Videos for YouTube: Best- practice tips. Obtenido de Search Engine Watch: https://searchenginewatch.com/ 2017/11/23/how-to-optimize-your-videosfor-youtube-best-practice-tips/.

- Bonelli, S. (26 de mayo de 2018). YouTube SEO: How to Find the Best TrafficGenerating Keywords. Obtenido de Search Engine Land: https://searchengineland.com/youtube-seo-find-best-traffic-generatingkeywords- 275690.

- Booth, A., Papaionnou, S., Anthea (2012). Systematic Approaches to a Successful Literature Review. London: Sage, 2012

- Briggs, Justin. (17 de enero de 2018) Entity Search Results. Obtenido de Briggsby: https://www.briggsby.com/entity- search-results-the-on-goingevolution-of-search/

- Brin, S., \& Page, L. The anatomy of a large-scale hypertextual web search engine. Stanford University. http://infolab.stanford.edu/ backrub/google.html

- Brown, M. (17 de enero de 2018). 5 Questions About Semantic SEO. Obtenido de Moz: https://moz.com/blog/semantic-seo-questions

- Bunce, M. (2015). Africa in the click stream: audience metrics and foreign correspondents in Africa. African journalism studies, v. 36, n. 4, pp. 12-29. https://doi.org/10.1080/23743670.2015.1119487

- Cámaras-León, N. (11 de enero de 2018). Linkbuilding 2018, guía de enlazado perfecto (+12 predicciones expertos). Obtenido de Unancor: https://www.unancor.com/blog/guia-linkbuilding

- Caminero, L., \& Sánchez-García, P. (2018). El perfil y formación del ciberperiodista en redacciones nativas digitales. Hipertext.net, (16), 4-15. doi: https://doi.org/10.31009/hipertext.net.2018.i16.04

- Carleton A., Mobius, M., \& Jenő, P. (2017). The Impact of Aggregators on Internet News Consumption (January 11, 2017). Stanford University Graduate 
School of Business Research Paper, No. 17-8. Available at SSRN:

https://ssrn.com/abstract=2897960

- Carlson, M. (2007). Order versus access: News search engines and the challenge to traditional journalistic roles". Media, culture \& society, v. 29, n. 6, pp. 1014-1030. https://doi.org/10.1177/0163443707084346

- Carlson, M. (2014). When news sites go native: Redefining the advertising editorial divide in response to native advertising. Journalism, v. 16, n. 7, pp. 849-865. https://doi.org/10.1177/1464884914545441

- Cebrián-Herreros, M. (2009). Nuevas formas de comunicación: cibermedios y medios móviles. Comunicar, 17(33). doi:10.3916/c33-2009-01-001

- Charlton, G. (15 de marzo de 2018). How much do journalists and editors need to know about SEO? Obtenido de Search Engine Watch:

https://searchenginewatch.com/2016/03/15/how-much-do-journalists-andeditors-need-to-know-about-seo/

- Chasinov, N. (9 de noviembre de 2018) Search Experience Optimization: Welcome to the New SEO. Obtenido de huffingtonpost: https://www.huffingtonpost.com/young-entrepreneur-council/searchexperience-optimiz_b_10378498.html?guccounter=1

- Chong, J. (22 de enero de 2018). The Ultimate Semantic SEO Guide: How To Do SEO Like An Expert. Obtenido de Seopressor: https://seopressor.com/blog/semantic-seo-guide-how-to-do-seo/

- Chrysanthos D., Sutanto, J., Calin, M., \& Palme, E. (2015) Attention Allocation in Information-Rich Environments: The Case of News Aggregators. Management Science, Vol. 62, No. 9 https://doi.org/10.1287/mnsc.2015.223

- Choudhari, K., \& Vinod B. (2015). Video Search Engine Optimization Using Keyword and Feature Analysis. Procedia Computer Science, 58: 691-697.

- Cobos, T. (2018). Las percepciones y experiencias sobre Google News de los editores de medios noticiosos latinoamericanos indexados en las ediciones de Colombia y México. Estudios sobre el Mensaje Periodístico, 24(2) 2018: 11831198. http://dx.doi.org/10.5209/ESMP.62208 
- Codina, L. (2000). Evaluación de recursos digitales en línea: conceptos, indicadores y métodos. Revista española de documentación científica, 23 (1), 944. https://doi.org/10.3989/redc.2000.v23.i1.315

- Codina, L., \& Marcos, M.C. (2005). Posicionamiento web: conceptos y herramientas. El profesional de la información, v. 14, n. 2, pp. 84-99.

- Codina, L., Marcos, M.C; \& Pedraza, R. (2009). Web semánticas y sistemas de información. Ediciones TREA, 2009.

- Codina, L., \& Pedraza-Jiménez, R. (2011). Tesauros y ontologías en sistemas de información documental. El profesional de la información, v. 20, n. 5, pp. 55563. https://doi.org/10.3145/epi.2011.sep.10

- Codina, L., Pedraza, R., Díaz-Noci, J., Rodríguez-Martínez, R., Pérez-Montoro, M., Cavaller-Reyes, V.(2014). Sistema Articulado de Análisis de Cibermedios (SAAC): Una propuesta sobre el qué y el cómo para estudiar medios de comunicación digitales. Hipertext.net, 12, e018. DOI: 10.2436/20.8050.01.13

- Codina L., Iglesias-García M., Pedraza R., \& García-Carretero L. (2016) Search engine optimization and online journalism: the SEO-WCP framework. Barcelona: Serie Editorial DigiDoc. Active audiences and journalism, 2016.

- Codina L., Iglesias-García, M., Pedraza R., \& García-Carretero, L.(2016). Visibilidad y posicionamiento web de informaciones periodísticas: el framework SEO-RCP. Barcelona: Serie editorial DigiDoc-UPF. http://repositori.upf.edu/handle/10230/26040

- Codina, L., \& Pedraza, R. (2016). Características y componentes de un sistema de análisis de medios digitales el SAAMD. Calidad en sitios web: método de análisis general, e-comerce, imágenes, hemerotecas y turismo. Coord. por Rafael Pedraza-Jiménez, Lluís Codina Bonilla, Javier Guallar Delgado, 2016, ISBN 978-84-9064-487-4, págs. 15-39

- Codina, L.; Iglesias-García, M.; Pedraza, R.; García-Carretero, L. (2016). Search Engine Optimization and Online Journalism: The SEO-WCP Framework. Barcelona: Universitat Pompeu Fabra.

- Codina L., Gonzalo-Penela C., Pedraza-Jiménez R., \& Rovira C. (2017) Posicionamiento web y medios de comunicación ciclo de vida de una campaña y 
factores SEO. Barcelona: Serie Digital Digidoc. Proyecto Comunicación Interactiva, 2017.

- Codina, L. (2018). Componentes Estructurales y Semánticos en el Diseño de la Navegación Web. Taxonomías, SEO y Software implicado en el caso de una Instalación con WordPress. Disponible en:

https://repositori.upf.edu/bitstream/handle/10230/27879/codina_2017_comp .pdf?sequence $=1 \&$ isAllowed $=y$

- Codina L., Lopezosa C. (2019) Optimizar el SEO de contenidos mediante análisis asistido por ordenador: el software Yoast SEO: guía de utilización para periodistas y comunicadores. Barcelona: Universitat Pompeu Fabra, Departamento de Comunicación, Área de Formatos Digitales y Documentación. 2019. 35 p.

- Colangelo, G. , \& Torti, V. (2018). Copyright, Online News Publishing and Aggregators: A Law and Economics Analysis of the EU Reform (September 26, 2018). International Journal of Law and Information Technology, (Forthcoming), http://dx.doi.org/10.2139/ssrn.3255449

- Coller, X. (2000). Estudio de Caso. Colección Cuadernos Metodológicos. Madrid: Editorial Centro de Investigaciones Sociológicas.

- Costa-Sánchez, C., Guarinos-Galán, V. (2018). Gestión de marca corporativa online de los canales públicos de televisión en Europa. Propuesta de indicadores para su medición. Revista latina de comunicación social, n. 73, pp. 895-910. https://doi.org/10.4185/RLCS-2018-1287

- Costa-Sánchez, C., \& Guarinos-Galán, V. (2018a). Gestión de marca corporativa online de los canales públicos de televisión en Europa. Propuesta de indicadores para su medición. Revista latina de comunicación social, n. 73, pp. 895-910. https://doi.org/10.4185/RLCS-2018-1287

- Cooper, J. (1 de abril de 2018). Link building tactics. The complete list. Obtenido de Point Blank SEO: http://pointblankseo.com/link-building-strategies

- Cramer, T. (23 de septiembre de 2018). The deal with disclosure and the ethics of native advertising. Obtenido de Digital content text: https://digitalcontentnext.org/blog/2016/09/06/the-deal-with-disclosure-andthe-ethics-of-native-advertising 
- Crestodina, A. (22 de enero de 2018). How to Future-Proof Your Search Engine Marketing: 5 Tips for Semantic SEO. Obtenido de Orbitmedia:

https://www.orbitmedia.com/blog/semantic-seo/

- Crowe, A. (23 de septiembre de 2018). Illustrated guide to link building. Obtenido de Search engine journal:

https://www.searchenginejournal.com/link-building-guide

- Cutts, M. (9 de noviembre de 2018). Do you think that Search Engine Optimization should be renamed? Obtenido de Youtube: https://www.youtube.com/watch?v=ZStQhWx8YPc [Fecha de consulta: 09/11/2018].

- Davies, D. (8 de agosto de 2018). Link building with Ahrefs: A how-to guide. Obtenido de Search engine watch: https://searchenginewatch.com/sew/howto/2359151/link-building-with-ahrefs-a-how-to-guide

- Davis, H. (2006). Search Engine Optimization. Sebastopol: O’Reilly Media.

- Dean, B. (11 de marzo de 2018). The definitive guide (2018 update). Obtenido de Backlinko: https://backlinko.com/link-building

- Dean, B. (6 de mayo de 2018). YouTube SEO: How to Rank YouTube Videos in 2018. Obtenido de Backlinko: https://backlinko.com/how-to-rank-youtubevideos

- Dennis, A. (13 de mayo de 2018). How to Rank \#1 on YouTube Search in 30 Days [Case Study]. Obtenido de Search Engine Land:

https://searchengineland.com/rank-1-youtube-search-30-days-case-study281198.

- Díaz-Campo, J. (2014). Las cadenas de televisión españolas en Internet: un estudio sobre la calidad de sus sitios web. Estudios sobre el Mensaje Periodístico, Vol. 20. http://dx.doi.org/10.5209/rev_ESMP.2014.v20.n1.45219

- Díaz-Noci, Javier y Salaverría, Ramón (2003). Manual de redacción ciberperiodística. Ariel: Barcelona.

- Díaz-Noci, J. (2008). Definición teórica de las características del ciberperiodismo: elementos de la comunicación digital. Doxa comunicación, n. 6, pp. 53-91. 
- Díaz-Noci, J. (2013). A history of journalism on the internet: A state of the art and some methodological trends. Revista internacional de historia de la comunicación, n.1, pp. 253- 272.

- Díaz-Noci, J. (2018) Hipertexto en periodismo: realidad e investigaciones de futuro, Anuario ThinkEPI. doi: https://doi.org/10.3145/thinkepi.2018.34

- DiSilvestro, A. (30 de enero de 2018). Semantic Search Means Semantic CEO: What It Means for you. Obtenido de Highervisibility: https://www.highervisibility.com/blog/semantic-search-means- semantic-seowhat-it-means-for-you/

- Doszkocs, T. (2010). Semantic a search engines mean well. Online, 34(2010) 3642.

- Edward, T. (7 de febrero de 2018). Leveraging Wikidata To Gain A Google Knowledge Graph Result. Obtenido de Search Engine Land: https://searchengineland.com/leveraging-wikidata-gain-google- knowledgegraph-result-219706

- Eisenhardt, K. (1989). Building theories from case study research". Academy of Management Review, v.14, n.4, pp. 532-550. https://doi.org/10.5465/amr.1989.4308385

- Ellcessor, E. (2012). Captions on, off, on TV, online: Accessibility and search engine optimization in online closed captioning. Television \& new media, v. 13, n. 4, pp. 329-352. https://doi.org/10.1177/1527476411425251

- Enge, E., Spencer, S.; Fishkin, R., \& Stricchiola, J. (2012). The Art of SEO. Sebastopol: O'Reilly. ISBN: 9780596518868

- Enge, E. (30 de febrero de 2018). The Definitive Guide to Google's Rich Answers. Obtenido de Stone Temple: https://www.stonetemple.com/the-growth-ofrich-answers-in-googles-search-results/

- Ferrer-Conill, R. (2016). Camouflaging church as state. Journalism studies, v. 17, n. 7, pp. 904-914. https://doi.org/10.1080/1461670X.2016.1165138

- Figueroa-Encina, P. (2016). Oportunidades y desafíos para cibermedios en el ecosistema móvil. Instant Articles de Facebook y los nuevos formatos móviles. 
Hipertext.net: Anuario académico sobre documentación digital y comunicación interactiva, n. 14. http://raco.cat/index.php/Hipertext/article/view/310534

- Fiorelli, G. (7 de febrero de 2018). Hummingbird Unleashed. Obtenido de Moz: https://moz.com/blog/hummingbird-unleashed

- Fishkin, R. (29 de enero de 2018). Targeted link building in 2016 - Whiteboard Friday. Obtenido de Moz: https://moz.com/blog/targeted-link-building-in-2016

- Fleischner, M. (2011). SEO made simple: Strategies for dominating the world's largest search engine. MarketingScoop. ISBN: 9780615178639

- Fons, R. (26 de mayo de 2018). Cómo ser Youtuber en el 2018. Obtenido de Romuald Fons: https://romualdfons.com/como-ser-youtuber/.

- Fons, R. (13 de mayo de 2018). SEO en Youtube: Cómo posicionar vídeos en 2018. Obtenido de Romuald Fons: https://romualdfons.com/seo-en-youtube/.

- Freixa, P., Soler-Adillon, J., Sora, C., \& Ribas, J. (2014). Aportaciones del découpage interactivo en la lectura y análisis de audiovisuales interactivos de los cibermedios. Hipertext.net, n. 12.

- Freixa, P., Sora, C., Soler-Adillón, J., \& Ribas, J. (2014a). Snow fall and a short history of the highrise: Two approaches to interactive communication design by The New York Times. Textual \& visual media, n. 7, pp. 63-84.

- García-Avilés, A., Carvajal, M., \& Arias, F (2018). Implantación de la innovación en los cibermedios españoles: análisis de las percepciones de los periodistas. Revista Latina de Comunicación Social, 73, pp. 369 a 384. doi: https://doi.org/10.4185/RLCS-2018-1260

- García-Carretero, L., Codina, L. Díaz-Noci, J., \& and Iglesias-García, M. (2016) Herramientas e indicadores SEO: características y aplicación para análisis de cibermedios. El profesional de la información 25 (3): 497-504. doi:10.3145/epi.2016.may.19.

- García-Carretero, L., Codina, L., \& Pedraza-Jiménez, R. (2016). Indicadores para el estudio de la visibilidad y del impacto de los cibermedios en el ecosistema digital. Barcelona: UPF. Departamento de Comunicación. Serie Editorial DigiDoc. 
https://repositori.upf.edu/bitstream/handle/10230/27455/garciac_digidoc_ind i.pdf

- García-González, A., \& Román-Portas, M. (2017). Sobre los nuevos modelos de negocio en las actividades radiofónicas. Revista de la Asociación Española de Investigación de la Comunicación, v. 4, n. 7, pp. 40-45.

- García-Orosa, B., López X. (2014). Headlines in major European digital media in Europe: More functional than conceptual. Estudios sobre el mensaje periodístico. DOI:10.5209/rev-ESMP.2015.v21.n2.50887

- García-Santamaría, J., Fernández-Beaumont, J., \&and Pérez-Bahón, F. (2016). La nueva prensa online en España: Diversidad de proyectos pero modelos de negocio poco innovadores. En SEP Sociedad Española de Periodística, Salamanca.

- Gandhi, M. (10 de noviembre de 2018). Why and How to Deliver the Best Search Experience in 2018. Obtenido de Seoclarity: https://www.seoclarity.net/blog/search-experience-optimization-2018-17568/

- Giomelakis, D., \& Veglis, A. (2015). Employing Search Engine Optimization Techniques in Online News Articles. Studies in Media and Communication, ISSN 2325-8071. 3:1, 22-33. doi:10.11114/smc.v3i1.683

- Giomelakis, D., \& Veglis, A. (2016) Investigating Search Engine Optimization Factors in Media Websites. Digital Journalism. 4:3 (2016) 379- 400. DOI: 10.1080/21670811.2015.1046992

- González, J. (13 de febrero de 2018). El Futuro del SEO: ¿Cómo afectarán RankBrain y las búsquedas por voz? Obtenido de Useo: http://useo.es/busquedas-voz-rank-brain/

- González, J. (30 de marzo de 2018). Cómo hacer link building: estrategias y ejemplos prácticos. Obtenido de Useo: https://useo.es/como-hacer-linkbuilding

- Gonzalo-Penela, C. (2006). Tipología y análisis de enlaces web: aplicación al estudio de los enlaces fraudulentos y de las granjas de enlaces. BiD: textos universitaris de biblioteconomia i documentación, n. 16. http://bid.ub.edu/16gonza2.htm 
- Gonzalo-Penela, C., Codina, L., Rovira, C. (2015). Recuperación de información centrada en el usuario y SEO: categorización y determinación de las intenciones de búsqueda en la Web". Index comunicación, v. 5, n. 3, pp. 19-27.

http://journals.sfu.ca/indexcomunicacion/index.php/indexcomunicacion/articl e/view/197/175

- Gonzalo-Penela, C. (2015). Posicionamiento web y dinámicas de información en motores de búsqueda: propuestas de análisis y estudio comparativo de visibilidad de contenidos digitales en el caso de procesos electorales. Tesis doctoral. Barcelona: UPF

- Google (14 de febrero de 2018). A reintroduction to Google's featured snippets. Obtenido de Google:

https://www.blog.google/products/search/reintroduction-googles-featuredsnippets/

- Google. (14 de febrero de 2018a) Introduction to Structured Data. Obtenido de Google: https://developers.google.com/search/docs/guides/intro-structureddata\#structured-data-guidelines

- Google. (14 de febrero de 2018b) Search Gallery. Obtenido de Google: https://developers.google.com/search/docs/guides/search-gallery

- Google. (15 de febrero de 2018). Introducing the Knowledge Graph: things, not strings. Obtenido de Google: https://googleblog.blogspot.com.es/2012/05/introducing-knowledge-graphthings-not.html

- Google. (15 de febrero de 2018a). Pagina web oficial del Gráfico de Conocimiento de Google. Obtenido de Google:

https://www.google.es/intl/es/insidesearch/features/search/knowledge.html

- Google. (16 de febrero de 2018a). Patente: Using concepts as contexts for query term substitutions. Obtenido de Google Patentes: https://www.google.com/patents/US9104750

- Google (12 de marzo de 2018). Search Quality Rating Guidelines. Obtenido de Google:

https://static.googleusercontent.com/media/www.google.com/es//insidesearc $\mathrm{h} /$ howsearchworks/assets/searchqualityevaluatorguidelines.pdf 
- Google (30 de marzo de 2018). Google guide making searches even easier. Search operators. Obtenido de Google:

http://www.googleguide.com/advanced_operators_reference.html

- Google (26 de mayo de 2019). Google News Help. Google. Obtenido de Google: https://support.google.com/googlenews/?hl=en\#topic=7688381

- Grappone, J., \& Couzin, G. (2006). Your one-month prep: Baseline and keywords. Search engine optimization: an hour a day. Indianapolis: Sibex, 2006. ISBN: 9780470902592

- Grundmann, J., \& Bench-Capon, S. (13 de mayo de 2018). Universal Search 2018: It's a Mobile World After All. Obtenido de Search Metrics: https://www.searchmetrics.com/knowledge-base/universal-search-study/

- Guallar, J., \& Abadal, E. (2009a). Evaluación de hemerotecas de prensa digital: indica- dores y ejemplos de buenas prácticas. El profesional de la información, v. 18, n. 3, pp. 255-269. https://doi.org/10.3145/epi.2009.may.02

- Guallar, J., \& Abadal, E. (2009b). Fuentes de información sobre prensa digital: una propuesta de clasificación. En: I Congreso internacional de ciberperiodismo y web 2.0. Bilbao, 11-13 nov. 2009. http://eprints.rclis.org/13767

- Guallar, J., \& Redondo, Sílvia (2010). Fonts d'informació professionals de premsa. Una panoràmica. En: 12es Jornades catalanes d'informació i documentació. Barcelona, 19-20 mayo. http://eprints.rclis.org/14644

- Guallar, J., \&Abadal, E. (2010). The digital press archives of the leading Spanish online newspapers. Information research, v. 15, n. 1.

- Guallar, J., Abadal, E.rnest; \& Codina, L. (2012). Hemerotecas de prensa digital. Evolución y tendencias. El profesional de la información, v. 21, n. 6, pp. 595-605 . https://doi.org/10.3145/epi.2012.nov.06

- Guallar, J., Abadal, E., Codina, L. (2013a). Sistema de análisis de hemerotecas de prensa digital. Trípodos, n. 31, pp. 37-64. http://eprints.rclis.org/19929

- Guallar, J., Abadal, E., \& Codina, L. (2013b). Sistemas de acceso a la información de prensa digital: tipología y evolución. Investigación bibliotecológica: archivonomía, bibliotecología e información, v. 27, n. 61, pp. 29-52. http://eprints.rclis.org/21044 
- Guallar, J. (2015). Prensa digital en 2013-2014. Anuario ThinkEPI, v. 9, pp. 153160. http://dx.doi.org/10.3145/thinkepi.2015.37

- Harry, D. (23 de septiembre de 2018). How search engines rank web pages. Obtenido de Search engine watch: https://searchenginewatch.com/sew/news/2064539/how-search-enginesrank-web-pages

- Hart, C. (2008). Doing a Literature Review: Releasing the Social Science Research Imagination. London: Sage, 2008

- Hassan, Y.; Martín-Fernández, F.; lazza, G. (10 de noviembre de 2018) Diseño Web Centrado en el Usuario: Usabilidad y Arquitectura de la Información. Obtenido de Hipertext: https://www.upf.edu/hipertextnet/numero2/diseno_web.html

- Heijmans, M. (17 de marzo de 2018). What to Do to Optimize Your News Site For SEO. Obtenido de Search Engine Journal: https://www.searchenginejournal.com/optimizing-news-site/168831

- Hernández, C. (22 de enero de 2018). El uso de Knowledge Graph en Google. Obtenido de Adrenalina: https://www.adrenalina.es/knowledge-graph-google/ (2018-01-22).

- Herrero-Solana, V., Arboledas, L., \& Legerén-Álvarez, E. (2014). Universidades y Google News: visibilidad internacional a través de los medios de comunicación online. Revista Española de Documentación Científica, 37 (3): e052, doi: http://dx.doi.org/10.3989/redc.2014.3.1130

- Hollingsworth, S. (26 de mayo de 2018). YouTube SEO from Basic to Advanced: How to Optimize Your Videos. Obtenido de Search Engine Journal: https://www.searchenginejournal.com/youtube-seo-videooptimization/260757/

- Humprecht, E., \& Esse, F. (2018). Mapping digital Journalism: Comparing 48 news websites form six countries. Journalism, vol. 19 (4) pp. 500-518. https://doi.org/10.1177\%2F1464884916667872 
- Hurley, S. (22 de enero de 2018). Smashing Semantic SEO in 2017 \& Beyond: The Ultimate Guide. Obtenido de Digital Current:

https://www.digitalcurrent.com/seo-engine-optimization/semantic-seo-guide/

- Iglesias-García, M., \& Fernández-Poyatos, M. (2011). Ciberperiodismo: definiciones, desarrollo y tipología. Bilbao: III Congreso Internacional de Ciberperiodismo y Web 2.0.

- Iglesias- García, M. (2012). Rutinas productivas de un cibermedio nativo digital. Cuadernos de Información, No 30 / 2012. doi: https://doi.org/10.7764/cdi.30.424

- Iglesias-García, M., \& Codina, L. (2016). Los cibermedios y la importancia estratégica del posicionamiento en buscadores (SEO). Opción, vol. 32, núm. 9, 2016, pp. 929-944. Universidad del Zulia. Maracaibo, Venezuela

- Jarboe, G. (6 de mayo de 2018). Video SEO for Universal Search: Tips, Tools \& Techniques to Get Found. Obtenido de Search Engine Journal: https://www.searchenginejournal.com/video-seo-for-universal-search/261159.

- Jiménez, L., Aguilar, C., Sánchez, L., Pérez-Montoro, M. (2018). User experience and the media: The three-click rule on newspaper websites for smartphones. Revista Latina de Comunicación Social, 73, 595-613. DOI: 10.4185/RLCS-20181271en

- Kakkar, D. (13 de mayo de 2018). How Videos Generate Quick SEO Results." Search Engine Watch. Obtenido de: https://searchenginewatch.com/2018/02/19/how-videos-generate-quick-seoresults/

- Kalogeropoulos, A., \& Nielsen, R. (2017). Investing in Online Video News. Journalism Studies. doi:10.1080/1461670X.2017.1331709

- Kellyanne, A., Díaz-Noci, J. (2019). Informatius de televisió i audiència activa: estudi de cas de TV3- Televisió de Catalunya. Comunicació: Revista de Recerca i d'Anàlisi [Societat Catalana de Comunicació] http://revistes.iec.cat/index.php/TC. Vol. 36 (1)), p. 9-29

- Kent, P. (2006). Building search-engine-friendly sites". Search engine optimization for dummies. Indianapolis: Wiley. 
- Kleinberg, J. (1998). Authoritative sources in a hyperlinked environment. In: Procs. of the ACM-SIAM Symposium on discrete algorithms, pp. 1-33. https://www.cs.cornell.edu/home/kleinber/auth.pdf

- Ksiazek, T., Peer, L., Lessard, K. 2016. User Engagement with Online News: Conceptualizing Interactivity and Exploring the Relationship between Online News Videos and User Comments. New Media \& Society, 18 (3): 502-520. doi:10.1177/1461444814545073.

- Kosaka, K. (13 de febrero de 2018). Semantic SEO: How to Change Your Game to Win in Search. Obtenido de Alexa: https://blog.alexa.com/semantic-seohow-to-change-your-game-to-win-in-search/

- Kukoo, I. (11 de noviembre de 2018). SEO Should Stand For Search Experience Optimization. Obtenido de DEE: https://dee.ie/it-blog/seo-should-stand-forsearch-experience-optimization/

- Labio-Bernal, A., Nogales-Bocio, A. (2010). Poder medios de comunicación, y periodismo. En: La dinámica periodística: perspectiva, contexto, métodos y técnicas. Sevilla, ISBN: 978-84-937600-0-7

- Lacy, L. (2005). OWL: Representing Information Using the web Ontology Language. Canadá: Ed. Trafford, 2005.

- Lemos, J.; Yoseph, J. (14 de noviembre de 2018). Search Engine Optimization to Enhance User Interaction. Obtenido de leexplore: https://ieeexplore.ieee.org/stamp/stamp.jsp?tp=\&arnumber $=8058379$

- Lewandowski, D. (2012). A framework for evaluating the retrieval effectiveness of search engines. In: Jouis, Christophe; Biskri, Ismail; Ganascia, Jean-Gabriel; Roux, Magali. Next generation search engine: Advanced models for information retrieval. Hershey, PA: IGI Global, pp. 456-479. ISBN: 9781466603318 https://arxiv.org/pdf/1511.05817.pdf

- Li, Y. (2017). Contest over authority. Journalism studies, pp. 1-19. https://doi.org/10.1080/1461670X.2017.1397531

- Linares, J., Codina, L.; Vàllez, M., \& Rodríguez-Martínez, R. (2016). Interactividad, Buscabilidad y Visibilidad en Cibermedios: Sistema de Análisis y Resultados. Barcelona: Departamento de Comunicación. Serie Editorial DigiDoc. 
- Litsa, T. (26 de mayo de 2018). 12 Video SEO Tips to Help Improve Your Search Rankings. Obtenido de Search Engine Watch:

https://searchenginewatch.com/2016/08/24/12-video-seo-tips-to-improveyour-rankings/.

- Liu, X. (2017). Large-scale SEO Optimization Algorithm based on Transfer Learning. Boletín Técnico, 55 (11), 587-593.

- Liu, D., Zhao, Y., Sui,K., Zou, L., Pei, D., Tao, Q., Chen, X., \& Tan, Dai (2016). Focus: Shedding light on the high search response time in the wild. In: IEEE Infocom 2016 - The 35th Annual IEEE intl conf on computer communications, pp. 1-9. https://doi.org/10.1109/INFOCOM.2016.7524413

- López- García, G. (2015). Periodismo digital: redes, audiencias y modelos de negocio. Revista de interculturalidad, comunicación y estudios europeos, n.10, pp. $175-176$

- López- García, X., Rodríguez-Vázquez, A. I., \& Pereira Fariña, X. (2017). Technological Skills and New Professional Profiles: Present Challenges for Journalism. Comunicar, 25 (53), 81-90. doi: https://doi.org/ 10.3916/C53-201708

- López-García, G. (2017). Comunicación política y discursos sobre el poder. El Profesional de la Información, v. 26, n.4, pp. 573-578. https://doi.org/10.3145/epi.2017.jul.01

- Lopezosa, C., \& Codina, L. (2018). Análisis de posicionamiento en medios de comunicación con herramientas SEO. Cobertura informativa de los premios Óscar 2017. Barcelona: Serie editorial DigiDoc-EPI.

- Lopezosa, Carlos; Codina, Lluís; Caldera-Serrano, Jorge (2018). SEO semántico: Framework ISS para la optimización de sitios intensivos en contenidos. Cuadernos de, Documentación Multimedia, 29, 97-123.

- Lopezosa, Carlos; Codina, Lluís; Gonzalo-Penela, Carlos (2018) Off-page SEO and link building: General strategies and authority transfer in the digital news media, El profesional de la información, v. 28, n. 1, e280107. https://doi.org//10.3145/epi.2019.ene.07

- Lopezosa, C., Codina, L., \& Freixa, P. (2018). Seo y comunicación audiovisual: análisis comparativo de portales de vídeo bajo demanda. Serie DigiDoc-EPI, n. 
3. Barcelona: Universitat Pompeu Fabra, Departamento de Comunicación; Ediciones Profesionales de la Información SL. ISBN: 9788409024315

- Lopezosa, C.; Codina, L., Rovira, C. (2019) Visibilidad Web de Portales de Televisión y Radio en España: ¿qué Medios Llevan a Cabo un Mejor Posicionamiento en Buscadores? Serie DigiDoc-EPI, n; Ediciones Profesionales de la Información SL.: Barcelona, Spain, 2019; ISBN 978-84-09-07716-8.

- Lopezosa, C. Orduna-Malea, E \& Pérez-Montoro, M. (2019) Making Video News Visible: Identifying the Optimization Strategies of the Cybermedia on YouTube Using Web Metrics, Journalism Practice, DOI: 10.1080/17512786.2019.1628657

- Lopezosa, C. Codia, L. Pérez-Montoro, M (2019) SEO and Digital News Media: Visibility of Cultural Information in Spain's Leading Newspapers, Trípodos, número 44, 41-61

- Lopezosa, Carlos and Codina, Lluís and Díaz-Noci, Javier and Ontalba, JoséAntonio (2020) SEO and the digital news media: From the workplace to the classroom. Comunicar, vol. 28, n. 63, pp. 65-75.

- Lopezosa, Carlos; Codina, Lluís; López-García, Guillermo; Corbella-Cordomi, Juan-María (2020). "Mapa de visibilidad y posicionamiento en buscadores de los principales grupos mediáticos españoles". El profesional de la información, v. 29, n. 2, e290203. https://doi.org/10.3145/epi.2020.mar.03

- Lopezosa, C.; Iglesias-García, M.; González-Díaz, C.; Codina, L. (2020). Experiencia de búsqueda en cibermedios: análisis comparativo de diarios nativos digitales. Revista Española de Documentación Científica, 43 (1), e254. https://doi.org/10.3989/redc.2020.1.1677

- Machill, M., Beiler, M., \& Zenke, M. (2008). Search-engine research: a European-American overview and systematization of an interdisciplinary and international research field. Sage Journals, Volume: 30 issue: 5, page(s): 591608 https://doi.org/10.1177/0163443708094010

- Maciá-Domene, F. (2011). Técnicas avanzadas de posicionamiento en buscadores. Anaya Multimedia. ISBN: 9788441529632

- Manish, R. (2013). Evolution of Search Engine Optimization and Investigating the Effect of Panda Update into it. International Journal of Scientific \& Engineering Research, 4 (12), 2013- 2045. 
- Marcos-Recio, J.C., Sánchez-Vigil, J.M., \& Olivera-Zaldúa, M. (2015). Google News y el impacto de la Ley de Propiedad Intelectual en la prensa: un nuevo amanecer para la información. Documentación de las Ciencias de la Información, Vol. 38: paginas. 67-81

- Martínez-Costa, M.P., Moreno, E., Amoedo, A. (2018). Mapa de la radio online en España: tipología y caracterización en el contexto de los cibermedios. EI profesional de la información, v. 27, n. 4, pp. 849-857. https://doi.org/10.3145/epi.2018.jul.14

- Mashable. (14 de febrero de 2018). How Google's Semantic Search Will Change SEO. Obtenido de Mashable: https://mashable.com/2012/03/22/googlesemantic-search-seo/\#whzognAilGqV

- Mathiasen, F. (23 de septiembre de 2018). 10 quick takeaways from native advertising days 2018. Obtenido de Native Advertising Institute: https://nativeadvertisinginstitute.com/blog/takeaways-native-advertisingdays-2018

- McClure, M. 2011. ABCs of Online Video: Building a Strategy. EContent, 34 (8): 22-26.

- Medina, M., Pérez-Latre, F., Sánchez-Tabernero, A., \& Díaz-Espina, C. (2017). Market Structure and Innovation Policies in Spain. In: van Kranenburg H. (eds) Innovation Policies in the European News Media Industry. Media Business and Innovation. Springer, Cham

- Meyers, P. (30 de enero de 2018). Posic Ranking \#0: SEO for Answers. Obtenido de Moz: https://moz.com/blog/ranking-zero-seo-for-answers

- Monterde, N. (4 de marzo de 2018). Introducción al link building. Obtenido de SEO azul: https://www.seoazul.com/introduccion-al-link-building

- Morabito, A. (12 de marzo de 2019). The new user engagement? Stick a pin in it. Obtenido de broadcastingcable.com: https://www.broadcastingcable.com/news/new-user-engagementstick-pin-it39227

- Morato, J., Sánchez-Cuadrado, S., Moreno, V., \& Moreiro, J. A. (2013). Evolución de los factores de posicionamiento web y adaptación de las 
herramientas de optimización. Revista Española de Documentación Científica, 36 (3), e018. http://dx.doi.org/10.3989/redc.2013.3.956

- Muerza, A. (2017). Producción de noticias radiofónicas en el contexto de la convergencia periodística: análisis de Radio Marca y sus sinergias con Marca y marca.com. Estudios sobre el Mensaje Periodístico, ISSN-e: 1988-2696. doi: http://dx.doi.org/10.5209/ESMP.59979

- Munroe, M. (12 de noviembre de 2018). From SEO To SXO: Search Experience Optimization. Obtenido de Search Engine Land: https://searchengineland.com/seo-sxo-search-experience-optimization-223812

- Murray, D. (2011). Search Engine Optimization in UK News Production. Journalism Practice, 5, no. 4 (2011): 462-77. https://doi.org/10.1080/17512786.2010.551020

- Nastic, R. (22 de enero de 2018). What Is Latent Semantic Indexing. Obtenido de Search Engine Journal: https://www.searchenginejournal.com/what-islatent-semantic-indexing-seo-defined/21642/

- Nechushtaia, E., \& Lewisb, S. (2019). What kind of news gatekeepers do we want machines to be? Filter bubbles, fragmentation, and the normative dimensions of algorithmic recommendations. Computers in Human Behavior, Volume 90, January 2019, Pages 298-307 https://doi.org/10.1016/j.chb.2018.07.043

- Newman, N.; David Levy, A.L. (2014). Reuters Institute Digital News Report 2014. Tracking the Future of News. Reuters Institute for the Study of Journalism, University of Oxford.

- Nogales, A., Sicilia, M., Sánchez- Alonso, S., \& Garcia-Barriocanal, E. (2015). Linking from Schema.org microdata to the Web of Linked Data: An empirical assessment, Computer Standards \& Interfaces. Computer Standards \& Interfaces. 45 doi: 10.1016/j.csi.2015.12.003

- Noam, E. (2017). Beyond the mogul: From media conglomerates to portfolio media. Journalism, Vol.19, n.8, pp.1096-1130. https://doi.org/10.1177/1464884917725941 
- Norris, C. (20 de marzo de 2018). SEO For Journalists: Introduction \& Keywords. Obtenido de MOZ: https://moz.com/ugc/seo-for-journalists-introductionkeywords-part-1-of-5

- Orduna-Malea, E., \& Alonso-Arroyo, A. (2017). Cybermetric Techniques to Evaluate Organizations Using Web-Based Data. Cambridge: Chandos Publishing.

- Ossman, M. (28 de mayo de 2019). How to Optimize Content for Google News. Obtenido de Pagely.com: https://pagely.com/blog/optimize-content-googlenews/

- Paolini, M. (22 de enero de 2018). What is Semantic SEO? Obtenido de Online Sales Marketing: https://online-sales-marketing.com/what-is-semantic-seo/

- Park, M. (2018). SEO for an open access scholarly information system to improve user experience. Information Discovery and Delivery, 46 (2), 77-82. https://doi.org/10.1108/IDD-08-2017-0060

- Patel, N. (28 de mayo de 2019). Cómo Publicar tu Sitio en Google News y Generar Más Tráfico en Tiempo Real. Obtenido de Neilpatel.com: https://neilpatel.com/es/blog/como-publicar-tu-sitio-en-google-news-ygenerar-mas-trafico-en-tiempo-real/

- Pedraza, B. (30 de enero de 2018). How the Google Hummingbird Update Changed Search. Obtenido de Search Engine Journal: https://www.searchenginejournal.com/google-algorithmhistory/hummingbird-update/

- Pedraza-Jiménez, R., Blanco, S., Codina, L., \& Cavaller, V. (2013). Diseño conceptual y especificación de requerimientos para el desarrollo y rediseño de sitios web. El profesional de la información, v. 22, n. 1, pp. 74-79. https://doi.org/10.3145/epi.2013.ene.10

- Pedraza-Jiménez, R., Codina, L., \& Guallar, J. (coords.) (2016). Calidad en sitios web. Método de análisis general, e-commerce, imágenes, hemerotecas y turismo. Colección EPI Scholar. Barcelona: Editorial UOC. ISBN: 978849064487 4

- Peer, L., \& and Ksiazek, T. (2011). YouTube and the Challenge to Journalism: New Standards for News Videos Online. Journalism Studies, 12 (1): 45-63. 
- Pérez-Montoro, M., \& Codina, L. (2016). Navigation Design and SEO for Content-Intensive Websites: A Guide for an Navigation Design and SEO for an efficient digital communication. Cambridge: Chandos Publishing.

- Pollitt, C. (23 de septiembre de 2018). The global guide to technology 2018. A resource for marketers, advertisers, media buyers, communicators, publishers and ad tech professionals. Obtenido de Native Advertising Institute: https://nativeadvertisinginstitute.com

- Pons, M., Monistrol, O. (2017). Técnicas de generación de información en investigación cualitativa II. En: Calderón C, Conde F, Fernández de Sanmamed MJ, Monistrol O, Pons M, Pujol E, Sáenz de Ormijana A. Curso de Introducción a la Investigación Cualitativa. Máster de Investigación en Atención Primaria. Barcelona: semFYC. Universitat Autònoma de Barcelona. Fundació Doctor Robert.

- Potter, B. (13 de noviembre de 2018). SEO: search experience optimisation. Obtenido de Econsultancy: https://econsultancy.com/seo-search-experienceoptimisation/

- Publisuites (15 de marzo de 2018). Estudio del uso de linkbuilding. Obtenido de Publisuite: https://www.publisuites.com/blog/estudio-de-linkbuildingpublisuites

- Qu, J., Hißbach, A., Gollub, T., \& Potthast, M. (2018). Towards Crowdsourcing Clickbait Labels for YouTube Videos. Aachen: HCOMP.

- Ramos, J. (27 de mayo de 2019). Cómo aparecer en Google News o Google Noticias. Consultor-seo.com. Obtenido de Consultor-SEO: https://www.consultor-seo.com/como-aparecer-en-google-news-o-googlenoticias/

- Reig, R. (2011). Los dueños del periodismo: claves de la estructura mediática mundial y de España. Barcelona, Editorial Gedisa, ISBN: 9788497846189

- Richmond, S. (2008). How SEO is changing journalism. British Journalism Review, 19. pp 5 https://doi.org/10.1177/0956474808100865 
- Reig, R. (2011). Los dueños del periodismo: claves de la estructura mediática mundial y de España. Barcelona: Editorial Gedisa. ISBN: 9788497846189.

- Rodríguez - Fernández, M.M., Sánchez-Amboage, E., Toural-Bran, C. (2018). Las radiotelevisiones publicas europeas en el entorno web. Revista latina de comunicación social, v. 73, pp. 911-926. https://doi.org/10.4185/RLCS-20181288

- Rodríguez-Martínez, R., Codina, L., \& Pedraza-Jiménez, R. (2010). Cibermedios y web 2.0: modelo de análisis y resultados de aplicación. El profesional de la información, v. 19, n. 1, pp. 35-44. https://doi.org/10.3145/epi.2010.ene.05

- Rodríguez-Martínez, R., Codina, L., \& and Pedraza-Jiménez, R. (2010). Cibermedios y web 2.0: modelo de análisis y resultados de aplicación. El profesional de la información, 19 (1): 35-44.

- Rodríguez-Martínez, R., Codina, L., \& Pedraza-Jiménez, R. (2012). Indicadores para la evaluación de la calidad en cibermedios: análisis de la interacción y de la adopción de la Web 2.0. Revista española de documentación científica, 35 (1): 61-93.

- Riffe, D., Aust, C. F., \& Lacy, S. R. (1993). The Effectiveness of Random, Consecutive Day and Constructed Week Sampling in Newspaper Content Analysis. Journalism Quarterly, 70(1), 133-139. https://doi.org/10.1177/107769909307000115

- Rovira, C., Codina, L., \& Marcos, M.C. (2009). Cómo contratar un servicio de posicionamiento Web. El profesional de la información, v. 18, n. 2, pp. 229-236. https://doi.org/10.3145/epi.2009.mar.14

- Rovira, C., Fernández-Cavia, J., Pedraza-Jiménez, R., \& Huertas, A. (2010). Posicionamiento en buscadores de las webs oficiales de capitales de provincia españolas. El profesional de la información, v. 19, n. 3, pp. 277-283. https://doi.org/10.3145/epi.2010.may.08

- Rovira, C., Codina, L., \& Monistrol, R. (2013). Rich snippets: información semántica para la mejora de la identidad digital y el SEO. El profesional de la información, 22:1 (2013) 554-561. http://dx.doi.org/10.3145/epi.2013.nov.08 
- Rovira, C., \& Marcos. M.C (2014). La importancia de las fuentes en la selección de artículos de prensa en línea: un estudio de Google Noticias mediante seguimiento ocular (eye-tracking). Investigación Bibliotecológica:

Archivonomía, Bibliotecología e Información, Volume 28, Issue 63, Pp.15-28 https://doi.org/10.1016/S0187-358X(14)72574-2

- Rowe, K. (12 de enero de 2018). 4 reports you can pull from Ahrefs that you didn't know existed. Obtenido de Search engine land:

https://searchengineland.com/4-reports-you-can-pull-from-ahrefs-that-youdidnt-know-existed-289376

- $\quad$ Rowe, K. (2 de febrero de 2018). How link building will change in 2018. Obtenido de Search Engine Journal: https://www.searchenginejournal.com/how-link-building-will-change/231707

- Salaverría, R., Martínez-Costa, M., \&Breiner, J (2018): Mapa de los cibermedios de España en 2018: análisis cuantitativo. Revista Latina de Comunicación Social, 73, pp. 1034 a 1053. doi: https://doi.org/10.4185/RLCS-2018-1295

- Sampedro, V. (2018). Dietética digital Para adelgazar al gran hermano. Barcelona: Icaría Editorial, Análisis contemporáneo, Comunicación y nuevas tecnologías.

- Sullivan, D. (29 de mayo de 2019).) Ways to succeed in Google News. Obtenido de Google: https://webmasters.googleblog.com/2019/01/ways-to-succeed-ingoogle-news.html

- Schachinger, K. (13 de febrero de 2018). How RankBrain Changes Entity Search. Obtenido de Search Engine Land:https://searchengineland.com/rankbrainchanges-entity-search-234345

- Schauster, E., Ferrucci, P., \& Neill, M. (2016). Native advertising is the new journalism: How deception affects social responsibility. American behavioral scientist, v. 60, n. 12, pp. 1408-1424. https://doi.org/10.1177/0002764216660135

- Schema.org. (27 de febrero de 2018). Documentation. Obtenido de Schema.org: http://schema.org/docs/documents.html

- Schema.org. (27 de febrero de 2018a). Organization of Schemas. Obtenido de Schema.org: http://schema.org/docs/schemas.html 
- Schubert, K. (23 de enero de 2018). Semantic SEO Guide. Obtenido de Ryte: https://en.ryte.com/magazine/semantic-seo-guide

- Serrano-Cobos, J. (2015). SEO: Introducción a la disciplina del posicionamiento en buscadores. Colección EPI Scholar. Barcelona: Editorial UOC. ISBN: 9788490649565

- Sistrix (27 de mayo de 2019). Optimización de Google News ¿ cómo puedo hacer eso? Obtenido de Sistrix: https://www.sistrix.es/preguntale-asistrix/optimizacion-onpage/optimizacion-de-google-news-como-puedo-hacereso/

- Smarty, A. (13 de mayo de 2018). 5 YouTube Optimization Tips to Improve Your Video Rankings. Obtenido de Search Engine Watch:

https://searchenginewatch.com/2018/03/02/5-youtube-optimization-tips-toimprove-your-video-rankings/

- Smyrnaios, N. (2015). Google and the Algorithmic Infomediation of News. Media Fields Journal, no. 10 pp 1-10. http://static1.1.sqspcdn.com/static/f/707453/26682448/1447830671177/Smyr naios_FINAL.pdf?token=u\%2FxVEz8CnJP\%2FzIKCNtq9ncMXcRo\%3D

- Smyrnaios, N; \& Sire, G. (2014). The News according to Google How Does Algorithmic Infomediation Frame the Work of French Journalists. Presented at JSS-ECREA 2014 Conference, Thessaloniki:

https://es.slideshare.net/smyrnaios/the-news-according-to-google-how-doesalgorithmic-infomediation-frame-the-work-of-french-journalists

- Smyrnaios, N; Rebillard, F. (2009). L'actualité selon Google. L'emprise du principal moteur de recherche sur l'information en ligne. Communication et Langages, no. 160 (2009): 95-109. https://www.cairn.info/revuecommunication-et-langages1-2009-2-page-95.htm DOI: $10.4074 /$ S0336150009002087

- Spencer, S. (26 de mayo de 2018). YouTube SEO 101. Obtenido de Search Engine Land: https://searchengineland.com/youtube-seo-101-289416.

- Stetzer, A. (13 de febrero de 2018). RankBrain: SEO friend or SEO Foe. Obtenido de Search Engine Watch:

https://searchenginewatch.com/sew/opinion/2434672/rankbrain-seo-friendor-foe 
- Suárez-Sucre, E. (2017). Comprendiendo a los cibermedios. Una propuesta estructural para el análisis de los medios de comunicación en la red. Estudios sobre el Mensaje Periodístico, 23(1), 273-288. doi: http://dx.doi.org/10.5209/ESMP.55596

- Sulé, A. (2015). Schema.org, la mejora de la visualización de los resultados en los buscadores y mucho más. BiD textos universitaris de biblioteconomia $i$ documentació, 34, 1-7.

- Sweetser, K., Joo, S., Golan, G., Hochman, A. (2016). Native advertising as a new public relations tactic. American behavioral scientist, v. 60, n. 12, pp. 14421457. https://doi.org/10.1177/0002764216660138

- Templeman, M. (11 de noviembre de 2018). SEO Has Evolved To Search 'Experience' Optimization. Obtenido de Forbes: https://www.forbes.com/sites/miketempleman/2016/02/16/seo-has-evolvedto-search-experience-optimization/\#6c18a0ed3f35

- Thelwall, M. (2004). Link analysis: An information science approach. Amsterdam: Elsevier. ISBN: 9780120885534

- Themistoklis, M., \& Symeonidis, A. (2015). Identifying valid search engine ranking factors in a Web 2.0 and Web 3.0 context for building efficient SEO mechanisms. Engineering Applications of Artificial Intelligence, 41, 75-91. http://dx.doi.org/10.1016/j.engappai.2015.02.002

- Tort, A., Olivé, A. (2015). An approach to website schema.org design. Data \& Knowledge Engineering. ISSN: 0169-023X. 99, (2015) 3-16. doi>10.1016/j.datak.2015.06.011

- Trillo-Domínguez, M., \& Ollero, J. (2018). Estrategias de comunicación periodística para publicar en Redes Sociales desde la prensa local: Plan de Acción de Grupo Joly". Hipertext.net, (16), 68-77. doi: https://doi.org/10.31009/hipertext.net.2018.i16.11

- Valles, M. (2002). Entrevistas cualitativas. Colección Cuadernos Metodológicos. Madrid: Editorial Centro de Investigaciones Sociológicas.

- Vàllez, M., Rovira, C., Codina, L., \& Pedraza-Jiménez, R. (2010). Procedures for extracting keywords from web pages, based on search engine optimization. 
Hipertext, net, n. 8. https://www.upf.edu/hipertextnet/en/numero-

8/keywords_extraction.html

- Vàllez, M. (2011). Keyword research: métodos y herramientas para identificar palabras clave. BiD: Textos universitaris de biblioteconomia i documentació, n. 27. http://bid.ub.edu/27/vallez2.htm

- Vàllez, M., Pedraza-Jiménez, R., Codina, L., Blanco, S., \& Rovira, C. (2015). Updating controlled vocabularies by analysing query logs. Online information review, v. 39, n. 7, pp. 870-884. https://doi.org/10.1108/OIR-06-2015-0180

- Van Dyke, P. (13 de noviembre de 2018). Search Engine Optimization VS. User Experience Optimization. Obtenido en SEO.com:

https://www.seo.com/blog/search-engine-optimization-vs-user-experienceoptimization/

- Villanueva, L. (14 de noviembre de 2018). Search Experience Optimization. Otra forma de entender el SEO. Obtenido de Luis Villanueva:

https://luismvillanueva.com/seo/search-experience-optimization-seo-sxo.html

- Wang, M. (14 de noviembre de 2018). Why search experience optimization is the new seo. Obtenido en WP Promote:

https://www.wpromote.com/blog/why-search-experience-optimization-is-thenew-seo/

- Williams, O. (14 de mayo de 2019). Google News Spain to be shut down: what does it mean? Obtenido de The Guardian:

https://www.theguardian.com/media-network/2014/dec/12/google-newsspain-tax-withdraws

- Wilson, L. (27 de mayo de 2019). How to Get Your Website Listed in Google News. Obtenido de Search Engine Journal:

https://www.searchenginejournal.com/how-to-get-your-website-listed-ingoogle-news-in-2016/159701/\#close

- Wilson, T.D. \& Maceviciute, E. (2013). What's newsworthy about 'information seeking'? An analysis of Google's News Alerts. Information Research, 18(1) paper 557. 
- Wolters, D., Heindorf, S., Kirchhoff, J., Engels, G. (2017). Linking services to websites by leveraging semantic data. In: Proceedings of the 24th Intl conf on web services (ICWS). IEEE.

- Wordtracker. (15 de marzo de 2018). A guide to SEO for editorial teams and journalists. Obtenido de

Wordtracker://www.wordtracker.com/academy/seo/getting-started/seo-foreditorial-teams-journalists

- Yandex. (27 de febrero de 2018). Schema.org. Obtenido de Yandex: https://yandex.com/support/webmaster/schema- org/what-is-schema-org.xml (2018-02-27).

- Yin, R. (2014). Case study research. Design and methods. Canada: SAGE. ISBN: 9781452242569

- YouTube. (14 de mayo de 2018). YouTube Creators. Obtenido de YouTube: https://creatoracademy.youtube.com/page/browse.

- Yu, J. (13 de mayo de 2018). Video Optimization: Do Not Underestimate the Power of YouTube. Obtenido de Search Engine Land: https://searchengineland.com/video-optimization-not-underestimate-poweryoutube-234618.

- Yu, W. (27 de febrero de 2018). How to Use Semantic SEO for Higher Rankings. Obtenido de Search Engine Journal: https://www.searchenginejournal.com/content-semantic-seo/201596/ (201801- 23).

- Zannettou, S., Chatzis, S., Papadamou, K., \& Sirivianos, M. (2018). The Good, the Bad and the Bait: Detecting and Characterizing Clickbait on YouTube. 2018 IEEE Security and Privacy Workshops (SPW) (2018): 63-69.

- Zhang, L., Mouratidis, K. \&Y. Li, Y. (2017). Continuous Top-k Monitoring on Document Streams, in IEEE Transactions on Knowledge and Data Engineering, vol. 29, no. 5, pp. 991-1003, 1 May 2017. Doi: 10.1109/TKDE.2017.2657622

- Zheng, N. (2016). Parasite or Partner? Coverage of Google News in an Era of News Aggregation. Journalism \& Mass Communication Quarterly, 93(4), 789815. https://doi.org/10.1177/1077699016629370 


\section{ANEXOS}

\section{Contenidos de esta edición}

Los contenidos de esta publicación proceden principalmente de la selección, revisión y nueva edición para esta versión, de materiales publicados originalmente como parte de la tesis doctoral de la que es autor el Dr. Carlos Lopezosa y que contó con la dirección del Dr. Lluís Codina y del Dr. Carlos Gonzalo. También hemos reutilizado el informe Framework SEO-RCP (Codina et al. 2016). No obstante, como ya hemos señalado, el grueso procede de la investigación de la tesis defendida en la Universitat Pompeu Fabra en noviembre de 2019 con el título: SEO, periodismo y comunicación: conceptos, herramientas y procesos para optimizar la visibilidad web de los medios digitales. La tesis recibió la calificación de Excelente Cum Laude. Esta tesis, a su vez, forma parte del proyecto del Plan Estatal RTI2018-095714-B-C21 (MICINN/FEDER) dentro del cual se inscribe esta línea de trabajos e informes.

COMPENDIO DE PUBLICACIONES DE LA INVESTIGACIÓN DOCTORAL

\begin{tabular}{|l|l|l|l|}
\hline N. & Título/ Fuente & Tipo & Idioma \\
\hline 1 & $\begin{array}{l}\text { SEO semántico: Framework ISS para la } \\
\text { optimización de sitios intensivos en contenidos. } \\
\text { Cuadernos de Documentación Multimedia. }\end{array}$ & Artículo & ES \\
\hline 2 & $\begin{array}{l}\frac{\text { Off-page SEO and link building: General strategies }}{\text { and authority transfer in the digital news media. }} \\
\text { El Profesional de la Información. }\end{array}$ & Artículo & EN \\
\hline 4 & $\begin{array}{l}\text { SEO and digital news media: visibility of cultural } \\
\text { information in Spain's leading digital newspapers. } \\
\text { Revista Trípodos. }\end{array}$ & Artículo \\
\hline 5 & $\begin{array}{l}\text { Seo semántico y cibermedios: Una aproximación a } \\
\text { los resultados de búsqueda enriquecidos. } \\
\text { Congreso Internacional CUICIID 2018 }\end{array}$ & $\begin{array}{l}\text { Acta y capítulo } \\
\text { de libro }\end{array}$ & ES \\
\hline 6 & $\begin{array}{l}\frac{\text { Seo semántico y web móvil: Optimización de }}{\text { Xontenidos digitales en Cibermedios. }} \\
\text { UPV/EHU. }\end{array}$ & Acta & ES \\
\hline
\end{tabular}




\begin{tabular}{|c|c|c|c|}
\hline 7 & $\begin{array}{l}\text { Making Video News Visible: Identifying the } \\
\text { Optimization Strategies of the Cybermedia on } \\
\text { YouTube using Web Metrics. } \\
\text { Journalism Practice }\end{array}$ & Artículo & EN \\
\hline 8 & $\begin{array}{l}\text { Experiencia de búsqueda y cibermedios: } \\
\text { estudio de caso de los medios nativos digitales en } \\
\text { Internet } \\
\text { Revista española de Documentación Científica. }\end{array}$ & Artículo & ES \\
\hline 9 & $\begin{array}{l}\text { Experiencia de búsqueda en cibermedios: } \\
\text { Propuesta de protocolo de Análisis. } \\
\text { XXV Congreso Internacional SEP }\end{array}$ & $\begin{array}{l}\text { Capítulo de } \\
\text { libro }\end{array}$ & ES \\
\hline 10 & $\begin{array}{l}\text { Mapa de visibilidad y posicionamiento en } \\
\underline{\text { buscadores de los principales grupos mediáticos }} \\
\underline{\text { españoles }} \\
\text { El profesional de la información }\end{array}$ & Artículo & ES \\
\hline 11 & $\begin{array}{l}\text { SEO and the digital news media: From the } \\
\text { workplace to the classroom } \\
\text { Revista Comunicar }\end{array}$ & Artículo & ES \\
\hline 12 & $\begin{array}{l}\text { Análisis de posicionamiento en medios de } \\
\text { comunicación con herramientas SEO: cobertura } \\
\text { informativa de los premios Oscar 2017. } \\
\text { Digidoc EPI. }\end{array}$ & informe & ES \\
\hline 13 & $\begin{array}{l}\text { SEO y comunicación audiovisual: análisis } \\
\text { comparativo de portales de vídeo bajo demanda. } \\
\text { Digidoc EPI. }\end{array}$ & Informe & ES \\
\hline 14 & $\begin{array}{l}\text { Visibilidad web de portales de televisión y radio en } \\
\text { España: ¿qué medios llevan a cabo un mejor } \\
\text { posicionamiento en buscadores? } \\
\text { Digidoc EPI. }\end{array}$ & Informe & ES \\
\hline 15 & $\begin{array}{l}\text { La Experiencia de búsqueda en las principales } \\
\text { agencias de noticias: revisión sistematizada, } \\
\text { protocolo de análisis comparativo y resultados. } \\
\text { Digidoc. }\end{array}$ & Informe & ES \\
\hline
\end{tabular}




\section{Publicaciones del Grupo DigiDoc sobre SEO y Periodismo}

- CODINA, L., IGLESIAS-GARCÍA, M., PEDRAZA, R. y GARCÍA-CARRETERO, L. (2016). Visibilidad y Posicionamiento Web de informaciones periodísticas: El Framework $\underline{S E O-R C P}$. Barcelona: Serie Editorial DigiDoc (UPF)

- Codina L., gONZALO-PENElA C., PEDRAZA-JIMÉNEZ R. y ROVIRA C. (2017). Posicionamiento web y medios de comunicación ciclo de vida de una campaña y factores SEO. Barcelona: Serie Editorial DigiDoc (UPF)

- GARCÍA-CARRETERO, L., CODINA, L., DÍAZ-NOCI, J. y IGLESIAS-GARCÍA, M. (2016). "Herramientas e indicadores SEO: características y aplicación para análisis de cibermedios", El profesional de la información, 25, (3), 497-504. https://doi.org/10.3145/epi.2016.may.19

- GARCÍA-CARRETERO L., CODINA L. y PEDRAZA-JIMÉNEZ R. (2016). Indicadores para el estudio de la visibilidad y del impacto de los cibermedios en el ecosistema digital: mapeo y caracterización de herramientas de análisis SEO online. Barcelona: Serie Editorial DigiDoc (UPF).

- GONZALO-PENELA C. (2004) "La selección de palabras clave para el posicionamiento en buscadores", Hipertext.net, 2.

- GONZALO-PENELA C. (2006). "Tipología y análisis de enlaces web : aplicación al estudio de los enlaces fraudulentos y de las granjas de enlaces". BiD: textos universitaris de biblioteconomia i documentació, 16.

- GONZALO-PENELA, C. (2014). Posicionamiento Web y dinámicas de información en motores de búsqueda: Propuestas de análisis y estudio comparativo de visibilidad de contenidos digitales en el caso de procesos electorales [tesis doctoral]. Barcelona: UPF

- gonzalo-Penela, C., CODINA, L. y ROVIRA, C. (2015). “Recuperación de Información centrada en el usuario y SEO: categorización y determinación de las intenciones de búsqueda en la Web", Index.comunicación, 5(3), 19-27.

- linARES, J., CODINA, L., VÀlleZ, M. y RODRíGUEZ-MARTínEZ R. (2016). Interactividad, buscabilidad y/visibilidad en cibermedios: sistema de análisis y resultados. Barcelona: Serie Editorial DigiDoc (UPF) 
- LOPEZOSA, C. y CODINA L. (2018). Análisis de posicionamiento en medios de comunicación con herramientas SEO: cobertura informativa de los premios Oscar 2017. Barcelona: Serie Editorial DigiDoc (UPF).

- LOPEZOSA, C., CODINA, L., y CALDERA-SERRANO, J. (2018). "SEO semántico: Framework ISS para la optimización de sitios intensivos en contenidos", Cuadernos De Documentación Multimedia, 29, 97-123. https://doi.org/10.5209/CDMU.60607

- LOPEZOSA, C., CODINA, L., FREIXA P. (2018). SEO y comunicación audiovisual: análisis comparativo de portales de vídeo bajo demanda. Barcelona: Serie Editorial DigiDoc (UPF).

- LOPEZOSA, C., CODINA, L., ROVIRA, C. (2019). Visibilidad web de portales de televisión y radio en España: ¿qué medios llevan a cabo un mejor posicionamiento en buscadores? Barcelona: Serie Editorial DigiDoc (UPF).

- Lopezosa C., ORDUNA-MALEA, E. y PÉREZ-MONTORO, M. (2019). “Making Video News Visible: Identifying the Optimization Strategies of the Cybermedia on YouTube Using Web Metrics", Journalism Practice, v14, n4. https://doi.org/10.1080/17512786.2019.1628657

- LOPEZOSA, C., CODINA, L. y PÉREZ-MONTORO, M. (2019). “SEO and Digital News Media: Visibility of Cultural Information in Spain's Leading Newspapers". Trípodos, 44, 41-61.

- MARCOS, M. C., GAVIN, F. y ARAPAKIS, I. (2015). "Effect of Snippets on User Experience in Web Search". Proceeding. Interacción '15 Proceedings of the XVI International Conference on Human Computer Interaction. Artículo No. 47. Vilanova i la Geltru: Spain, ACM New York, NY, USA.

- PÉREZ-MONTORO, M. y CODINA, L. (2017). Navigation Design and SEO for Content-Intensive Websites: A Guide for an Efficient Digital Communication. Oxford: Chandos Publishing - Elsevier. (ISBN 9780081006764)

\section{Sitios web relacionados}

- Observatorio de cibermedios (OCM-UPF)

- Sitio web de Carlos Lopezosa

- Sitio web de Lluís Codina

- Sitio web de Carlos Gonzalo 